\title{
Article \\ Improving the Dynamic Performance of a Variable Speed DFIG for Energy Conversion Purposes Using an Effective Control System
}

\author{
Mahmoud A. Mossa ${ }^{1,2, *(\mathbb{D})}$, Mahmoud K. Abdelhamid ${ }^{1}\left(\mathbb{D}\right.$, Ahmed A. Hassan ${ }^{1}$ and Nicola Bianchi $^{2}$ \\ 1 Electrical Engineering Department, Faculty of Engineering, Minia University, Minia 61111, Egypt; \\ mahmoud_khalifa@mu.edu.eg (M.K.A.); ahmed.hasan@mu.edu.eg (A.A.H.) \\ 2 Department of Industrial Engineering, University of Padova, Via Gradenigo 6/a, 35131 Padova, Italy; \\ nicola.bianchi@unipd.it \\ * Correspondence: mahmoud_a_mossa@mu.edu.eg
}

check for

updates

Citation: Mossa, M.A.; Abdelhamid,

M.K.; Hassan, A.A.; Bianchi, N.

Improving the Dynamic Performance of a Variable Speed DFIG for Energy Conversion Purposes Using an Effective Control System. Processes 2022, 10, 456. https://doi.org/ $10.3390 /$ pr10030456

Academic Editors: Chang-Hua Lin and Jahangir Hossain

Received: 7 January 2022

Accepted: 20 February 2022

Published: 24 February 2022

Publisher's Note: MDPI stays neutral with regard to jurisdictional claims in published maps and institutional affiliations.

Copyright: (c) 2022 by the authors. Licensee MDPI, Basel, Switzerland. This article is an open access article distributed under the terms and conditions of the Creative Commons Attribution (CC BY) license (https:// creativecommons.org/licenses/by/ $4.0 /)$.

\begin{abstract}
The present paper aims to introduce an effective control system which enhances the dynamics of a doubly fed induction generator (DFIG) operating at fixed and variable speeds. To visualize the effectiveness of the formulated control algorithm, the performance of the DFIG is evaluated using other control techniques as well. Each control algorithm is primarily described by showing its operation principles and how it is adapted to manage the DFIG's operation. The main used control strategies are stator voltage-oriented control (SVOC), model predictive current control (MPCC), model predictive direct torque control (MPDTC), and the formulated predictive voltage control (PVC) algorithm. A detailed comparison is performed between the controllers' performances, through which the advantages and shortcomings of each method are outlined, and finally, the most effective technique is identified amongst them. The obtained results reveal that the proposed PVC approach possesses multiple advantages such as a faster dynamic response and simpler control structure when compared with SVOC and a faster dynamic response, reduced ripples, and reduced computational burdens when compared with the MPCC and MPDTC approaches. In addition, the robustness of the proposed PVC scheme is confirmed by performing extensive performance evaluation tests considering the parameters' variation.
\end{abstract}

Keywords: DFIG; predictive control; field orientation; current control; torque control; ripples; computation burden; dynamic response

\section{Introduction}

The escalating demand for clean energy sources in our lives forces developers to think about new control techniques to achieve maximum power extraction from renewable energy sources, such as wind, geothermal, solar, and wave energies [1,2]. There are various topologies of the electric generators used with wind energy conversion systems, such as synchronous generators (SGs), self-excited induction generators (SEIGs), and doubly fed induction generators (DFIGs) [3-11]. The DFIG has commonly been used with wind turbines during recent years and is still being used as it has many features; the most attractive one is the ability to generate output voltages with constant amplitude and frequency irrespective of the wind speed variations [12-15]. Another major feature of the DFIG is the flexibility of the control, as it can be controlled either from the stator side or the rotor side [16]. Controlling the DFIG from the rotor side leads to reducing the rating of the power electronic devices used in the inverter as they only need to process the slip power, which reduces the converter losses and, accordingly, the total cost [17-20].

Due to the several advantages of the DFIG as a generation unit, researchers have made great efforts to develop various control techniques and then test them with the DFIG. In [21-25], the vector orientation control (VOC) technique is performed, while in [26-28], 
the direct torque control (DTC) technique is used. The VOC technique has been performed in various configurations according to the selected variable to be aligned with the direct (d) axis of the rotating synchronous frame. For instance, in [21], the stator field was chosen to rotate with a speed equal to that of the synchronous frame, while in [22], the stator voltage was chosen to be aligned with the direct axis of the synchronous frame. In [23-25], the rotor field was chosen to be oriented in the same direction as the direct axis of the rotating frame. The VOC schemes have succeeded in improving the torque response and reducing ripples; consequently, a smooth dynamic response for the DFIG is achieved. However, the VOC schemes still have some defects, such as that they depend on the machine parameters during the variables' estimation, which can be influenced by environmental factors such as temperature change. Furthermore, they require coordinate transformations and utilize PI regulators, which affects the system simplicity and causes a delay in the dynamic response, in addition to the need to use a modulation stage.

An attempt was made to overcome the complexity of the VOC structure by replacing the PI regulators with hysteresis torque and rotor flux comparators, which formulated the DTC of DFIGs [26-28]. DTC offers the advantage of a fast response, but the ripples issue remains the main challenge [29]. Recently, researchers have tried to think about a new control method which obviates the defects of VOC and DTC, so predictive control (PC) came to light [30-35]. It uses a cost function, which replaces the PI regulators and current control loops of VOC and the hysteresis comparators used by DTC. This has contributed to achieving a quick dynamic response, producing a better steady-state performance, and minimizing the complication and ripples as well. The adopted cost function has two components of the absolute error of the variables that need to be controlled; it also has the merit of flexibility and ability to handle different control objectives at the same time. Model PC (MPC) is used in many applications; in [36], it is used to improve the performance of the power system, and in [37], it is used with a microgrid system. PC has two topologies which are usually adopted with a DFIG: finite control set predictive control (FCS PC), which was adopted in $[30,38]$, and continuous control set predictive control (CCS PC), which was adopted in $[32,39]$. CCS PC has a fixed switching frequency as it requires a PWM modulator so that the selected optimal voltages can be applied to the machine; meanwhile, FCS PC does not need a modulator as it chooses the voltages from specific vectors (usually eight vectors (six active and two null)), which reduces the system's complexity, but on the other hand, its switching frequency is variable. FCS PC reduces the switching actions in comparison with CCS PC, resulting in a lower number of commutations. The control structures of FCS PC and CCS PC are shown in Figures 1 and 2, respectively, clarifying the difference between the two topologies. The vector $u(k)$ refers to the controlled variable and $S(k)$ refers to the switching state, while $d(k)$ refers to the duty ratio.

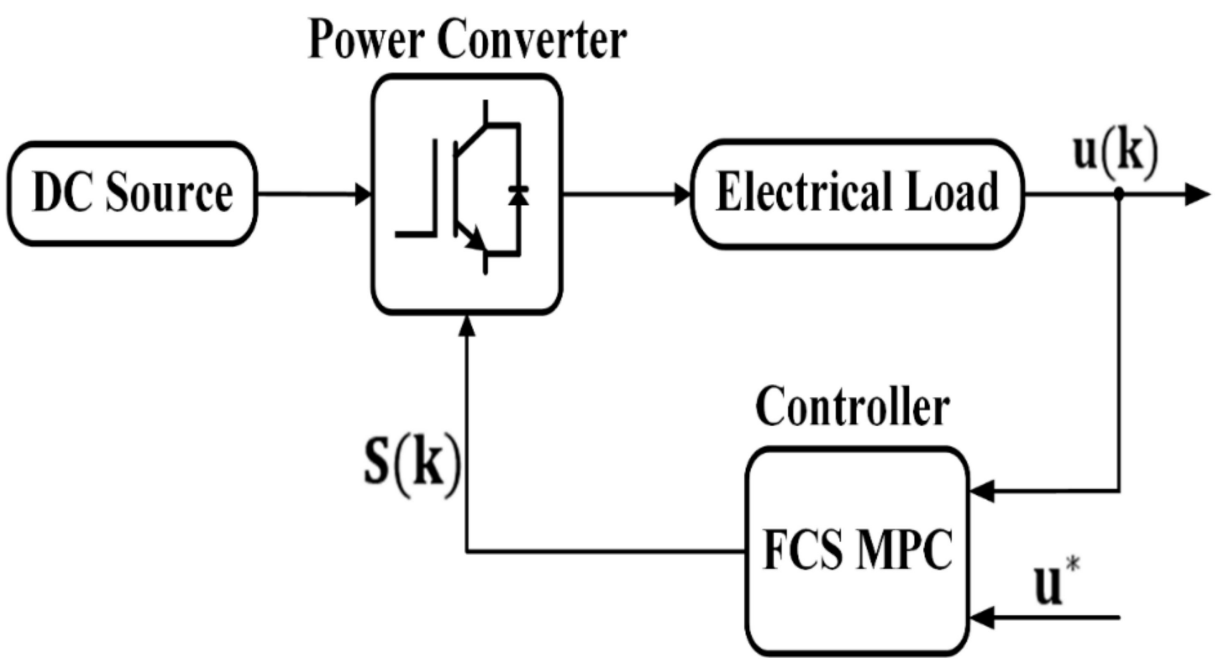

Figure 1. FCS PC structure. 


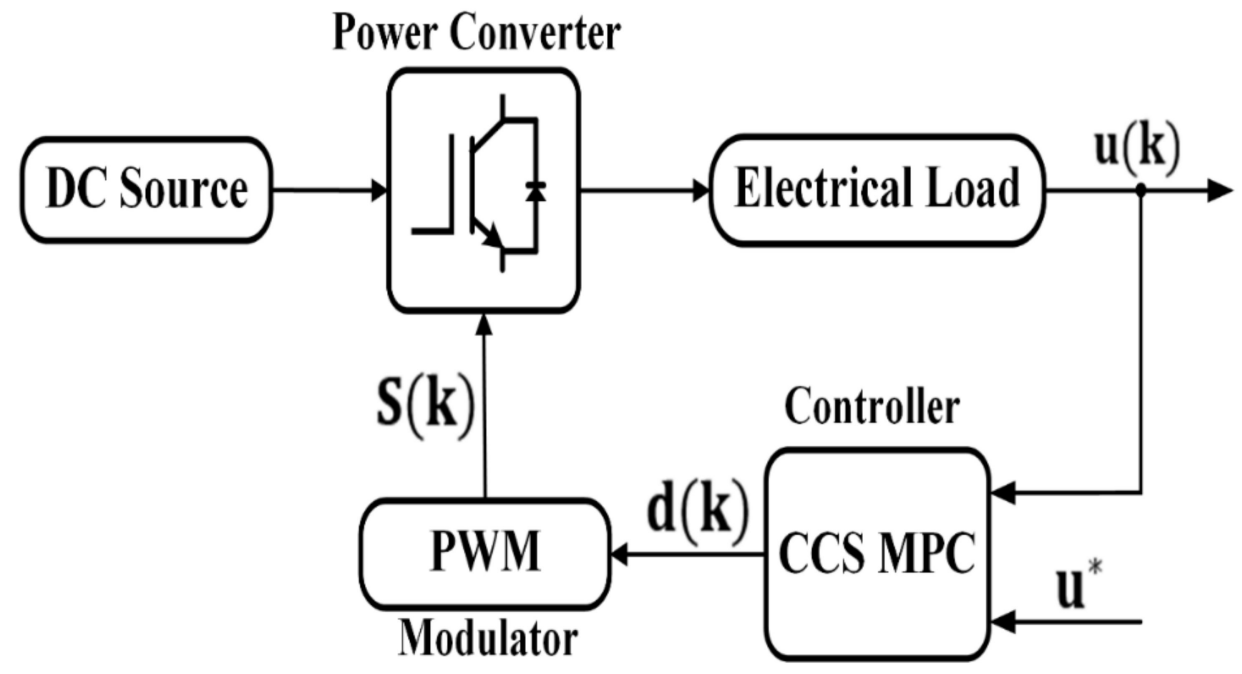

Figure 2. CCS PC structure.

To overcome some of the DTC defects such as increased ripples, model predictive DTC (MPDTC), which adopted FCS PC, has been used. MPDTC aims to minimize the error between the reference and predicted values of the torque and rotor flux. MPDTC, unfortunately, suffers from some defects: firstly, the cost function requires a weighting factor $\left(\omega_{f}\right)$, which is necessary to achieve the equilibrium between the torque and rotor flux. Furthermore, the ripples in the torque and rotor flux are exposed to increase due to any inadequate selection of $\omega_{f}$. Another defect facing MPDTC is that the components of the cost function need to be estimated, so any mismatch or change in the model parameters can influence the estimated variables. Moreover, the computational burden is considered a dilemma for MPDTC, as it requires estimation and prediction of the rotor flux and torque $[20,40-44]$.

To overcome the shortages of MPDTC — especially the noticeable ripples-some modifications were made by implementing more than one vector within the same sampling interval $[45,46]$. This action contributed effectively to reducing the flux and torque fluctuations around their references; however, the computation time increased again. Other researchers adopted an online adaptation of the weighting factor in order to achieve an optimal balance between the flux and torque variations [47]. A good performance was obtained using the online weighting update, but the system's computational burden was increased, which made this solution unfit for all applications in which the execution capacity of the micro-processors is restricted. Other studies considered the insertion of adaptive flux estimators so as to achieve smooth flux and torque variations $[48,49]$. Appropriate results were obtained using the adaptive estimators; however, the system's complexity was negatively affected.

Another topology of PC is model predictive current control (MPCC), which tries to overcome some of the defects of MPDTC; it has lower torque and flux ripples compared with MPDTC. Furthermore, its cost function does not need a weighting factor scale, which formulates the simplicity of this controller. MPCC agrees with MPDTC on disposing of the PI regulators which are commonly adopted by the VOC technique $[38,48]$. Unfortunately, the response of MPCC is slower than that of MPDTC, and it still suffers from high computational burden. Moreover, its cost function includes variables that need to be estimated using the machine model, which can be easily influenced by the operating conditions $[50,51]$.

To achieve a compromise between the suitable computational burden and reduced ripples when considering predictive control, the design of a cost function and its terms must be suitably performed [52-54]. For this reason, the current study presents a design for predictive control that uses a cost function with similar terms. The components of the cost function are the differences between the actual and reference values of the $(d-q)$ components 
of the rotor voltage. The main factor that affects the operation of the designed PVC is the generation of voltage commands. The $d-q$ voltage references can be obtained using the deadbeat principle. However, considering the deadbeat principle to generate the reference voltages is not a perfect solution as it depends on utilizing the machine physical model, liable to uncertainties, which can result in steady-state offset and oscillatory output [55-58]. This fact was determined by analyzing the mechanism by which deadbeat control works. Deadbeat control is concerned with eliminating the system poles by making the nominator of the controller equal to the denominator of the system; in practice, there is always a modeling mistake or parameter perturbation that changes the actual system. Therefore, the mathematical controller will not work properly. Thus, in the current study, the reference voltages are developed using two designed proportional-integral regulators instead of direct calculation using the machine model.

Furthermore, a fair comparison between different control topologies for the DFIG must be presented to outline the most effective procedure in terms of dynamic response, structure simplicity, ripples, and computational burdens. For these reasons, in the present paper, different control topologies for the DFIG are explored, clarifying the base operation principle of each. In addition, an effective PVC technique is formulated for managing the operation of the DFIG. In addition, in order to visualize the features of each technique, a comparison of the dynamic performance is performed between the formulated PVC and three other control topologies: SVOC, MPCC, and MPDTC. The performance analysis is carried out under two different operating conditions: in the first one, the reference active power is kept constant while the driven speed is varied, whereas in the second condition, the reference power is varied but the driven speed is kept constant. Eventually, the features of each control technique will be outlined and the most appropriate technique can be identified.

The contributions of the paper are as follows:

- $\quad$ The paper formulates an effective predictive voltage control (PVC) approach which overcomes the shortages present in previous DFIG control schemes.

- The paper presents a comprehensive performance analysis for the DFIG using the formulated PVC scheme and other control techniques under different operating conditions.

- The paper introduces a detailed description for the presented control algorithms in order to visualize the base principle of each method, showing when it works properly and when it fails.

- The obtained results reveal and confirm the superiority of the formulated PVC over the other control schemes in terms of the fast dynamic response, simplicity, and reduced ripples and computational burdens.

- Compared with recent control schemes that adopt an equivalent operating theory, the proposed PVC proves its enhanced robustness against parameter variation.

- The designed PVC scheme can be used with other machine configurations after considering the structure and operation theory of each type.

The article is arranged as follows. Firstly, the mathematical model of the DFIG is presented, and then, the SVOC, MPCC, and MPDTC schemes and the formulated PVC scheme are described in a systematic manner. The following section introduces the test results and its related analysis, and lastly, the conclusions are presented.

\section{Mathematical Model of DFIG}

In the model of the DFIG shown in Figure 3, the stator voltage was chosen to be aligned with the direct axis of the rotating synchronous frame, so the frame in which the variables are expressed rotates with a speed equal to that of the stator voltage vector $\left(\omega_{\bar{u}_{s}}\right)$.

Here, the variables $\bar{u}_{s}^{s v}, \bar{u}_{r}^{S v}, \bar{i}_{s}^{S v}, \bar{i}_{r}^{S v}, \bar{\Psi}_{s}^{S v}$, and $\bar{\Psi}_{r}^{s v}$ are the stator voltage vector, rotor voltage vector, stator current vector, rotor current vector, stator flux vector, and rotor flux vector, respectively; the superscript ${ }^{s v \prime}$ means that all variables are defined in the stator voltage frame which rotates with the synchronous speed $\left(\omega_{\bar{u} s}\right) ; R_{s}, R_{r}, L_{l s}, L_{l r}$, and $L_{m}$ are 
the stator resistance, rotor resistance, stator leakage inductance, rotor leakage inductance, and mutual inductance respectively; and $\omega_{m e}$ is the rotor mechanical speed.

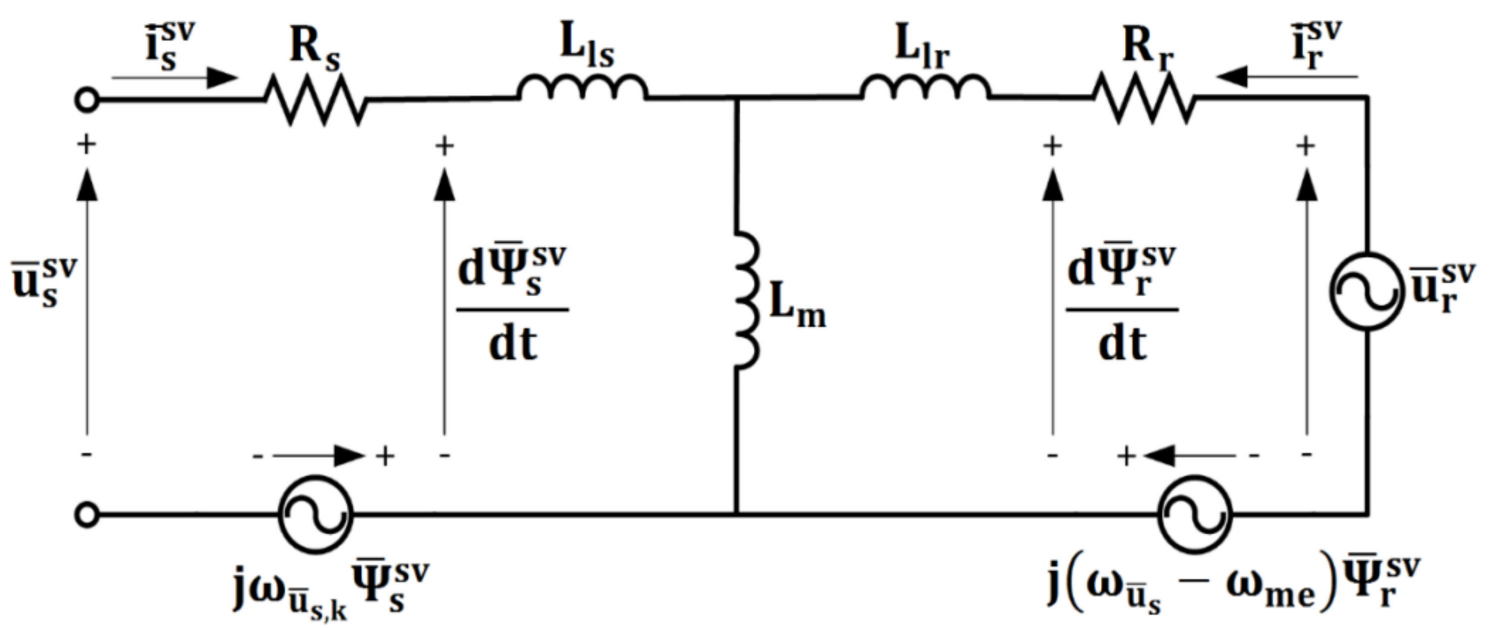

Figure 3. Equivalent circuit model of DFIG.

From Figure 1, and using a sampling time $\left(T_{s}\right)$, the voltage balance in the stator and rotor can be expressed at instant $\left(K T_{s}\right)$ as follows:

$$
\begin{gathered}
\bar{u}_{s . k}^{s v}=R_{s} \bar{l}_{s, k}^{s v}+\frac{d \bar{\Psi}_{s, k}^{s v}}{d t}+j \omega_{\bar{u}_{s, k}} \bar{\Psi}_{s, k}^{s v} \\
\bar{u}_{r, k}^{s v}=R_{r} \bar{l}_{r, k}^{s v}+\frac{d \bar{\Psi}_{r, k}^{s v}}{d t}+j \overbrace{\left(\omega_{\bar{u}_{s, k}}-\omega_{m e, k}\right)}^{\omega_{s l i p, k}} \bar{\Psi}_{r, k}^{s v}
\end{gathered}
$$

Using the flux-current equations, the stator and rotor flux linkages can be expressed by the following:

$$
\begin{aligned}
& \bar{\Psi}_{s, k}^{s v}=L_{s} \bar{l}_{s, k}^{s v}+L_{m} \bar{l}_{r, k}^{s v} \\
& \bar{\Psi}_{r, k}^{s v}=L_{r} \bar{l}_{r, k}^{s v}+L_{m} \bar{l}_{s, k}^{s v}
\end{aligned}
$$

where $L_{S}$ and $L_{r}$ are the stator and rotor inductances, respectively, which can be defined as

$$
\begin{aligned}
& L_{s}=L_{l s}+L_{m} \\
& L_{r}=L_{l r}+L_{m}
\end{aligned}
$$

Using Equations (1) and (2), the dynamic model of the DFIG in this coordinate system can be represented as follows:

$$
\begin{gathered}
\frac{d \bar{\Psi}_{s, k}^{s v}}{d t}=\bar{u}_{s, k}^{s v}-R_{s} \bar{l}_{s, k}^{s v}-j \omega_{\bar{u} s, k} \bar{\Psi}_{s, k}^{s v} \\
\frac{d \bar{\Psi}_{r . k}^{s v}}{d t}=\bar{u}_{r, k}^{s v}-R_{r} \bar{l}_{r, k}^{s v}-j \omega_{\bar{u} s l i p, k} \bar{\Psi}_{r, k}^{s v} \\
\frac{d \omega_{m e, k}}{d t}=\frac{p}{J}\left(T_{m e, k}-T_{d, k}\right)
\end{gathered}
$$

where $p$ and $J$ are the number of pole pairs and inertia of the DFIG, respectively, and $T_{m e}$ and $T_{d}$ are the mechanical torque applied to the shaft and the torque developed by the DFIG, respectively. 
The torque developed by the DFIG can be defined by the following:

$$
T_{d, k}=1.5 p L_{m}\left(i_{d r, k}^{s v} i_{q s, k}^{s v}-i_{q r, k}^{s v} i_{d s, k}^{i v}\right)
$$

After deriving the mathematical model of the DFIG, it can be used to construct the control schemes as described in the following section.

\section{Control Techniques of DFIG}

\subsection{SVOC Technique}

VOC is a strategy that depends in its operation on decomposing the stator current into two components: the torque component, which produces the torque, and the magnetizing component, which produces the flux. Thereafter, the two components are decoupled and individually controlled.

In [20], the SVOC principle is adopted, in which the stator voltage vector $\bar{u}_{s, k}$ is set in the direction of the $d$-axis of the synchronous frame, which rotates with a speed of $\omega_{\bar{u} s, k}$, as shown in Figure 4, so there is no voltage along the $q$-axis. As noted in Figure 4, there are three reference frames: the stationary reference frame $\left(\alpha^{s}-\beta^{s}\right)$, the rotor reference frame $\left(d^{r}-q^{r}\right)$, and the synchronous rotating frame $\left(d^{\bar{u}_{s}}-q^{\bar{u}_{s}}\right)$.

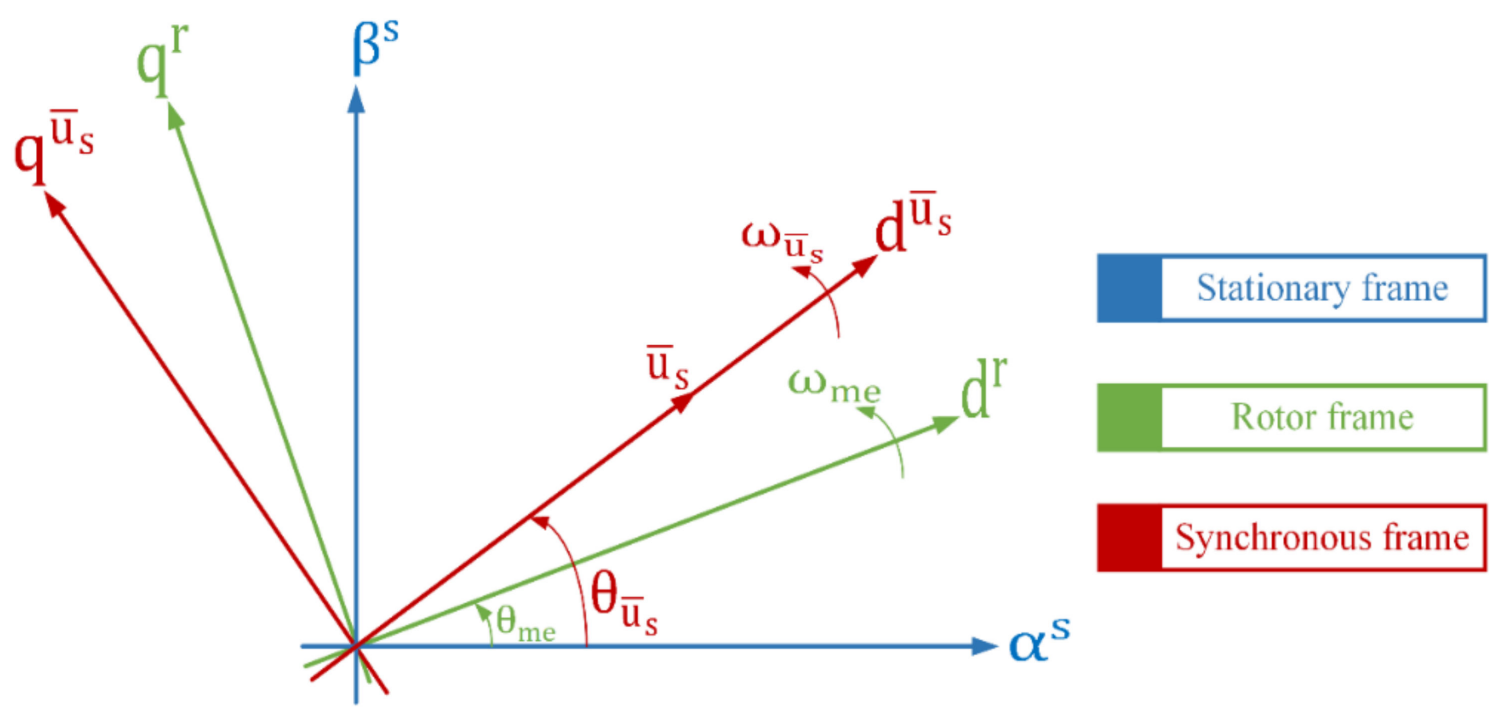

Figure 4. Relationships between reference frames.

Thus, by considering the orientations presented in Figure 4, the following relations can be concluded under SVOC:

$$
u_{d s, k}^{s v}=\left|\bar{u}_{s, k}^{s v}\right| \quad \text { and } \quad u_{q s, k}^{s v}=0
$$

Equation (1) can be represented in the $d-q$ axes as follows:

$$
\begin{aligned}
& u_{d s, k}^{s v}=R_{s} i_{d s, k}^{s v}+\frac{d \Psi_{d s, k}^{s v}}{d t}-\omega_{\bar{u}_{s, k}} \Psi_{q s, k}^{s v} \\
& u_{q s, k}^{s v}=R_{s} i_{q s, k}^{i v}+\frac{d \Psi_{q s, k}^{s v}}{d t}+\omega_{\bar{u}_{s, k}} \Psi_{d s, k}^{s v}
\end{aligned}
$$

Using Equations (12) and (13), and taking into consideration that the stator voltage drop on the resistance $R_{S}$ is very small compared with the other terms and can be neglected, 
it is found that $\frac{d \bar{\Psi}_{s, k}^{s v}}{d t} \cong 0.0$ under steady-state operation, and the following relationships can be derived:

$$
\Psi_{d s, k}^{s v} \approx \frac{u_{q s, k}^{s v}}{\omega_{\bar{u}_{s, k}}} \approx 0.0 \text { and } \Psi_{q s, k}^{s v} \approx\left|\Psi_{s, k}^{s v}\right| \approx-\frac{u_{d s, k}^{s v}}{\omega_{\bar{u}_{s, k}}}
$$

Using Equation (14), Equation (3) can be represented in the $d-q$ axes as follows:

$$
\begin{gathered}
\Psi_{d s, k}^{s v}=L_{s} i_{d s, k}^{s v}+L_{m} i_{d r, k}^{s v} \approx 0.0 \\
\Psi_{q s, k}^{s v}=L_{s} i_{q s, k}^{s v}+L_{m} i_{q r, k}^{s v} \approx-\frac{u_{d s, k}^{s v}}{\omega_{\bar{u}_{s, k}}}
\end{gathered}
$$

From Equations (15) and (16), the following can be concluded:

$$
\begin{gathered}
i_{d s, k}^{s v}=-\left(\frac{L_{m}}{L_{s}}\right) i_{d r, k}^{s v} \\
i_{q s, k}^{s v}=\frac{\Psi_{q s, k}^{s v}}{L_{s}}-\left(\frac{L_{m}}{L_{s}}\right) i_{q r, k}^{s v}=-\left(\frac{L_{m}}{L_{s}}\right) i_{q r, k}^{s v}-\frac{u_{d s, k}^{s v}}{\omega_{\bar{u}_{s, k}} L_{s}}
\end{gathered}
$$

Using Equations (11), (17) and (18), the active power $\left(P_{s, k}\right)$ and reactive power $\left(Q_{s, k}\right)$ of the DFIG under SVOC can be calculated as follows:

$$
\begin{gathered}
P_{s, k}=1.5\left(u_{d s, k}^{s v} i_{d s}^{s v}+u_{q s, k}^{s v} i_{\mathrm{qs}}^{s v}\right)=1.5 u_{d s, k}^{s v} i_{d s}^{s v}=-1.5 \frac{L_{m}}{L_{s}} u_{d s, k}^{s v} i_{d r, k}^{s v} \\
Q_{s, k}=1.5\left(u_{q s, k}^{s v} i_{d s}^{s v}-u_{d s, k}^{s v} i_{\mathrm{q}}^{s v}\right)=-1.5 u_{d s, k}^{s v} i_{\mathrm{qs}}^{s v}=1.5\left[\frac{L_{m}}{L_{s}} u_{d s, k}^{s v} i_{q r, k}^{s v}+\frac{\left(u_{d s, k}^{s v}\right)^{2}}{\omega_{\bar{u}_{s, k}} L_{s}}\right] \\
=1.5 \frac{L_{m}}{L_{s}} u_{d s, k}^{s v}\left(i_{q r, k}^{s v}+\frac{u_{d s, k}^{s v}}{\omega_{\bar{u}_{s, k}} L_{m}}\right)
\end{gathered}
$$

Furthermore, the developed torque $T_{e, k}$ can be reformulated by substituting from Equations (17) and (18) into (10) as follows:

$$
\begin{gathered}
T_{e, k}=1.5 p L_{m}\left[i_{d r, k}^{s v}\left(-\frac{L_{m}}{L_{s}} i_{q r, k}^{s v}-\frac{u_{d s, k}^{s v}}{\omega_{\bar{u}_{s, k}} L_{s}}\right)+i_{q r, k}^{s v}\left(\frac{L_{m}}{L_{s}}\right) i_{d r, k}^{s v}\right] \\
=1.5 p \frac{L_{m}}{L_{s}}\left(-L_{m} i_{d r, k}^{s v} i_{q r, k}^{s v}-\frac{u_{d s, k}^{s v}}{\omega_{\bar{u}_{s, k}}^{s v}} i_{d r, k}^{s v}+L_{m} i_{d r, k}^{s v} i_{q r, k}^{s v}\right)=-1.5 p \frac{L_{m}}{L_{s} \omega_{\bar{u}_{s, k}}} u_{d s, k}^{s v} i_{d r, k}^{s v}
\end{gathered}
$$

Equations (19)-(21) show that the active power and developed torque can be controlled by adjusting the torque current component $i_{d r, k^{\prime}}^{s v}$, while the reactive power can be controlled by adjusting the excitation current component $i_{q r, k}^{s v}$.

Using Equations (19) and (20), the reference values of the rotor current $i_{d r, k}^{*}$ and $i_{q r, k}^{*}$ can be calculated as follows:

$$
\begin{gathered}
i_{d r, k}^{*}=-\frac{L_{s}}{1.5 L_{m} u_{d s, k}^{s v}} P_{s, k}^{*} \\
i_{q r, k}^{*}=\frac{L_{s}}{1.5 L_{m} u_{d s, k}^{s v}} Q_{s, k}^{*}-\frac{u_{d s, k}^{s v}}{\omega_{\bar{u}_{s, k}} L_{m}}
\end{gathered}
$$

Equation (4) can be represented in the $d-q$ axes as follows:

$$
\begin{aligned}
& \Psi_{d r, k}^{s v}=L_{r} i_{d r, k}^{i v}+L_{m} i_{d s, k}^{s v} \\
& \Psi_{q r, k}^{s v}=L_{r} i_{q r, k}^{s v}+L_{m} i_{q s, k}^{s v}
\end{aligned}
$$


Using Equation (17), Equation (24) can be represented as follows:

$$
\Psi_{d r, k}^{s v}=L_{r} i_{d r, k}^{s v}+L_{m}\left(-\frac{L_{m}}{L_{s}} i_{d r, k}^{s v}\right)=\frac{L_{s} L_{r}-L_{m}^{2}}{L_{s}} i_{d r, k}^{s v}=\sigma L_{r} i_{d r, k}^{s v}
$$

where $\left(\sigma=\frac{L_{s} L_{r}-L_{m}^{2}}{L_{s} L_{r}}=1-\frac{L_{m}^{2}}{L_{s} L_{r}}\right)$ is the leakage factor.

Equation (26) can be reformulated in a general case as the following:

$$
\Psi_{d r, k}^{s v}=\frac{L_{m}}{L_{s}} \Psi_{d s, k}^{s v}+\sigma L_{r} i_{d r, k}^{s v}
$$

Using Equation (18), Equation (25) can be represented as follows:

$$
\Psi_{q r, k}^{s v}=L_{r} i_{q r, k}^{s v}+L_{m}\left(\frac{\Psi_{q s, k}^{s v}}{L_{s}}-\frac{L_{m}}{L_{s}} i_{q r, k}^{s v}\right)=\frac{L_{m}}{L_{s}} \Psi_{q s, k}^{s v}+\frac{L_{s} L_{r}-L_{m}^{2}}{L_{s}} i_{q r, k}^{s v}=\frac{L_{m}}{L_{s}} \Psi_{q s, k}^{s v}+\sigma L_{r} i_{q r, k}^{i v}
$$

Equation (2) can be represented in the $d-q$ axes as follows:

$$
\begin{aligned}
& u_{d r, k}^{s v}=R_{r} i_{d r, k}^{s v}+\frac{d \Psi_{d r, k}^{s v}}{d t}-\omega_{s l i p, k} \Psi_{q r, k}^{s v} \\
& u_{q r, k}^{s v}=R_{r} i_{q r, k}^{s v}+\frac{d \Psi_{q r, k}^{s v}}{d t}+\omega_{s l i p, k} \Psi_{d r, k}^{s v}
\end{aligned}
$$

Using Equations (26) and (28), and being $\left(\frac{d \bar{\Psi}_{s, k}^{s v}}{d t} \cong 0.0\right)$ under-steady state operation, Equations (29) and (30) can be reformulated as follows:

$$
\begin{gathered}
u_{d r, k}^{s v}=\underbrace{R_{r} i_{d r, k}^{s v}+\sigma L_{r} \frac{d i_{d r, k}^{s v}}{d t}}_{u_{d r, k}^{\prime}=\text { Activeterm }}-\underbrace{\omega_{\text {slip }, k}\left(\frac{L_{m}}{L_{s}} \Psi_{q s, k}^{s v}+\sigma L_{r} i_{q r, k}^{s v}\right)}_{\Delta u_{d r, k}^{s v}=\text { Compensationterm }} \\
u_{q r, k}^{s v}=R_{r} i_{q r, k}^{s v}+\frac{L_{m}}{L_{s}} \frac{d \Psi_{q s, k}^{s v}}{d t}+\sigma L_{r} \frac{d i_{q r, k}^{s v}}{d t}+\omega_{s l i p, k} \sigma L_{r} i_{d r, k}^{s v v} \\
=\underbrace{R_{r} i_{q r, k}^{s v}+\sigma L_{r} \frac{d i_{q r, k}^{s v}}{d t}}_{u_{q r, k}^{\prime}=\text { Activeterm }}++\underbrace{\omega_{\text {slip }, k} \sigma L_{r} i_{d r, k}^{s v}}_{\Delta u_{q r, k}^{s v}=\text { Compensationterm }}
\end{gathered}
$$

Equations (31) and (32) formulate the base operation of SVOC, as the reference $d-q$ rotor voltage components are obtained by summing the active voltage terms provided by the PI current controllers and the compensating terms calculated in terms of motor variables.

Figure 5 provides a schematic for SVOC, in which the reference components of the rotor current can be calculated using the reference values of the active and reactive powers; then, they are compared with their actual components. After that, the errors are fed to the PI current regulators to generate the active terms of rotor voltage $u_{d r, k}^{\prime}$ and $u_{q r, k}^{\prime} ;$ then, a phase-locked loop (PLL) is used to evaluate the stator voltage angle $\left(\theta_{\bar{u}_{s}}\right)$ which is required for the coordinates' transformation and further used in calculating the slip frequency, which is needed for calculating the compensation voltage components $\Delta u_{d r, k}^{s v}$ and $\Delta u_{q r, k}^{s v}$. Finally, the rotor voltage components $u_{d r, k}^{s v}$ and $u_{q r, k}^{s v}$ can be easily obtained after adding the compensation terms to the active terms as stated in Equations (31) and (32). 


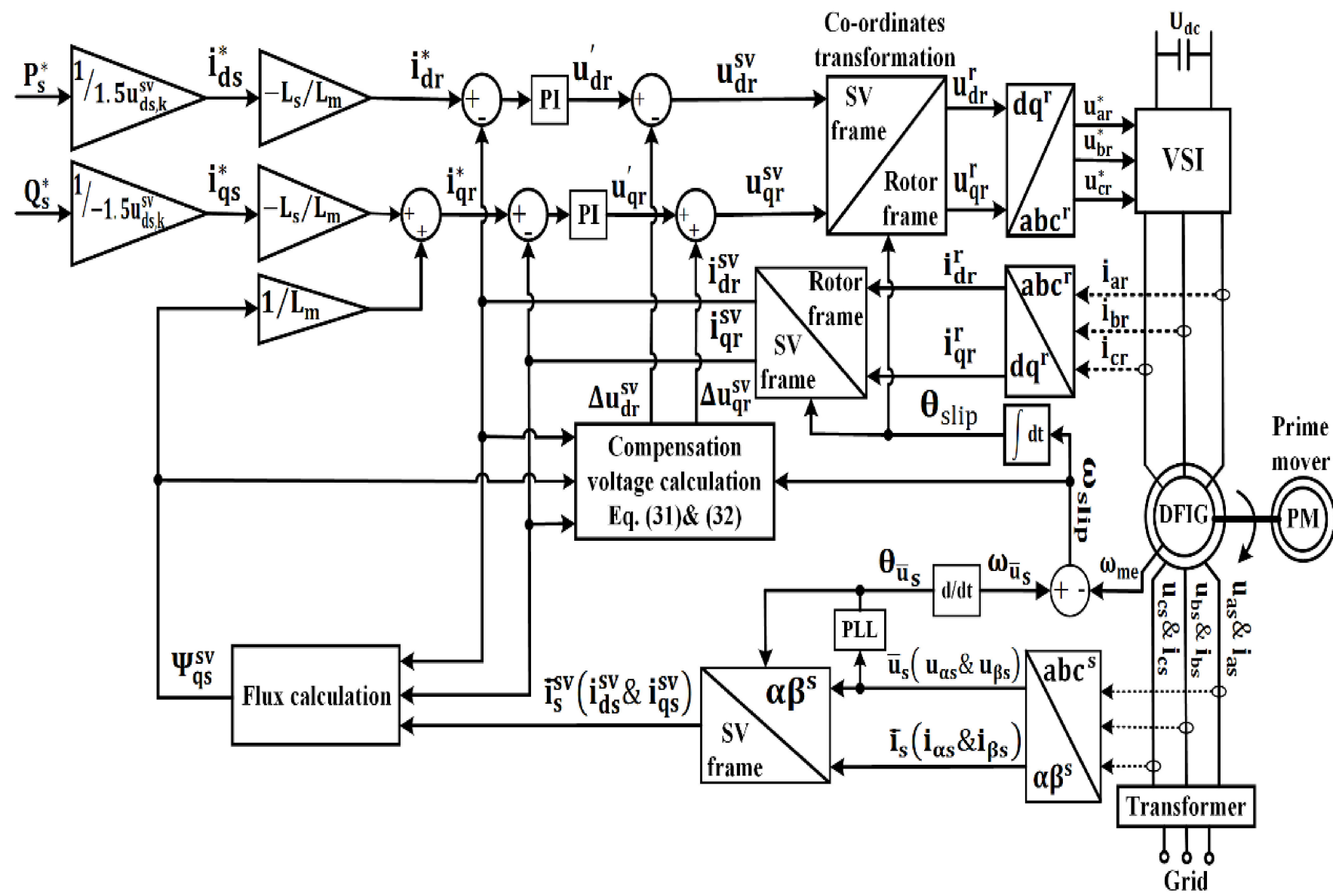

Figure 5. SVOC technique for the DFIG.

\subsection{MPCC Technique}

MPCC utilizes a simple cost function consisting of two similar terms, which are the errors between the actual and reference values of the rotor current, so it does not need a weighting factor. The actual rotor current components $i_{d r, k+1}^{s v}$ and $i_{q r, k+1}^{s v}$ can be predicted using Taylor expansion, while the reference values of the rotor current $i_{d r, k+1}^{*}$ and $i_{q r, k+1}^{*}$ can be directly obtained using the reference values of the active and reactive powers.

The scheme of MPCC can be constructed as shown in Figure 6. First, the stator voltage, stator current, and rotor current are measured and then sampled. The rotor speed $\left(\omega_{m e, k}\right)$ is measured and then integrated to find the rotor position $\left(\theta_{m e, k}\right)$. The rotor position can be estimated at instant $(k+1) T_{s}$ using the following formulation:

$$
\theta_{m e, k+1}=\theta_{m e, k}+\left(\frac{\theta_{m e, k}-\theta_{m e, k-1}}{\Delta T}\right) T_{S}
$$

In the same manner, the stator voltage angle $\left(\theta_{\bar{u}_{s, k}}\right)$ can be evaluated using a phaselocked loop (PLL) and then estimated at instant $(k+1) T_{s}$ using the following formulation:

$$
\theta_{\bar{u}_{s, k+1}}=\theta_{\bar{u}_{s, k}}+\left(\frac{\theta_{\bar{u}_{s, k}}-\theta_{\bar{u}_{s, k-1}}}{\Delta T}\right) T_{S}
$$




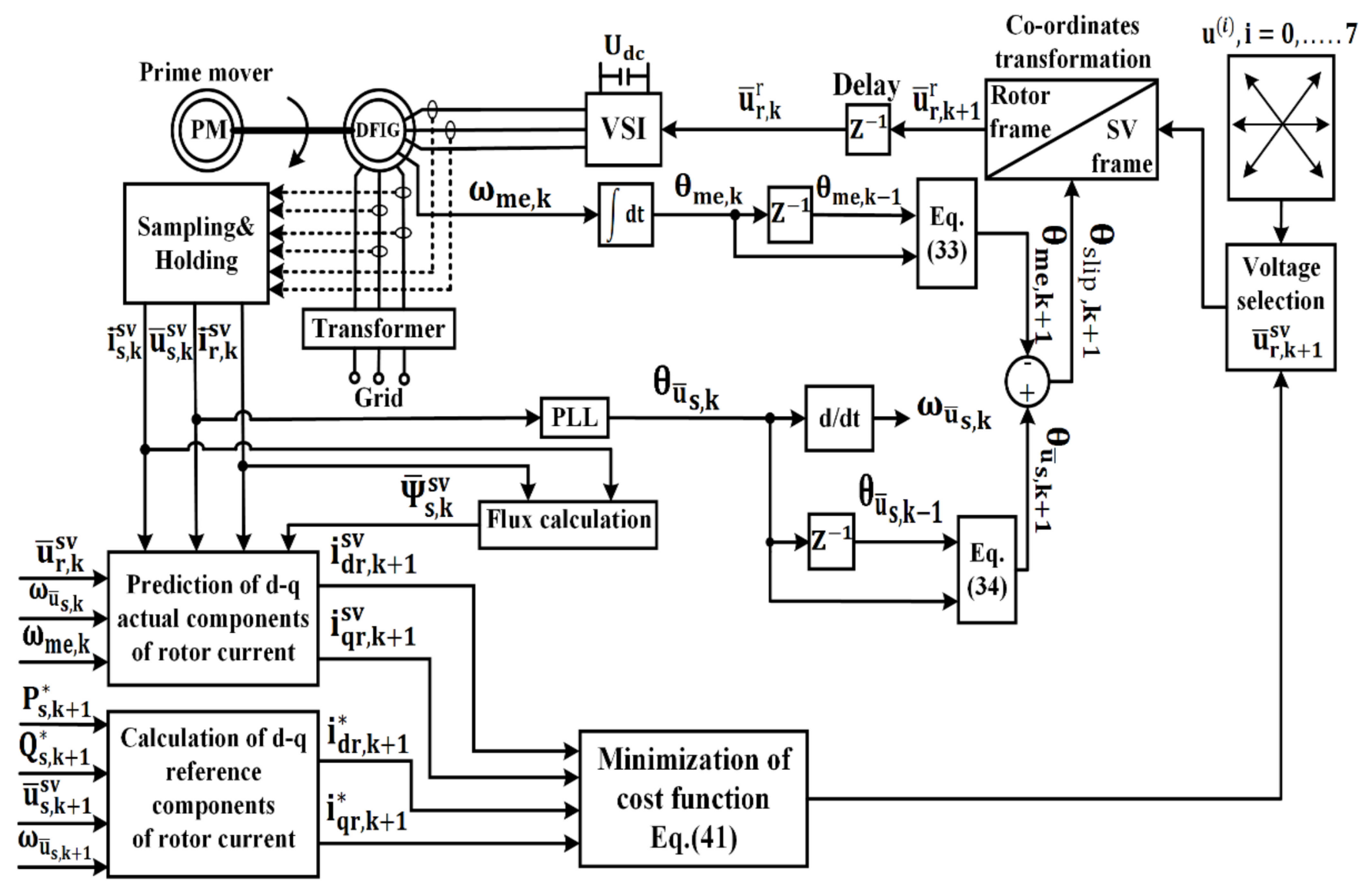

Figure 6. MPCC technique for the DFIG.

Prediction of the actual values of the rotor current can be implemented using Taylor expansion as follows:

$$
\begin{aligned}
& i_{d r, k+1}^{s v}=i_{d r, k}^{s v}+\left(\frac{d i_{d r, k}^{s v}}{d t}\right) T_{s} \\
& i_{q r, k+1}^{s v}=i_{q r, k}^{s v}+\left(\frac{d i_{q r, k}^{s v}}{d t}\right) T_{s}
\end{aligned}
$$

The derivatives of the rotor current components can be found using Equations (31) and (32), as introduced in [56-58], as follows:

$$
\begin{aligned}
& \frac{d i_{d r, k}^{s v}}{d t}=\frac{L_{m}^{2}+L_{r} L_{t}}{L_{r}^{2} L_{t}}\left[u_{d r, k}^{s v}-R_{r} i_{d r, k}^{s v}+\frac{L_{r}}{L_{m}} \omega_{s l i p, k}\left(\Psi_{q s, k}^{s v}-L_{t} i_{q s, k}^{s v}\right)\right]-\frac{L_{m}}{L_{r} L_{t}}\left(u_{d s, k}^{s v}-R_{s} i_{d s, k}^{s v}+\omega_{\bar{u}_{s, k}} \Psi_{q s, k}^{s v}\right) \\
& \frac{d i_{q r, k}^{s v}}{d t}=\frac{L_{m}^{2}+L_{r} L_{t}}{L_{r}^{2} L_{t}}\left[u_{q r, k}^{s v}-R_{r} i_{q r, k}^{s v}-\frac{L_{r}}{L_{m}} \omega_{s l i p, k}\left(\Psi_{d s, k}^{s v}-L_{t} i_{d s, k}^{s v}\right)\right]-\frac{L_{m}}{L_{r} L_{t}}\left(u_{q s, k}^{s v}-R_{s} i_{q s, k}^{s v}-\omega_{\bar{u}_{s, k}} \Psi_{d s, k}^{s v}\right)
\end{aligned}
$$

where $\left(L_{t}=\frac{L_{s} L_{r}-L_{m}^{2}}{L_{r}}=L_{s}-\frac{L_{m}^{2}}{L_{r}}=\sigma L_{s}\right)$ is the stator transient inductance. The stator flux components $\Psi_{d s, k}^{s v}$ and $\Psi_{q s, k}^{s v}$ can be calculated using Equations (15) and (16). Equations (37) and (38) prove that the cost function of MPCC depends on the machine parameters as it includes estimated variables.

Equations (22) and (23) can be reformulated to evaluate the reference values of the rotor current at instant $(k+1) T_{s}$ as follows:

$$
i_{d r, k+1}^{*}=-\frac{L_{s}}{1.5 L_{m} u_{d s, k+1}^{s v}} P_{s, k+1}^{*}
$$




$$
i_{q r, k+1}^{*}=\frac{L_{s}}{1.5 L_{m} u_{d s, k+1}^{s v}} Q_{s, k+1}^{*}-\frac{u_{d s, k+1}^{s v}}{\omega_{\bar{u}_{s, k+1}} L_{m}}
$$

Finally, the actual and reference rotor current components are fed to the cost function, which can be expressed by the following:

$$
\Gamma^{i}=\left|i_{d r, k+1}^{*}-i_{d r, k+1}^{s v}\right|^{i}+\left|i_{q r, k+1}^{*}-i_{q r, k+1}^{s v}\right|^{i}
$$

where the superscript ${ }^{i}$ denotes the sectors $(0, \ldots, 7)$.

The cost function (41) represents the core of the MPCC, based upon which the optimal voltage vectors are selected.

\subsection{MPDTC Technique}

MPDTC depends in its operation on regulating the torque and rotor flux [55], which can be accomplished by eliminating the difference between the reference and predicted actual torque signals $\left(T_{e, k+1}^{*}\right.$ and $\left.T_{e, k+1}\right)$ and between the reference and predicted actual rotor flux signals $\left(\bar{\Psi}_{r, k+1}^{*}\right.$ and $\left.\bar{\Psi}_{r, k+1}^{s v}\right)$; thus, the cost function can be expressed as follows:

$$
\Lambda^{i}=\left|T_{e, k+1}^{*}-T_{e, k+1}\right|^{i}+|| \bar{\Psi}_{r, k+1}^{*}|-| \Psi_{r, k+1}^{s v} \|^{i}
$$

Equation (42) includes variables that need to be evaluated using the machine parameters; it also requires current calculation, which is used for estimating and predicting the torque and rotor flux, and all of this increases the computation time. Furthermore, the function needs a weighting value that is required for ensuring the equilibrium between the torque and rotor flux. If the weighting factor is inappropriately selected, the torque and rotor flux ripples are negatively affected. As mentioned in [55], there is a procedure which tried to choose the optimal weighting factor in an online manner, which reduced the deviations in the torque and rotor flux, but unfortunately, the computational burden was affected. Hence, the weighting factor is still a major obstacle to MPDTC.

The reference value of rotor flux $\left|\bar{\Psi}_{r, k+1}^{*}\right|$ can be evaluated as follows:

$$
\left|\bar{\Psi}_{r, k+1}^{*}\right|=\sqrt{\left(\Psi_{d r, k+1}^{*}\right)^{2}+\left(\Psi_{q r, k+1}^{*}\right)^{2}}
$$

where $\Psi_{d r, k+1}^{*}$ and $\Psi_{q r, k+1}^{*}$ can be calculated as follows:

$$
\begin{aligned}
& \Psi_{d r, k+1}^{*}=L_{r} i_{d r, k+1}^{*}+L_{m} i_{d s, k+1}^{*} \\
& \Psi_{q r, k+1}^{*}=L_{r} i_{q r, k+1}^{*}+L_{m} i_{q s, k+1}^{*}
\end{aligned}
$$

where $i_{d r, k+1}^{*}$ and $i_{q r, k+1}^{*}$ are directly computed using Equations (39) and (40), while $i_{d s, k+1}^{*}$ and $i_{q s, k+1}^{*}$ can be expressed as follows:

$$
\begin{gathered}
i_{d s, k+1}^{*}=\frac{P_{s, k+1}}{1.5 u_{d s, k+1}^{s v}} \\
i_{q s, k+1}^{*}=\frac{Q_{s, k+1}}{-1.5 u_{d s, k+1}^{s v}}
\end{gathered}
$$

The reference value of the torque at instant $(k+1) T_{S}$ can be represented as follows:

$$
T_{e, k+1}^{*}=-1.5 p \frac{L_{m}}{L_{s} \omega_{\bar{u}_{s, k+1}}} u_{d s, k+1}^{s v} i_{d r, k+1}^{*}
$$


The actual value of the rotor flux $\left|\Psi_{d r, k+1}^{s v}\right|$ can be predicted and calculated at instant $(k+1) T_{s}$ in the following manner:

$$
\left|\Psi_{r, k+1}^{s v}\right|=\sqrt{\left(\Psi_{d r, k+1}^{s v}\right)^{2}+\left(\Psi_{q r, k+1}^{s v}\right)^{2}}
$$

where $\Psi_{d r, k+1}^{s v}$ and $\Psi_{q r, k+1}^{s v}$ can be formulated as follows:

$$
\begin{aligned}
& \Psi_{d r, k+1}^{s v}=L_{r} i_{d r, k+1}^{s v}+L_{m} i_{d s, k+1}^{s v} \\
& \Psi_{q r, k+1}^{s v}=L_{r} i_{q r, k+1}^{s v}+L_{m} i_{q s, k+1}^{s v}
\end{aligned}
$$

where the rotor current components $i_{d r, k+1}^{s v}$ and $i_{q r, k+1}^{s v}$ can be predicted using Equations (35)-(38), and the stator current components $i_{d s, k+1}^{s v}$ and $i_{q s, k+1}^{s v}$ can be predicted in the same manner.

The actual predicted value of the torque $T_{e, k+1}$ can be expressed by the following:

$$
T_{e, k+1}=1.5 p L_{m}\left(i_{d r, k+1}^{s v} i_{q s, k+1}^{s v}-i_{q r, k+1}^{s v} i_{d s, k+1}^{s v}\right)
$$

The scheme of MPDTC is illustrated in Figure 7, in which the stator voltage, stator current, and rotor current are measured and then sampled. The rotor speed $\left(\omega_{m e, k}\right)$ is measured and then integrated to find the rotor position $\left(\theta_{m e, k}\right)$, and then, the rotor position can be estimated at instant $(k+1) T_{s}$ as stated in Equation (33). The stator voltage angle $\left(\theta_{\bar{u}_{s, k}}\right)$ can be estimated at instant $(k+1) T_{s}$ as stated in Equation (34). The actual values of the stator and rotor currents are predicted using Taylor expansion, and these components are then used to calculate the actual values of the torque and rotor flux. The reference values of the stator and rotor currents are calculated using the reference active and reactive powers; after that, these components are used to compute the reference values of the torque and rotor flux. Finally, the reference and actual predicted values of the torque and rotor flux are fed to the cost function in Equation (42).

\subsection{Proposed PVC Technique}

The proposed PVC utilizes a very simple cost function which has two similar terms, which are the errors between the reference and actual values of the rotor voltage. The actual rotor voltage components $u_{d r, k+1}^{s v}$ and $u_{q r, k+1}^{s v}$ can be easily obtained using the switching states of the voltage source inverter (VSI), while the reference values of the rotor voltage $u_{d r, k+1}^{*}$ and $u_{q r, k+1}^{*}$ are obtained using two PI current regulators, which are designed as follows.

In order to design the PI rotor current regulators, the transfer function between the inputs, which are the rotor currents, and the outputs, which are the rotor voltages, must be formulated, and this can be performed under the SVOC principle and by reformulating Equations (31) and (32) to be represented at instant $(k+1) T_{S}$ as follows:

$$
\begin{aligned}
u_{d r, k+1}^{s v}= & \underbrace{R_{r} i_{d r, k+1}^{s v}+\sigma L_{r} \frac{d i_{d r, k+1}^{s v}}{d t}}_{u_{d r, k+1}^{\prime}=\text { Activeterm }}-\underbrace{\omega_{s l i p, k+1}\left(\frac{L_{m}}{L_{s}} \Psi_{q s, k+1}^{s v}+\sigma L_{r} i_{q r, k+1}^{s v}\right)}_{\Delta u_{d r, k+1}^{s v}=\text { Compensationterm }} \\
u_{q r, k+1}^{s v}= & R_{r} i_{q r, k+1}^{s v}+\frac{L_{m}}{L_{s}} \frac{d \Psi_{q s, k+1}^{s v}}{d t}+\sigma L_{r} \frac{d i_{q r, k+1}^{s v}}{d t}+\omega_{\text {slip }, k+1} \sigma L_{r} i_{d r, k+1}^{s v} \\
& =\underbrace{R_{r} i_{q r, k+1}^{s v}+\sigma L_{r} \frac{d i_{q r, k+1}^{s v}}{d t}}_{u_{q r, k+1}^{\prime}=\text { Activeterm }}+\underbrace{\omega_{\text {slip }, k+1} \sigma L_{r} i_{d r, k+1}^{s v}}_{\Delta u_{q r, k+1}^{s v}=\text { Compensationterm }}
\end{aligned}
$$


The actual values of the rotor current $i_{d r, k+1}^{s v}$ and $i_{q r, k+1}^{s v}$ are predicted using Equations (35)(38). In the same manner, $i_{q s, k+1}^{s v}$ can be predicted, which will then be utilized to evaluate $\Psi_{q s, k+1}^{s v}$ using Equation (16) after being reformulated at instant $(k+1) T_{s}$.

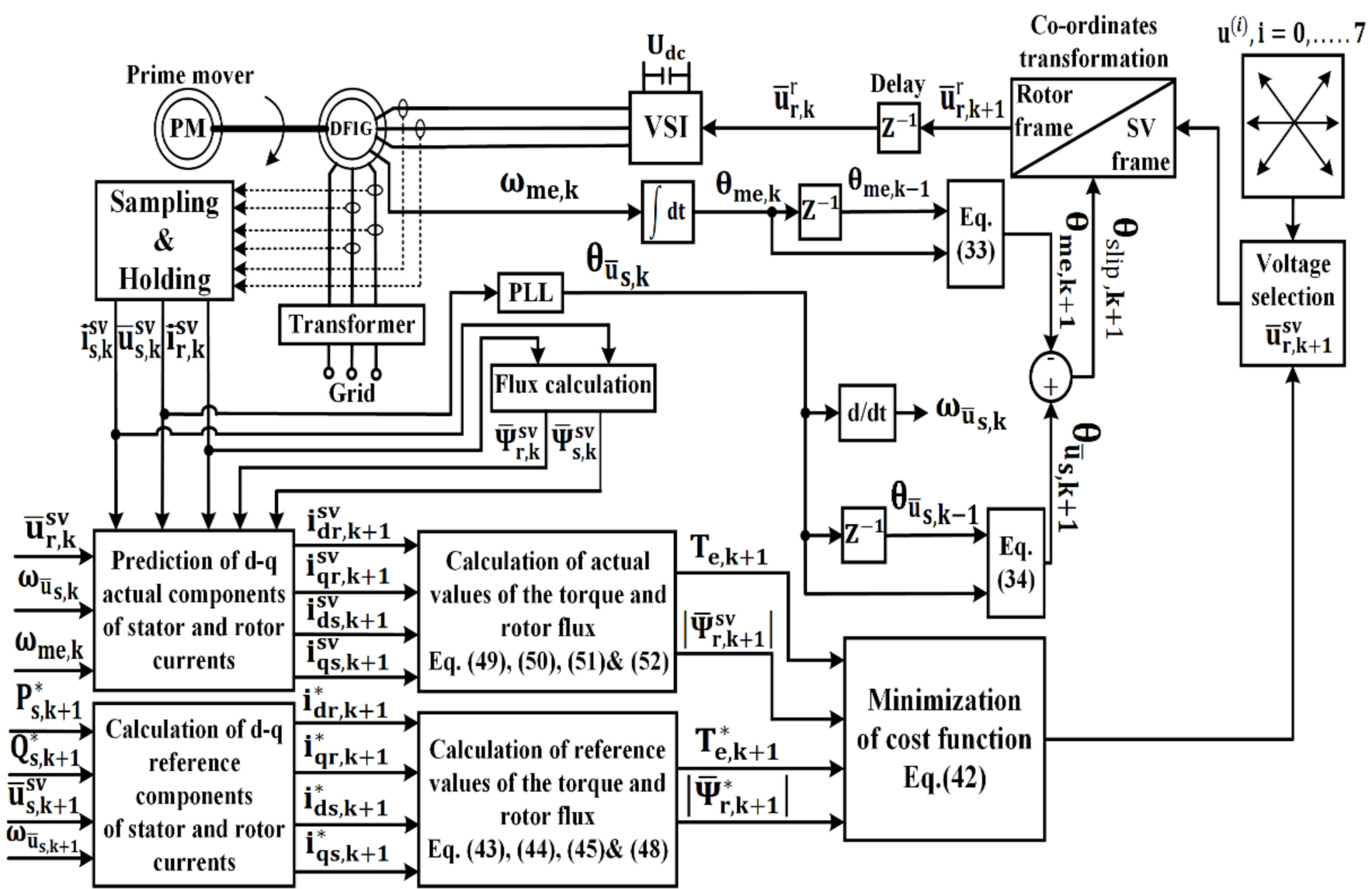

Figure 7. MPDTC technique for the DFIG.

The disturbances can be suppressed with the help of the compensation terms, while the active terms are used to achieve the desired change in the rotor current and drive the transfer function, which determines the response of the rotor voltage to any change in the rotor current. Then, the Laplace transform is applied to the active terms, assuming the initial current to be zero, resulting in the following:

$$
\begin{gathered}
u_{d r, k+1}^{\prime}(s)=R_{r} i_{d r, k+1}^{s v}(s)+\sigma L_{r}\left[s i_{d r, k+1}^{s v}(s)-i_{d r, k+1}^{s v}(0)\right] \\
u_{d r, k+1}^{\prime}(s)=R_{r} i_{d r, k+1}^{s v}(s)+\sigma L_{r} s i_{d r, k+1}^{s v}(s) \\
u_{d r, k+1}^{\prime}(s)=i_{d r, k+1}^{s v}(s)\left[R_{r}+\sigma L_{r} s\right] \\
\frac{i_{d r, k+1}^{s v}(s)}{u_{d r, k+1}^{\prime}(s)}=\frac{1}{R_{r}+\sigma L_{r} s}
\end{gathered}
$$

In the same manner, the following formulation can be obtained:

$$
\frac{i_{q r, k+1}^{s v}(s)}{u_{q r, k+1}^{\prime}(s)}=\frac{1}{R_{r}+\sigma L_{r} s}
$$


The transfer function of the PI rotor current regulators can also be represented by the following:

$$
\begin{aligned}
& u_{d r, k+1}^{\prime}(s)=\overbrace{\left(k_{p}+\frac{k_{i}}{s}\right)}^{P I} \overbrace{\left[i_{d r, k+1}^{*}(s)-i_{d r, k+1}^{s v}(s)\right]}^{d-\text { currenterror }} \\
& u_{q r, k+1}^{\prime}(s)=\underbrace{\left(k_{p}+\frac{k_{i}}{s}\right)}_{P I} \underbrace{\left[i_{q r, k+1}^{*}(s)-i_{q r, k+1}^{s v}(s)\right]}_{q-\text { currenterror }}
\end{aligned}
$$

In Equations (55)-(58), the transfer function of both PI rotor current regulators is similar, which can be derived as follows.

By dividing both sides of Equations (57) and (58) on $i_{d r, k+1}^{s v}(s)$ and $i_{q r, k+1}^{s v}(s)$, respectively, we obtain

$$
\begin{aligned}
& \frac{u_{d r, k+1}^{\prime}(s)}{i_{d r, k+1}^{s v}(s)}=\left(\frac{k_{p} s+k_{i}}{s}\right)\left[\frac{i_{d r, k+1}^{*}(s)}{i_{d r, k+1}^{s v}(s)}-1\right] \\
& \frac{u_{q r, k+1}^{\prime}(s)}{i_{q r, k+1}^{s v}(s)}=\left(\frac{k_{p} s+k_{i}}{s}\right)\left[\frac{i_{q r, k+1}^{*}(s)}{i_{q r, k+1}^{s v}(s)}-1\right]
\end{aligned}
$$

Then, by substituting the voltage component $\left\{u_{d r, k+1}^{\prime}(s)\right\}$ from Equation (55) into Equation (59), it results in the following:

$$
\begin{gathered}
\frac{i_{d r, k+1}^{s v}(s)}{i_{d r, k+1}^{s v}(s)}\left(R_{r}+\sigma L_{r} s\right)=\left(\frac{k_{p} s+k_{i}}{s}\right)\left[\frac{i_{d r, k+1}^{*}(s)}{i_{d r, k+1}^{s v}(s)}-1\right] \\
R_{r}+\sigma L_{r} s=\frac{k_{p} s+k_{i}}{s}\left[\frac{i_{d r, k+1}^{*}(s)}{i_{d r, k+1}^{s v}(s)}\right]-\frac{k_{p} s+k_{i}}{s} \\
\frac{k_{p} s+k_{i}}{s}\left[\frac{i_{d r, k+1}^{*}(s)}{i_{d r, k+1}^{s v}(s)}\right]=R_{r}+\sigma L_{r} s+\frac{k_{p} s+k_{i}}{s} \\
\frac{i_{d r, k+1}^{*}(s)}{i_{d r, k+1}^{s v}(s)}=\left(\frac{R_{r} s+\sigma L_{r} s^{2}+k_{p} s+k_{i}}{s}\right) * \frac{s}{k_{p} s+k_{i}} \\
\frac{i_{d r, k+1}^{s v}(s)}{i_{d r, k+1}^{*}(s)}=\frac{k_{p} s+k_{i}}{\sigma L_{r} s^{2}+\left(R_{r}+k_{p}\right) s+k_{i}}
\end{gathered}
$$

In the same manner, we can obtain

$$
\frac{i_{q r, k+1}^{s v}(s)}{i_{q r, k+1}^{*}(s)}=\frac{k_{p} s+k_{i}}{\sigma L_{r} s^{2}+\left(R_{r}+k_{p}\right) s+k_{i}}
$$

The denominator of both Equations (61) and (62) is considered as the characteristic equation which controls the dynamics of the PI current regulators, and this equation should have negative real roots to achieve system stability; then, the following must be accomplished:

$$
\sigma L_{r} s^{2}+\left(R_{r}+k_{p}\right) s+k_{i}=0
$$

By dividing both sides of Equation (63) by $\left(\sigma L_{r}\right)$, we obtain

$$
s^{2}+\frac{\left(R_{r}+k_{p}\right)}{\sigma L_{r}} s+\frac{k_{i}}{\sigma L_{r}}=0
$$


Then, to calculate the parameters $k_{p}$ and $k_{i}$ of the PI rotor current regulators, we must compare the terms of Equation (64) with that of the characteristic equation of the second-order system, which is represented by

$$
s^{2}+2 D \omega_{n} s+\omega_{n}^{2}=0
$$

Finally, by comparing Equations (64) and (65), the parameters of the PI current regulators can be calculated as follows:

$$
k_{p}=2 D \omega_{n} \sigma L_{r}-R_{r} \text { and } k_{i}=\sigma L_{r} \omega_{n}^{2}
$$

where $(D)$ is the damping factor and $\left(\omega_{n}\right)$ is the natural frequency of the system.

After completing the design of the PI current regulators, the reference components of the rotor voltage $u_{d r, k+1}^{*}$ and $u_{q r, k+1}^{*}$ can be obtained and then utilized by the cost function. Figure 8 presents the scheme of the designed PVC, which starts with measuring the stator voltage and stator current and then sampling these signals. As mentioned previously, Taylor expansion is used to predict the actual components of the stator and rotor current, as stated in Equations (35)-(38). The actual rotor current components $i_{d r, k+1}^{s v}$ and $i_{q r, k+1}^{s v}$ are then compared with the reference $d-q$ rotor current components $i_{d r, k+1}^{*}$ and $i_{q r, k+1}^{*}$, which can be evaluated using Equations (39) and (40), respectively. After that, the errors of the rotor current components are fed to the two designed PI current regulators to obtain the active term components of the rotor voltage $u_{d r, k+1}^{\prime}$ and $u_{q r, k+1}^{\prime}$, which are then added to the compensation voltage components $\Delta u_{d r, k+1}^{s v}$ and $\Delta u_{q r, k+1}^{s v}$ to obtain the reference $d-q$ components of the rotor voltage $u_{d r, k+1}^{*}$ and $u_{q r, k+1}^{*}$ as stated in Equations (53) and (54), respectively. As mentioned earlier, the actual components of the rotor voltage $u_{d r, k+1}^{s v}$ and $u_{q r, k+1}^{s v}$ are directly obtained using the switching states of the inverter. Finally, the actual and reference rotor voltage components are utilized by the cost function, which can be expressed by

$$
C^{i}=\left|u_{d r, k+1}^{*}-u_{d r, k+1}^{s v}\right|^{i}+\left|u_{q r, k+1}^{*}-u_{q r, k+1}^{s v}\right|^{i}
$$

In Equation (67), there is no need for a weighting factor, which leads to avoiding the wrong selection, which may occur with MPDTC. Furthermore, it does not involve any estimated variables that depend on the machine parameters as in MPCC and MPDTC. All of these modifications make PVC more robust and more suitable to be utilized. 


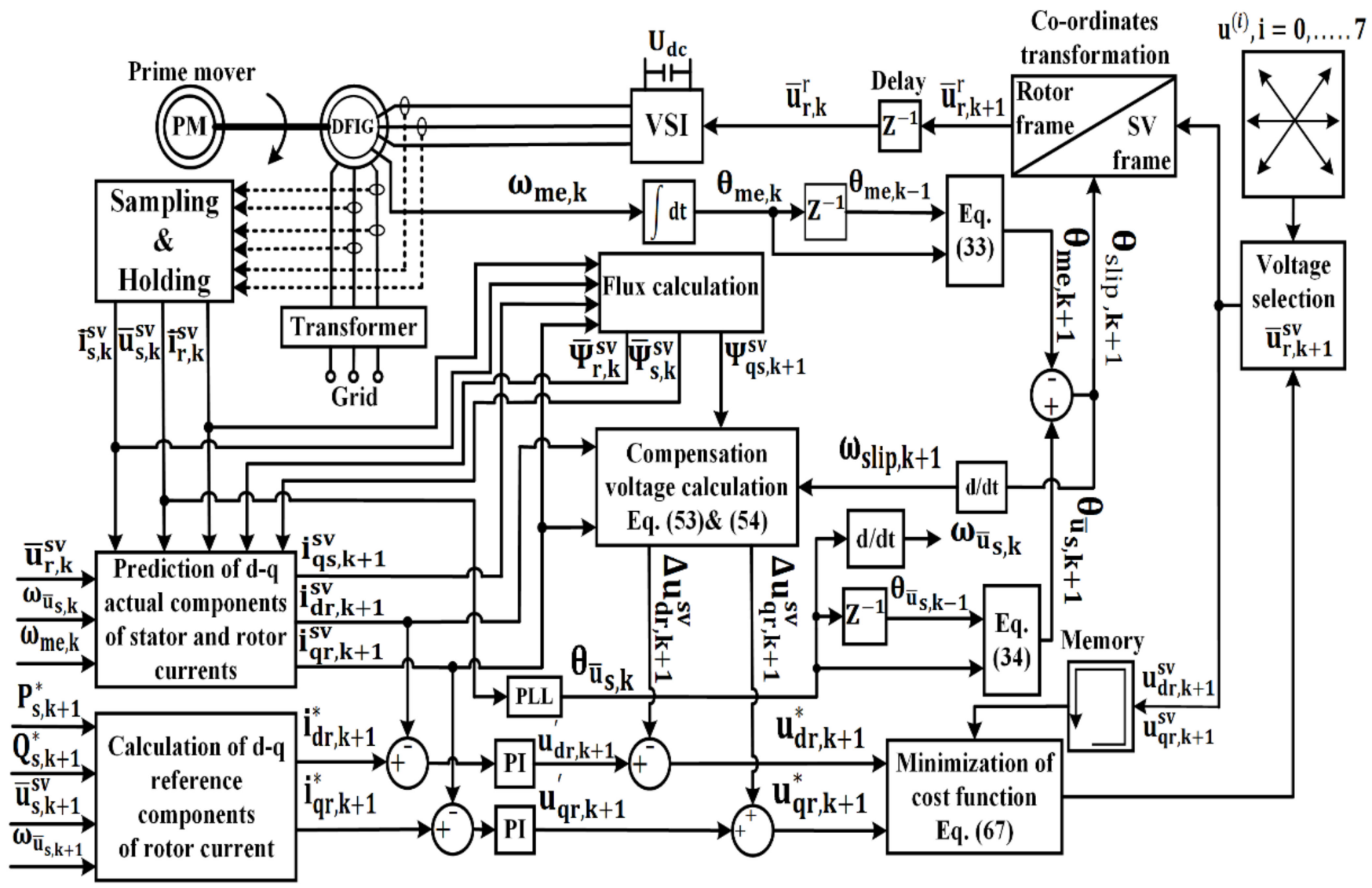

Figure 8. Proposed PVC technique for the DFIG.

\section{Test Results}

Tests were carried out using MATLAB simulation (Simulink) for the four control techniques (SVOC, MPCC, MPDTC, and proposed PVC) under two different operating conditions. In the first one, the active and reactive power reference values $\left(P_{s, k}^{*}\right.$ and $\left.Q_{s, k}^{*}\right)$ were kept constant and set to $50 \mathrm{~kW}$ and 0.0 var, respectively, while the DFIG was driven by various wind-driven operating speeds (sub-synchronous $=-30 \%$ of $\omega_{\bar{u}_{s, k}}$; synchronous $=\omega_{\bar{u}_{s, k}}$; super-synchronous $=+30 \%$ of $\omega_{\bar{u}_{s, k}}$ ), as shown in Figure 9 . The DFIG was driven by different operating speeds to ensure the control's ability to maintain the desired power ratings regardless of the speed variations. Meanwhile, in the second condition, the reference power was initially set to $25 \mathrm{~kW}$ and then changed to $50 \mathrm{~kW}$ while maintaining the reactive power at 0.0 var. Regarding the wind-driven speed, it was kept constant and set to a synchronous speed $\left(\omega_{\bar{u}_{s, k}}=314 \mathrm{rad} / \mathrm{s}\right)$. The parameters of DFIG are presented in Table A1 in Appendix A.

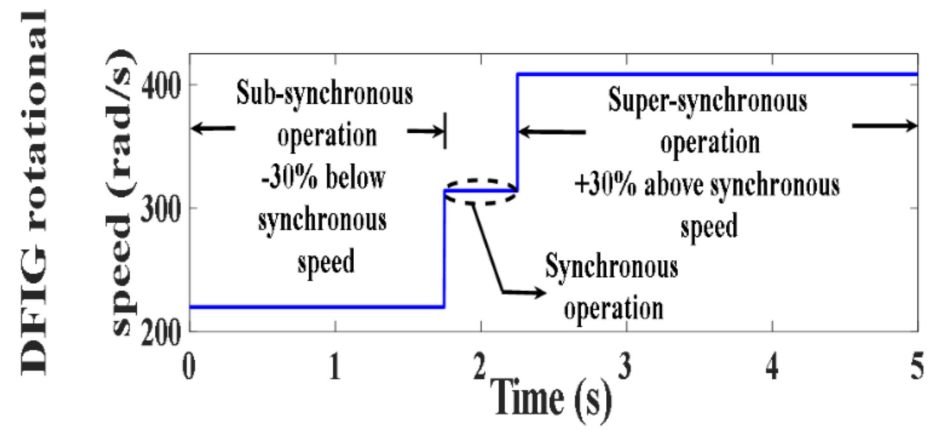

Figure 9. Prime mover operating speeds ( $\mathrm{rad} / \mathrm{s})$. 


\subsection{Testing with SVOC Technique}

The DFIG's performance was tested with the SVOC technique for two different operating regimes: the first under speed variation as shown in Figure 9 and the other under a fixed speed of $314 \mathrm{rad} / \mathrm{s}$. The results obtained for both conditions, which are shown in Figures 10-15 for the variable speed and constant active power and in Figures 16-20 for the fixed speed and variable active power profile, demonstrate that the active power, reactive power, developed torque, and rotor flux smoothly follow their reference values. In addition, the stator and rotor currents track the power change as shown in Figures 21 and 22. It can be concluded that the SVOC is ripple-free, and the estimated values of the powers, torque, and rotor flux are tracking their references in a good manner. The main shortages are the control system complexity and the delayed dynamic response caused by the current regulators.

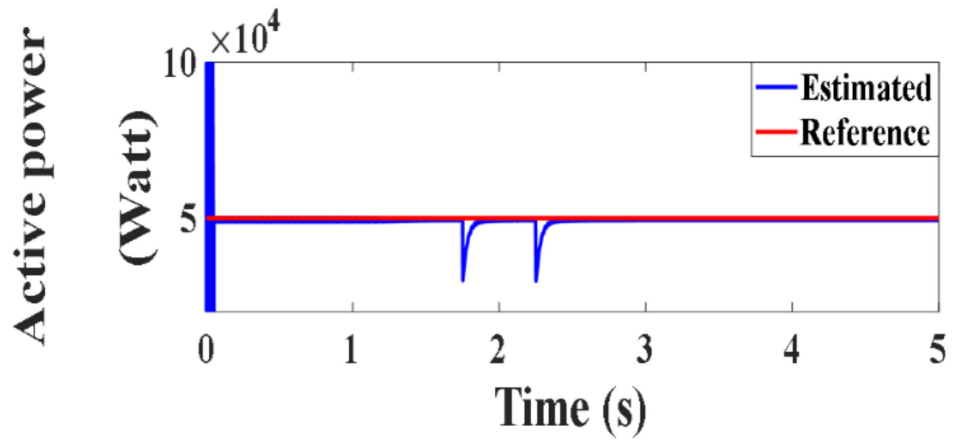

Figure 10. Active power under SVOC (Watt).

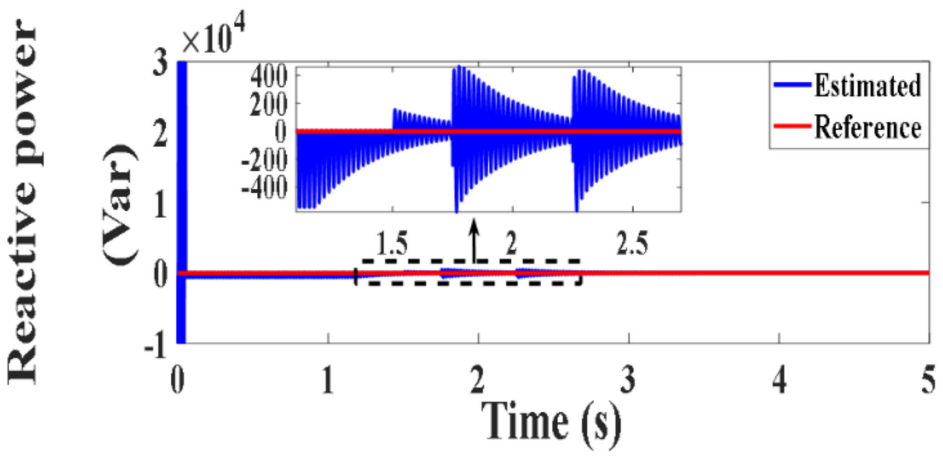

Figure 11. Reactive power under SVOC (var).

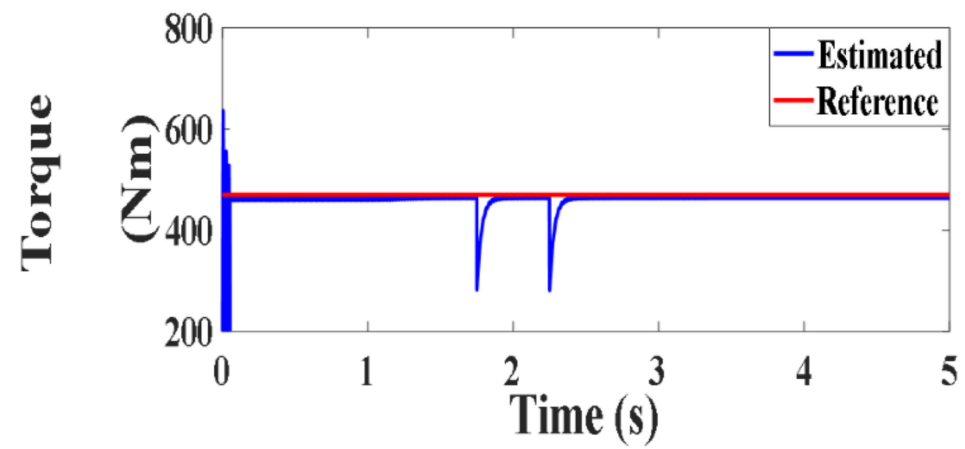

Figure 12. Developed torque under SVOC (Nm). 


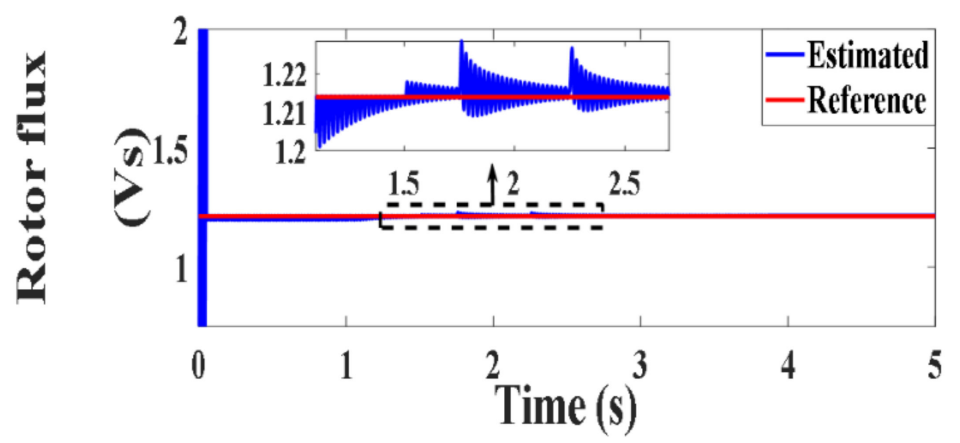

Figure 13. Rotor flux under SVOC (Vs).

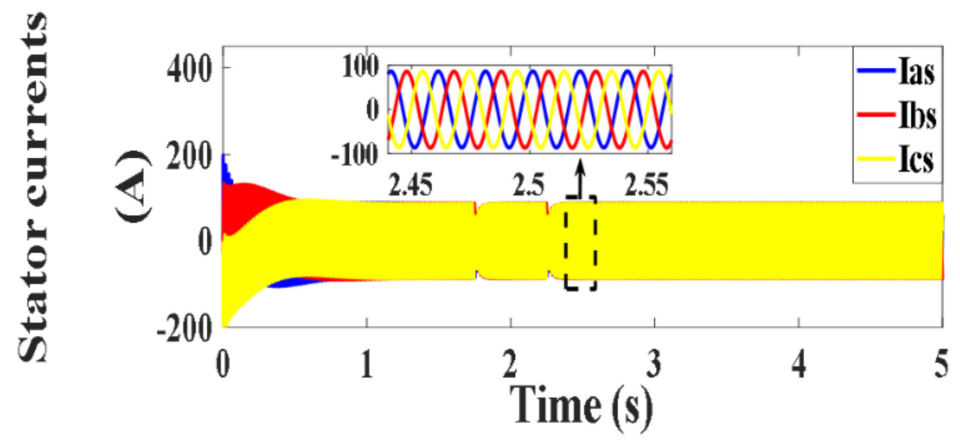

Figure 14. Stator currents under SVOC (A).

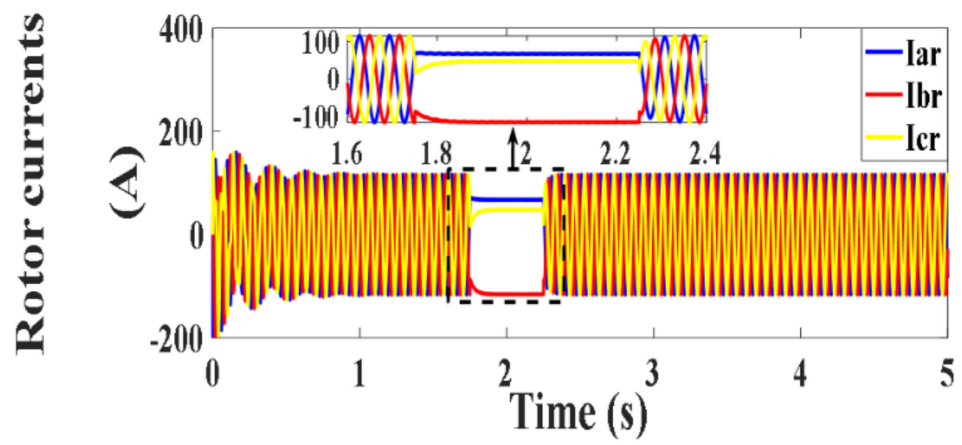

Figure 15. Rotor currents under SVOC (A).

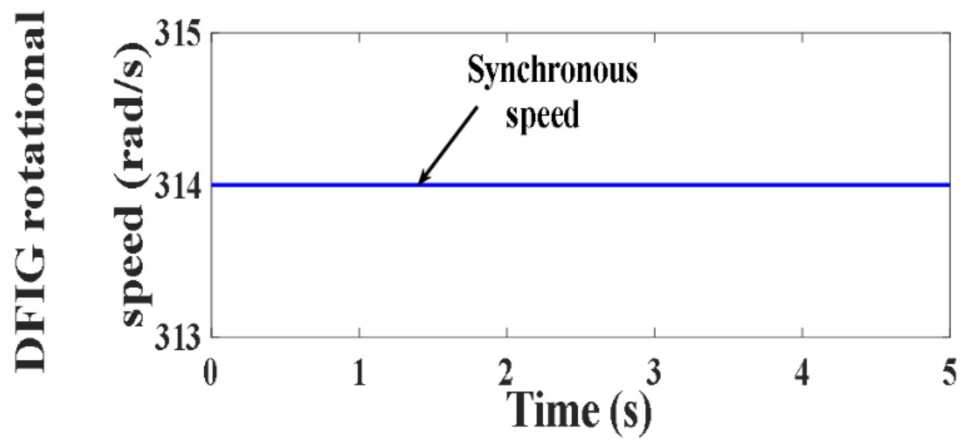

Figure 16. Prime mover operating speed ( $\mathrm{rad} / \mathrm{s})$. 


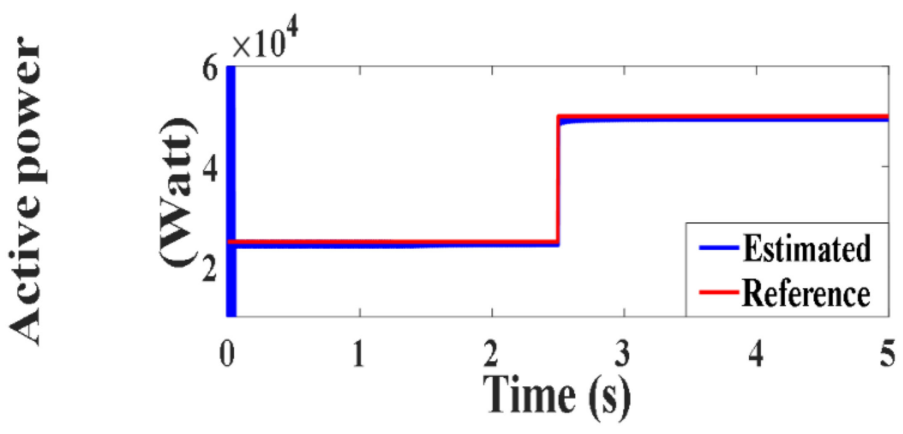

Figure 17. Active power under SVOC (Watt).

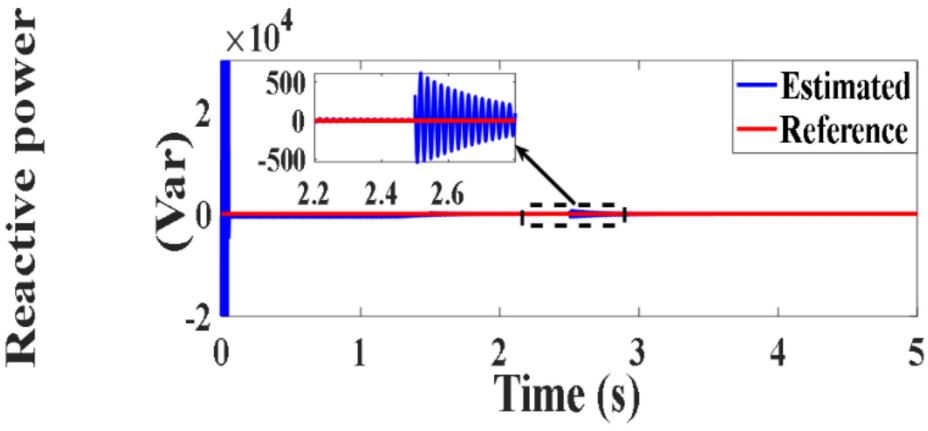

Figure 18. Reactive power under SVOC (var).

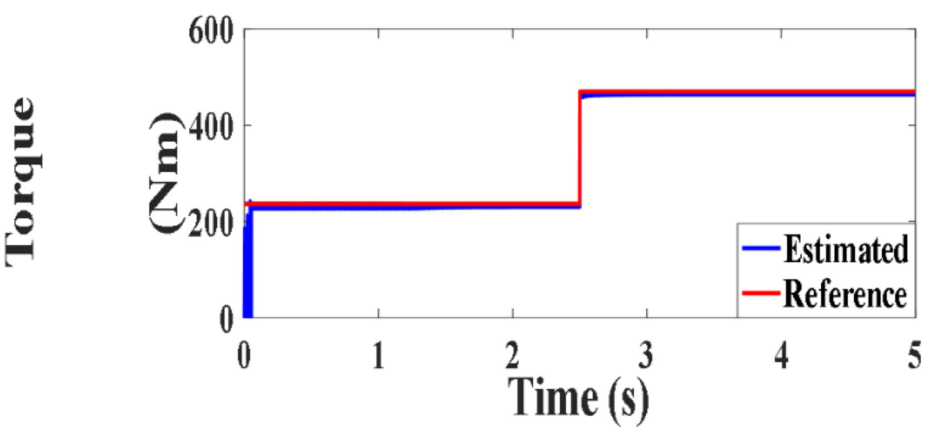

Figure 19. Developed torque under SVOC (Nm).

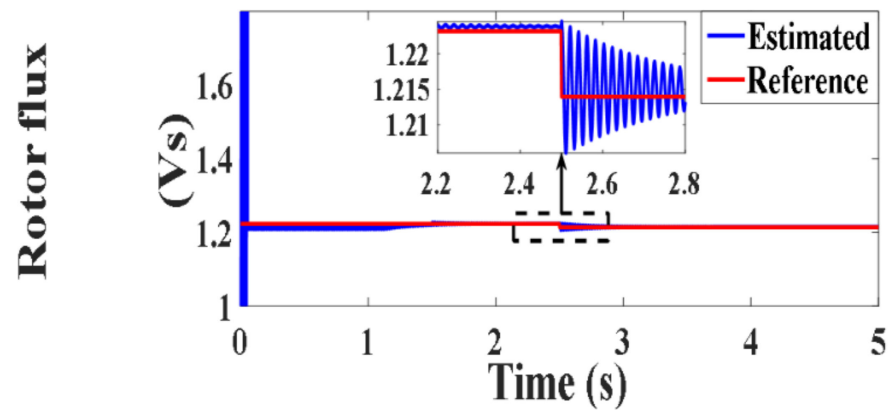

Figure 20. Rotor flux under SVOC (Vs). 


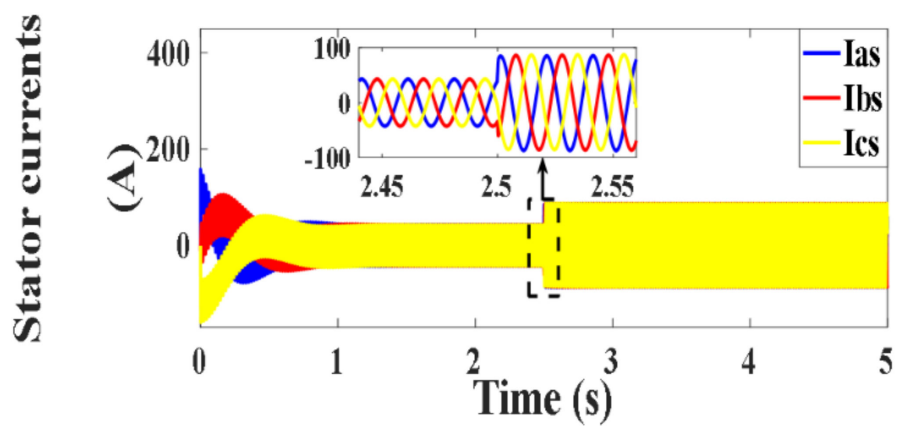

Figure 21. Stator currents under SVOC (A).

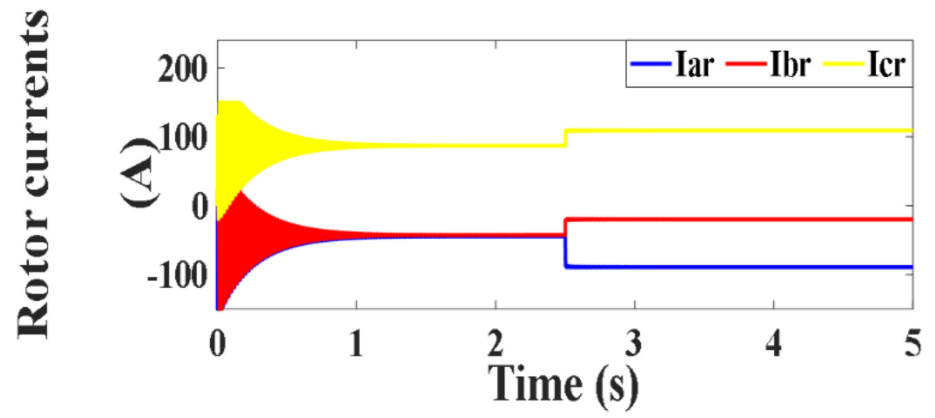

Figure 22. Rotor currents under SVOC (A).

\subsection{Testing with MPCC Technique}

The DFIG's performance was tested with the MPCC technique for the same operating conditions presented in Section 4.1. The results are shown in Figures 23-29 for variable speed operation and in Figures 30-36 for fixed speed operation. The captured results indicate that the actual values of the active and reactive powers, torque, and rotor flux follow their references with a dynamic response faster than that of the SVOC principle; however, its ripples are remarkable in comparison with the SVOC technique.

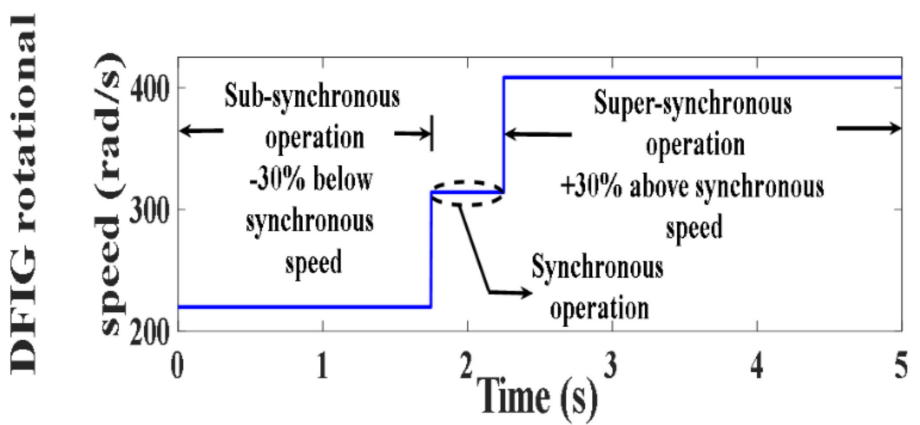

Figure 23. Prime mover operating speeds ( $\mathrm{rad} / \mathrm{s})$.

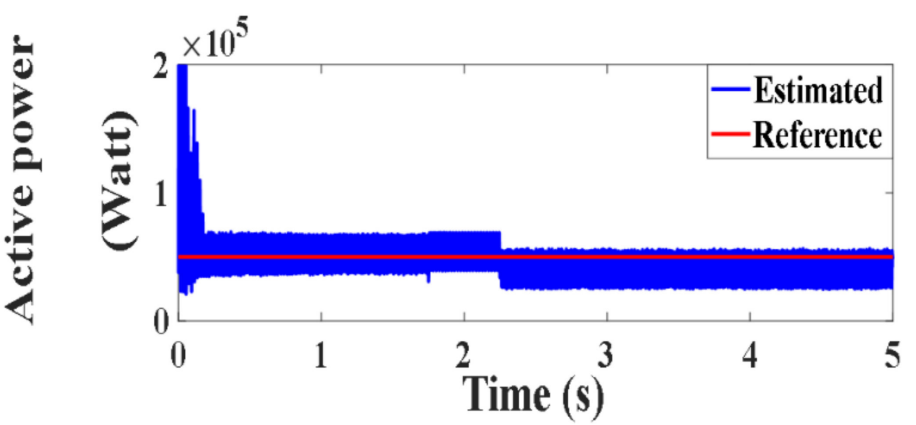

Figure 24. Active power under MPCC (Watt). 


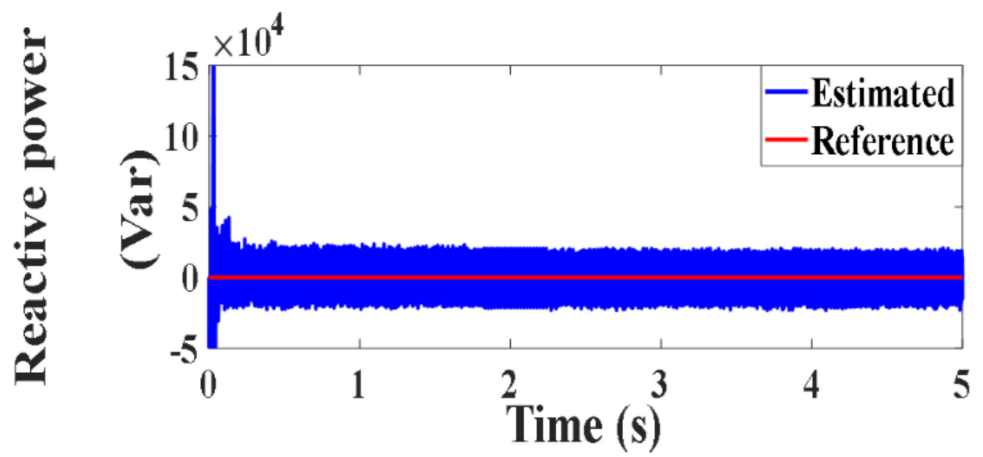

Figure 25. Reactive power under MPCC (var).

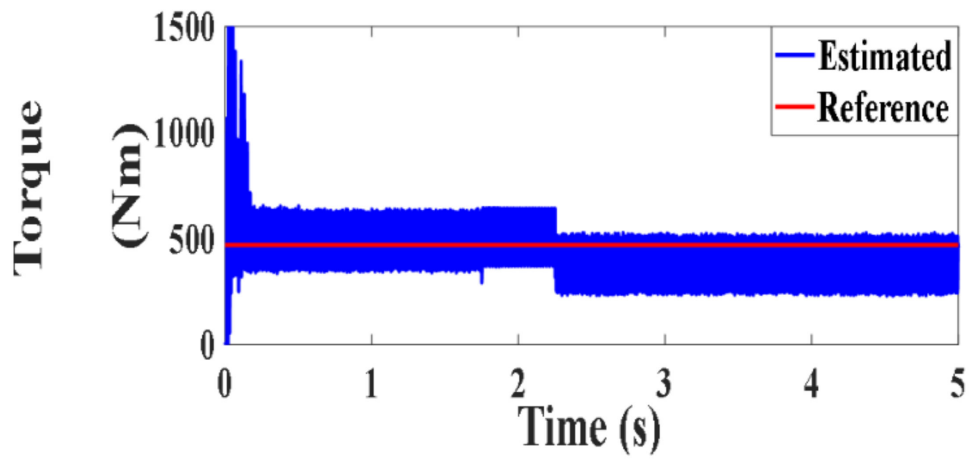

Figure 26. Developed torque under MPCC (Nm).

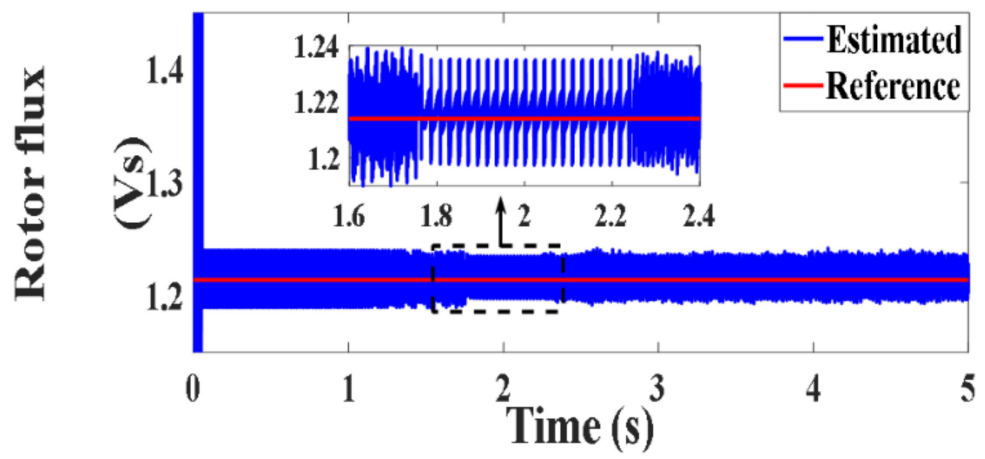

Figure 27. Rotor flux under MPCC (Vs).

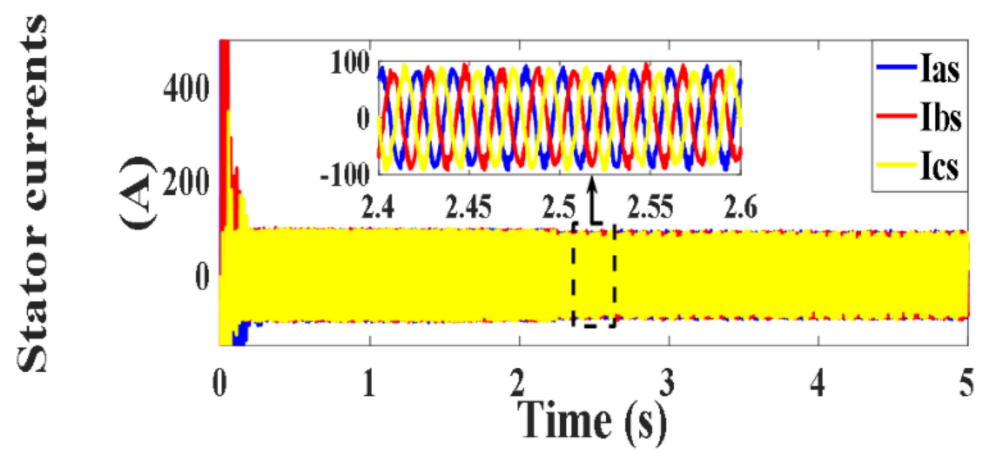

Figure 28. Stator currents under MPCC (A). 


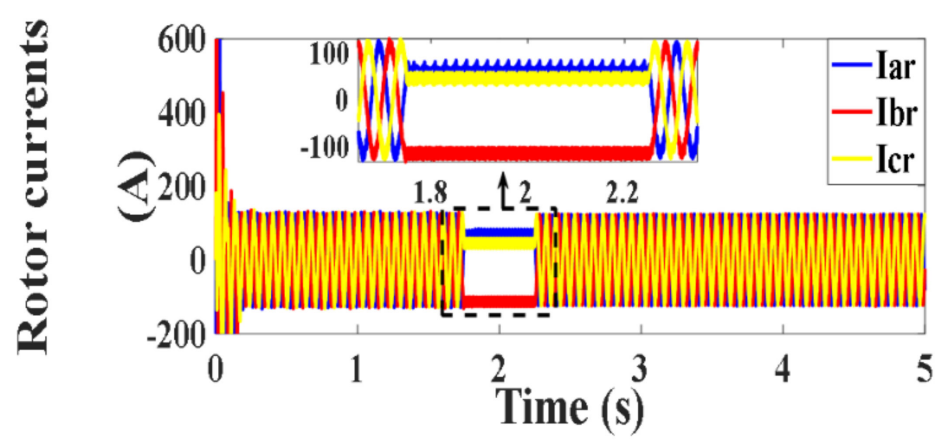

Figure 29. Rotor currents under MPCC (A).

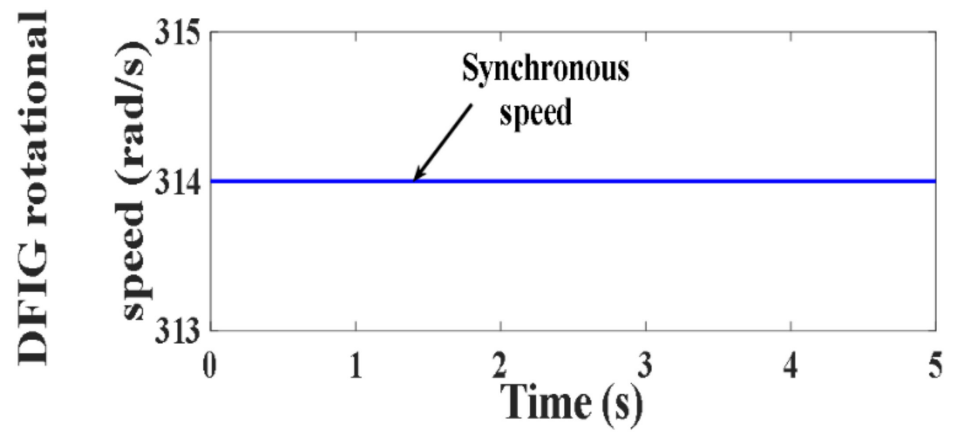

Figure 30. Prime mover operating speed ( $\mathrm{rad} / \mathrm{s})$.

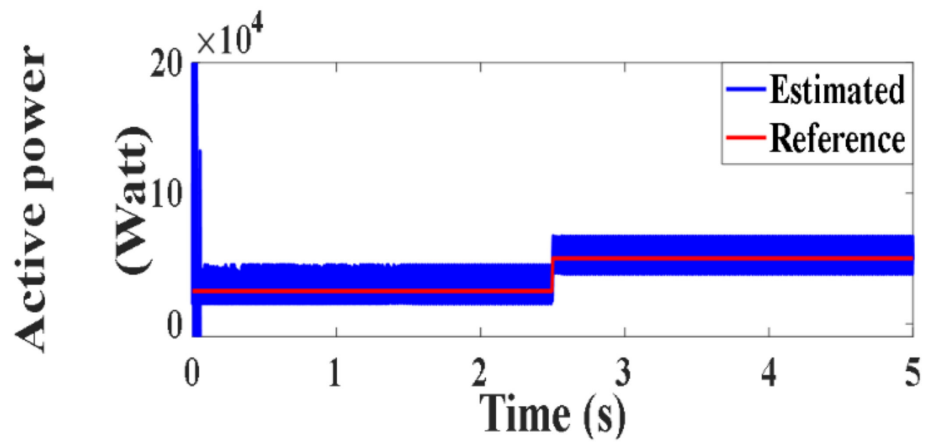

Figure 31. Active power under MPCC (Watt).

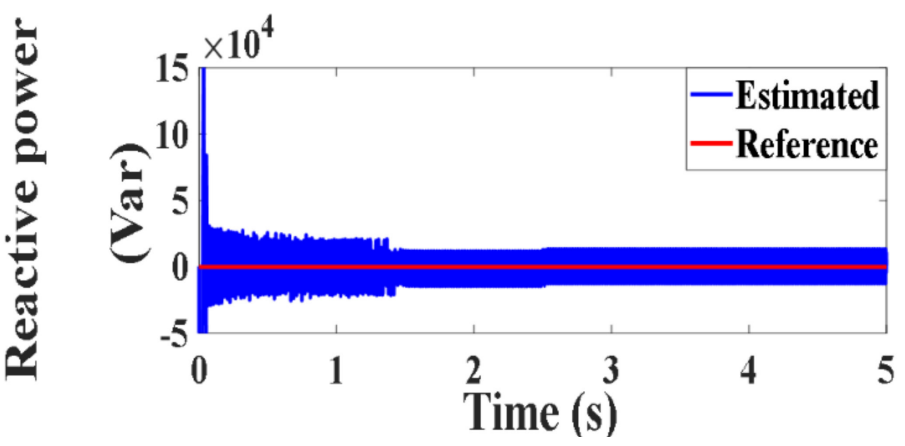

Figure 32. Reactive power under MPCC (var). 


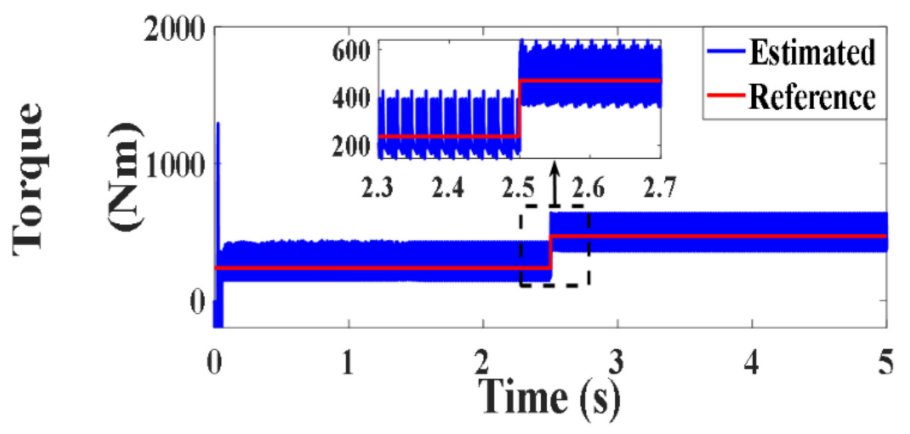

Figure 33. Developed torque under MPCC (Nm).

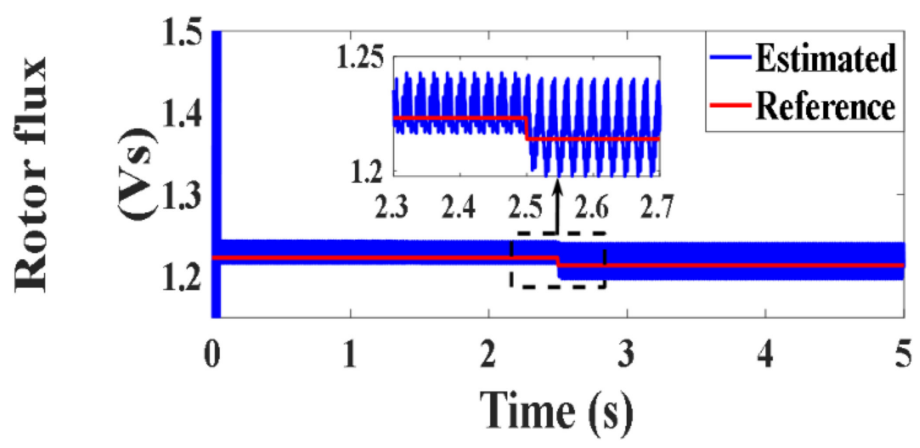

Figure 34. Rotor flux under MPCC (Vs).

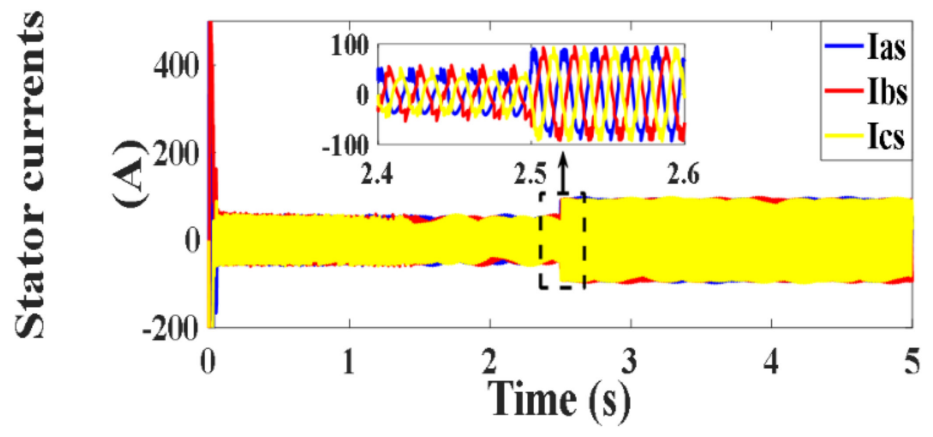

Figure 35. Stator currents under MPCC (A).

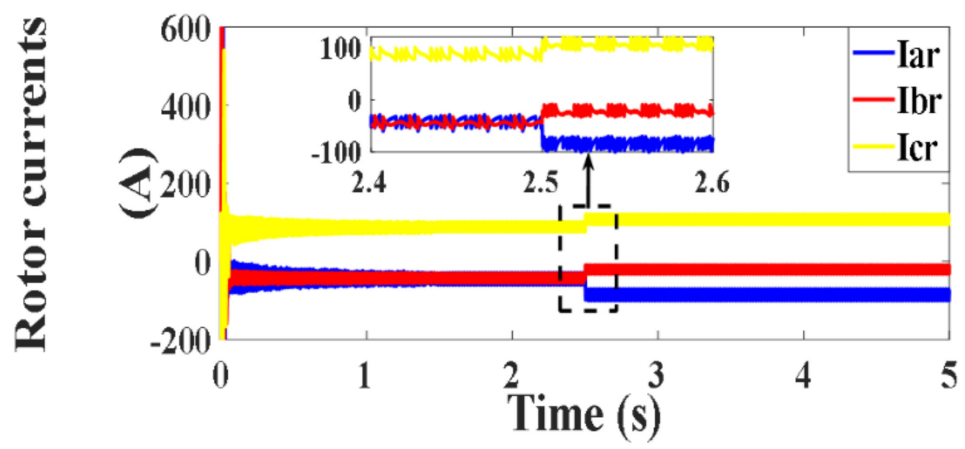

Figure 36. Rotor currents under MPCC (A).

\subsection{Testing with MPDTC Technique}

The DFIG's performance was tested with the MPDTC technique, and the results for both operating conditions are respectively shown in Figures 37-50, which illustrate that the actual values of the powers, torque, and rotor flux follow their references with a dynamic response faster than that of the MPCC and SVOC principles, but unfortunately, it has more ripples than the MPCC and SVOC techniques. 


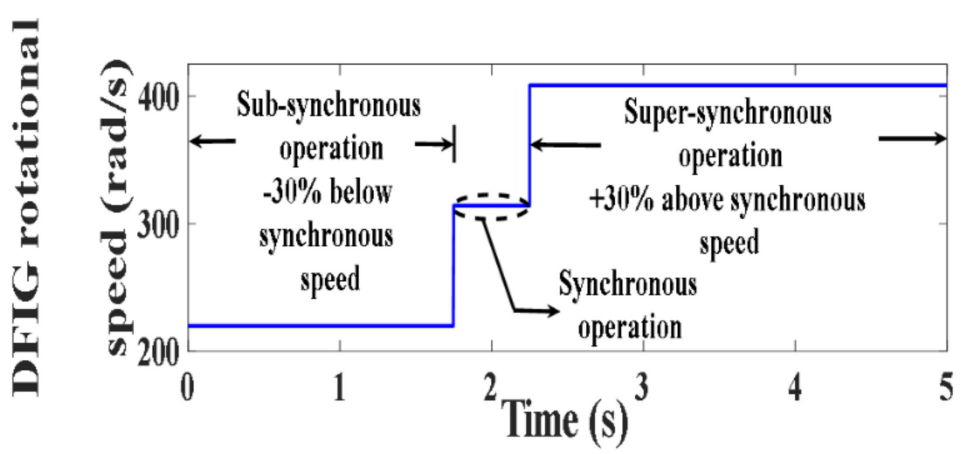

Figure 37. Prime mover operating speeds ( $\mathrm{rad} / \mathrm{s})$.

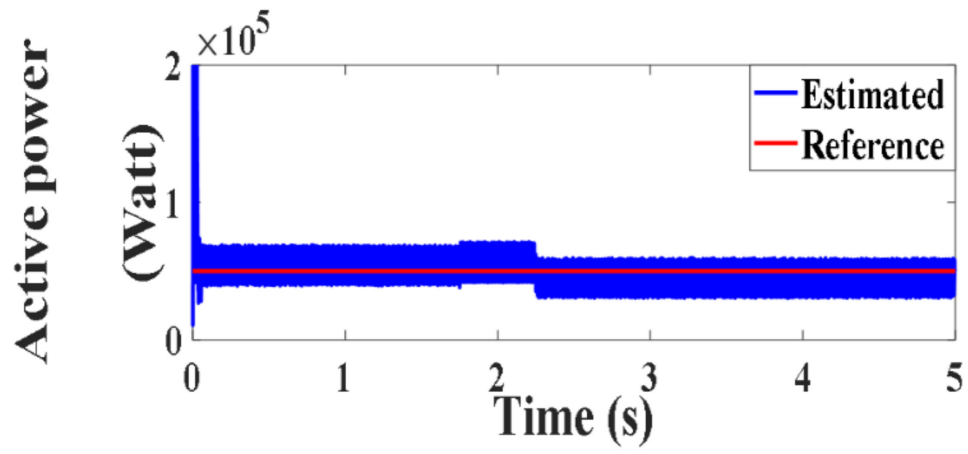

Figure 38. Active power under MPDTC (Watt).

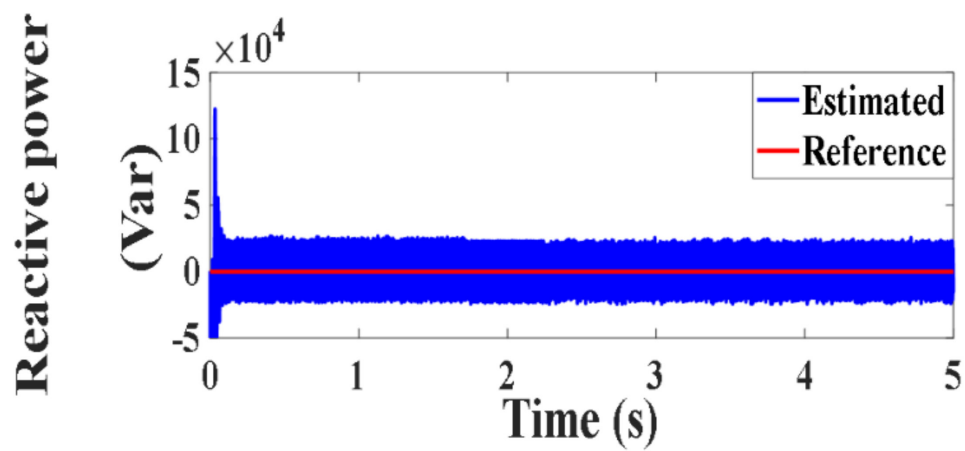

Figure 39. Reactive power under MPDTC (var).

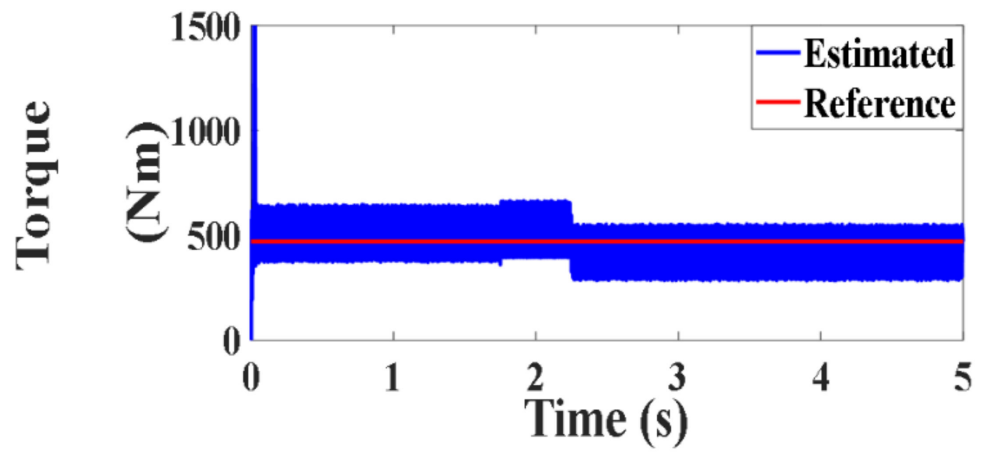

Figure 40. Torque under MPDTC (Nm). 


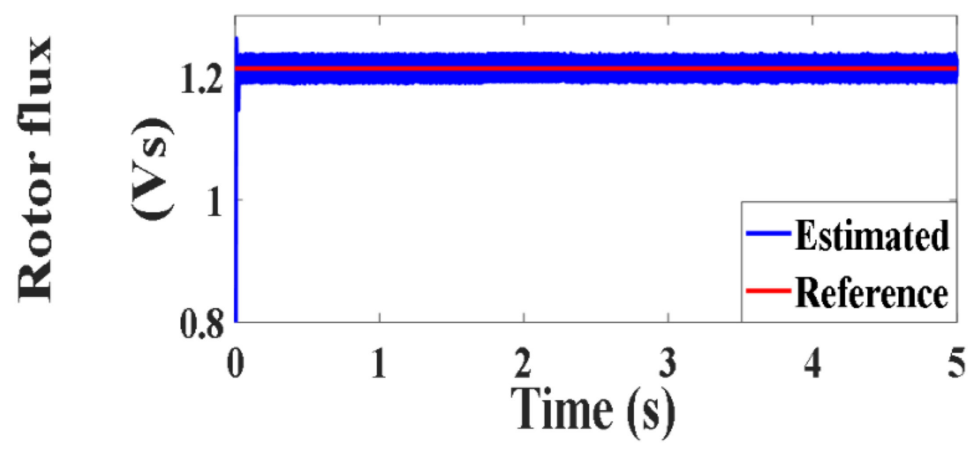

Figure 41. Rotor flux under MPDTC (Vs).

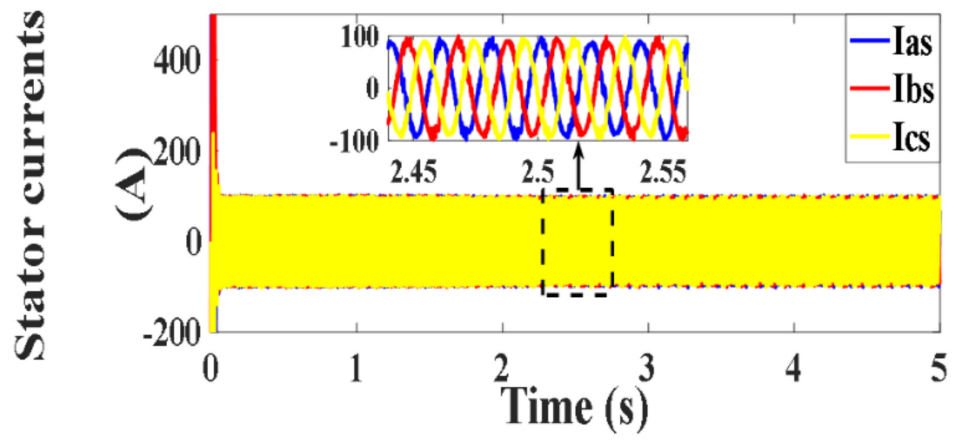

Figure 42. Stator currents under MPDTC (A).

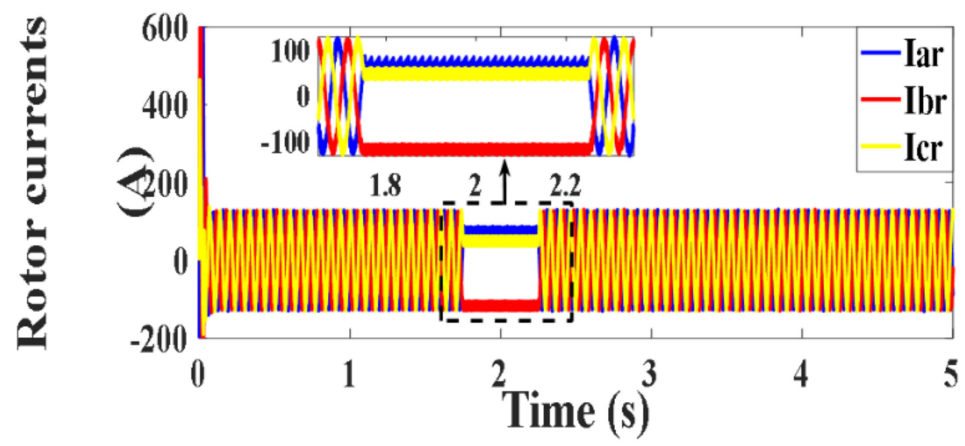

Figure 43. Rotor currents under MPDTC (A).

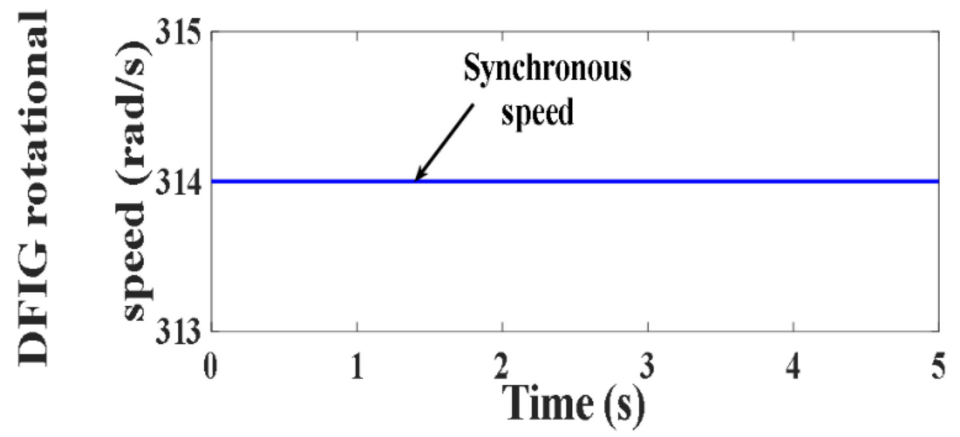

Figure 44. Prime mover operating speed ( $\mathrm{rad} / \mathrm{s})$. 


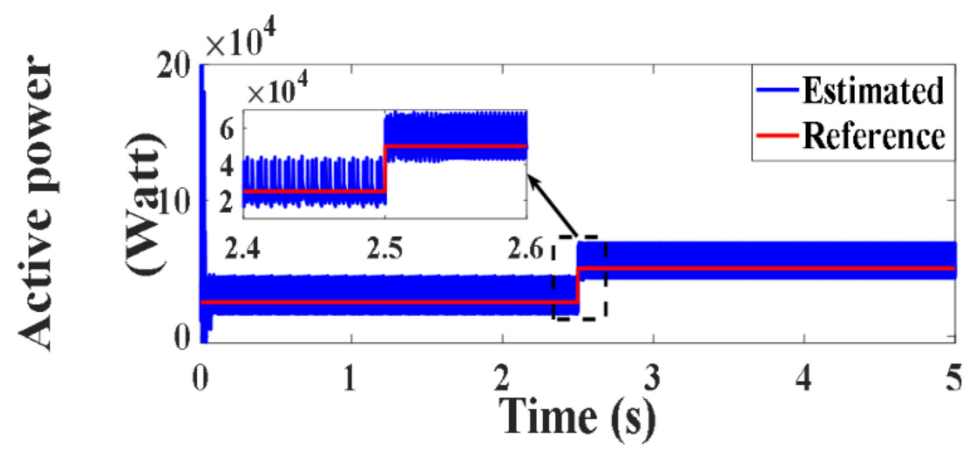

Figure 45. Active power under MPDTC (Watt).

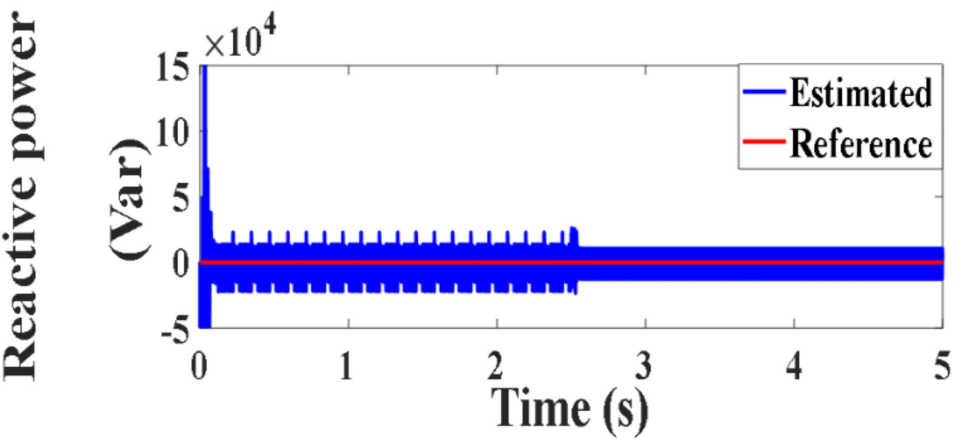

Figure 46. Reactive power under MPDTC (var).

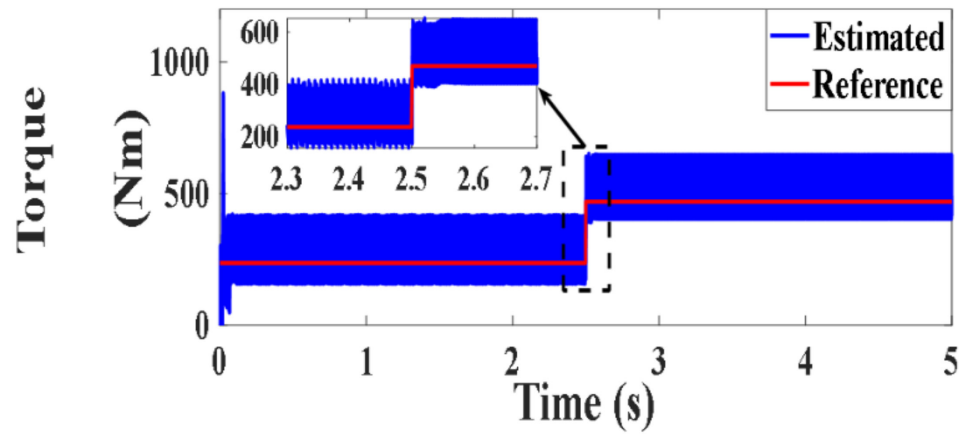

Figure 47. Torque under MPDTC (Nm).

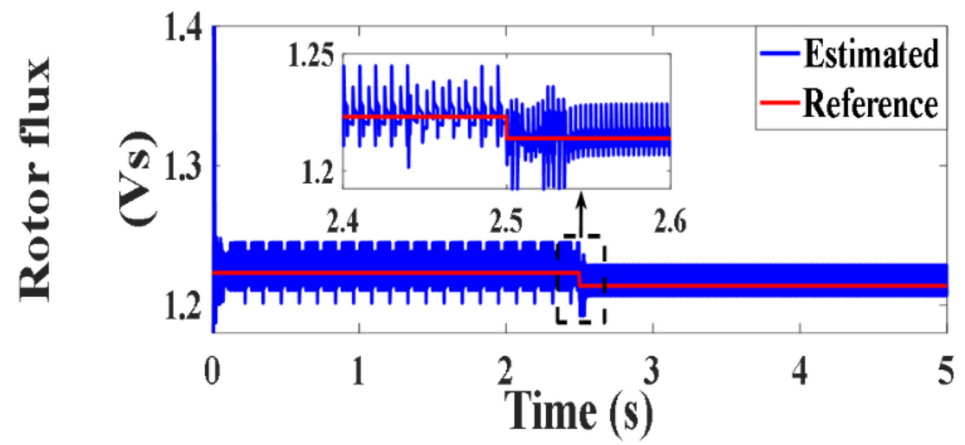

Figure 48. Rotor flux under MPDTC (Vs). 


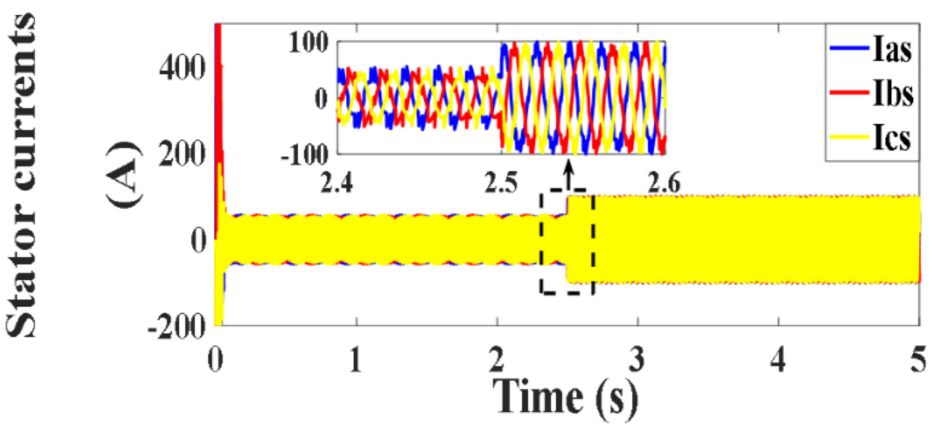

Figure 49. Stator currents under MPDTC (A).

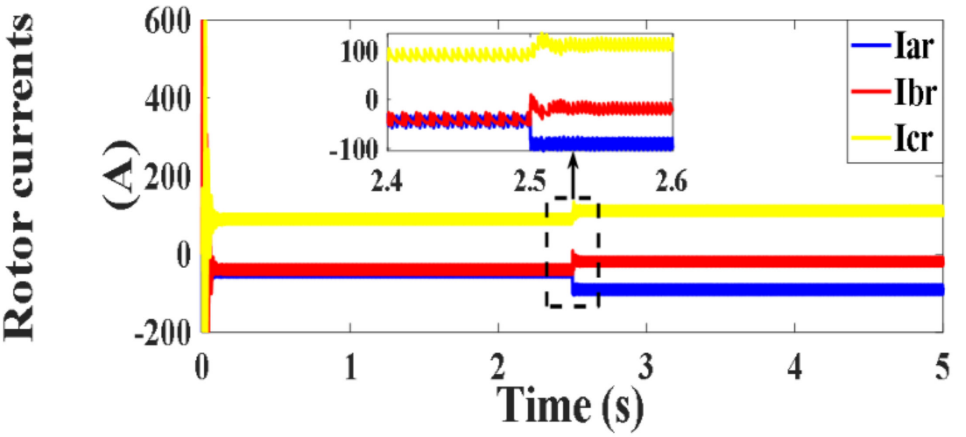

Figure 50. Rotor currents under MPDTC (A).

\subsection{Testing with Proposed PVC}

The DFIG's performance was tested with the proposed PVC technique, and the results are shown in Figures 51-57 for the variable speed operation and Figures 58-64 for the fixed speed operation. These results prove and confirm that the proposed PVC control system has successfully achieved its targets, as the actual estimated values of the powers, torque, and rotor flux follow their references with high precision in the two conditions. Furthermore, the ripples' content is effectively suppressed compared to the values under MPDTC and MPCC. In addition, the dynamic response of PVC is the fastest in comparison with that of the MPDTC, MPCC, and SVOC techniques.

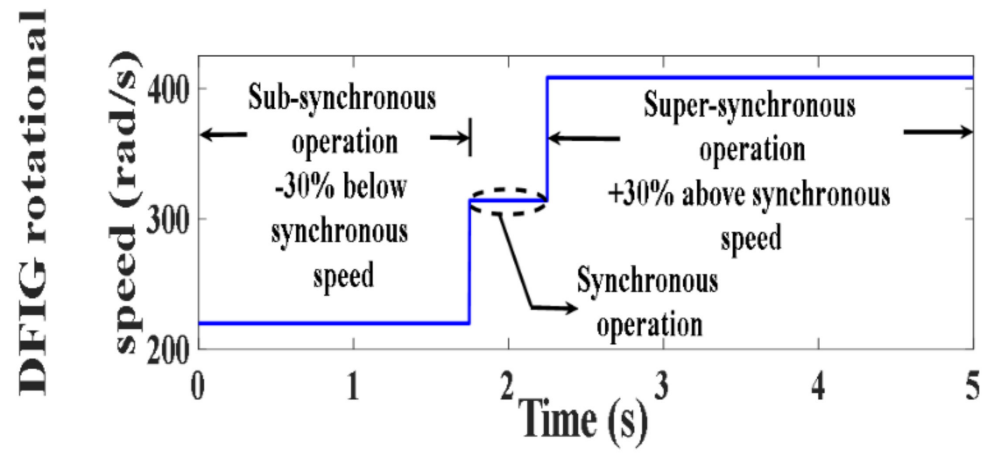

Figure 51. Prime mover operating speeds ( $\mathrm{rad} / \mathrm{s})$. 


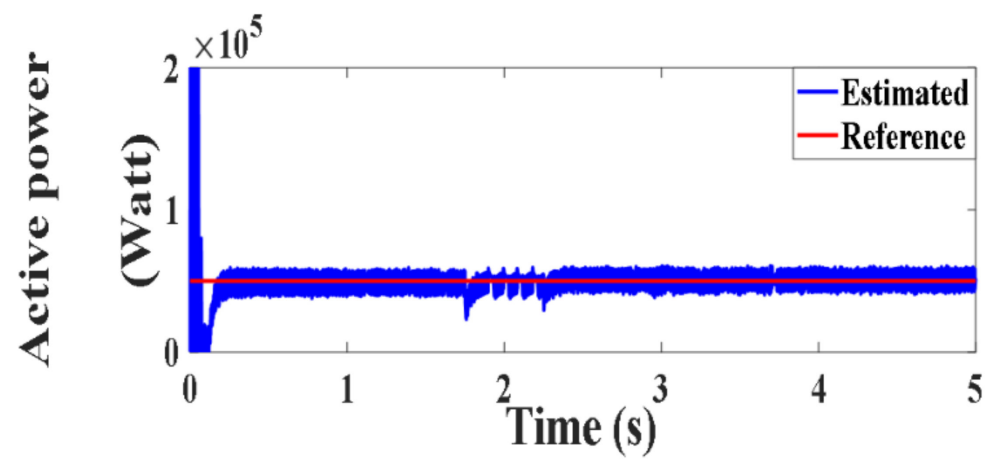

Figure 52. Active power under PVC (Watt).

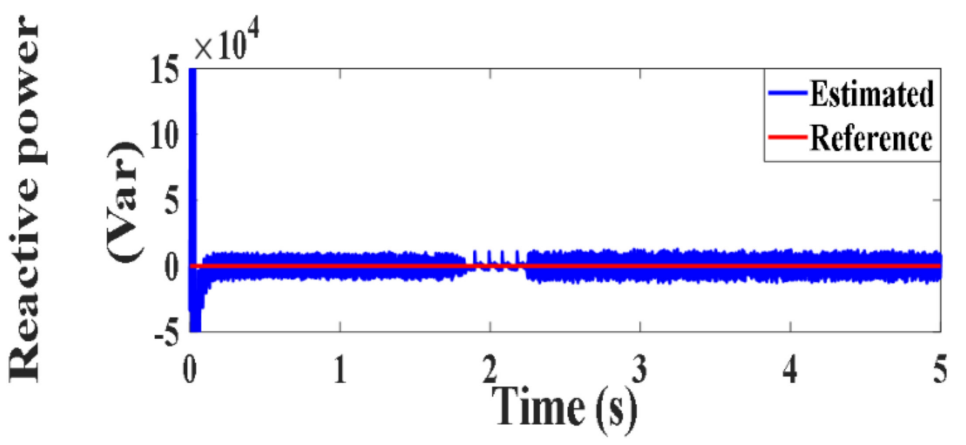

Figure 53. Reactive power under PVC (var).

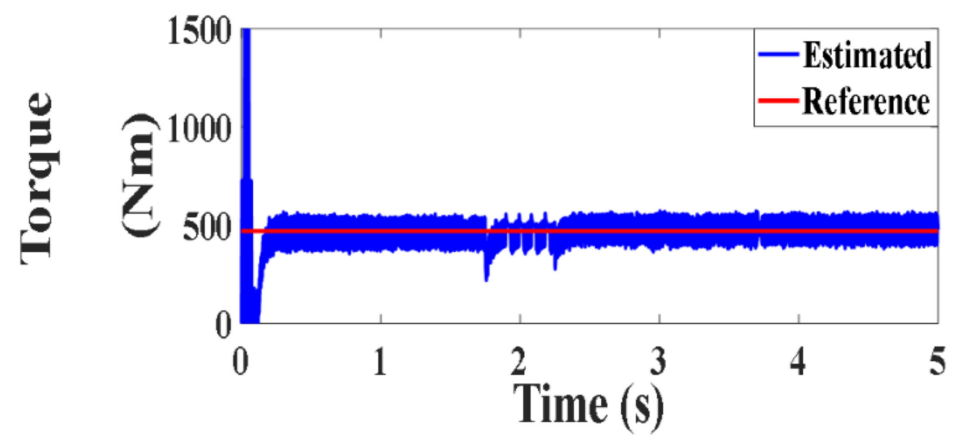

Figure 54. Developed torque under PVC (Nm).

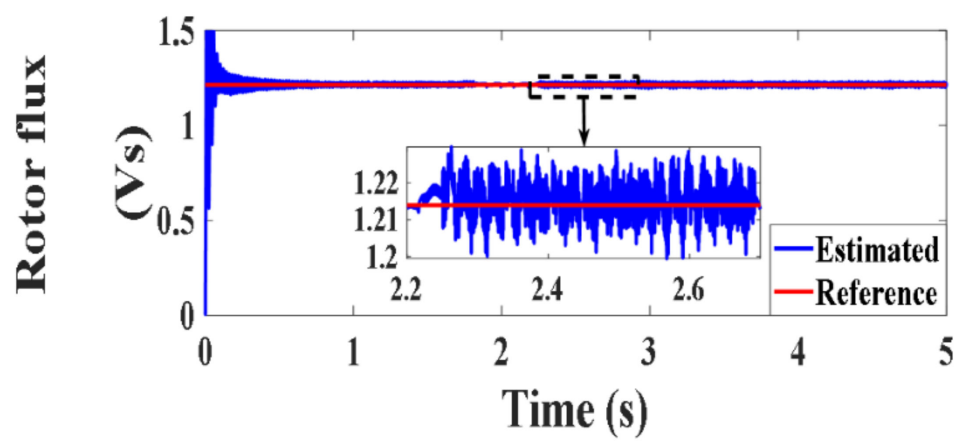

Figure 55. Rotor flux under PVC (Vs). 


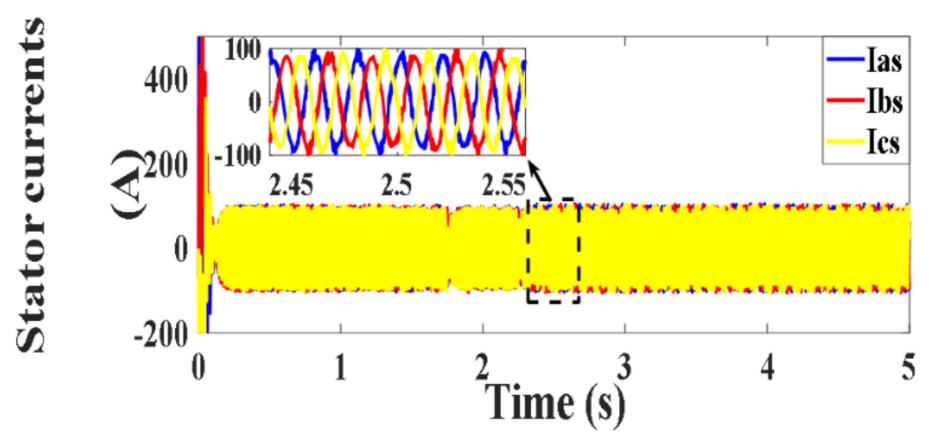

Figure 56. Stator currents under PVC (A).

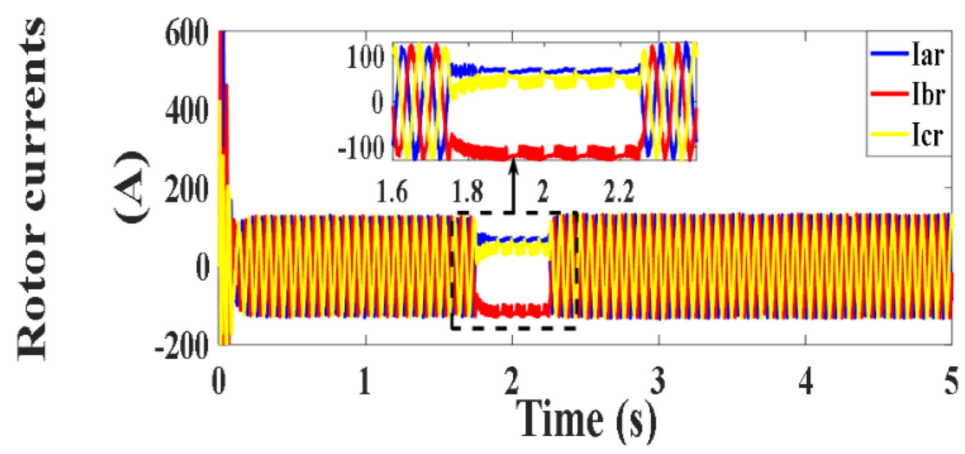

Figure 57. Rotor currents under PVC (A).

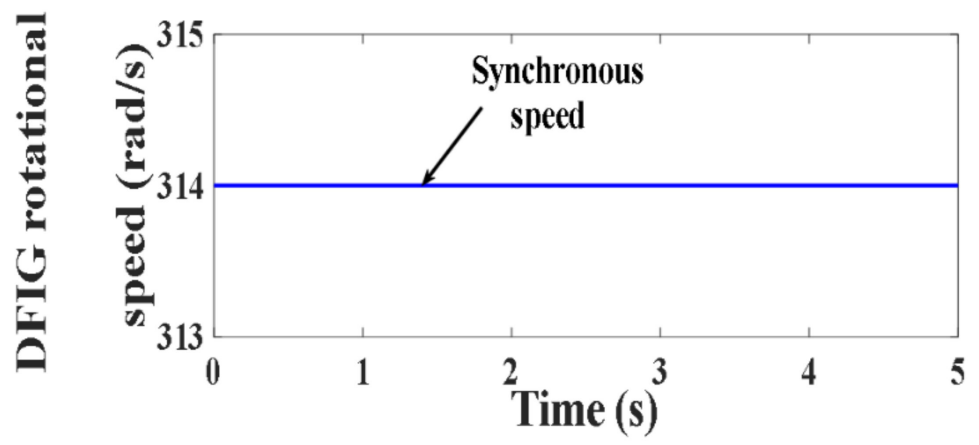

Figure 58. Prime mover operating speed ( $\mathrm{rad} / \mathrm{s})$.

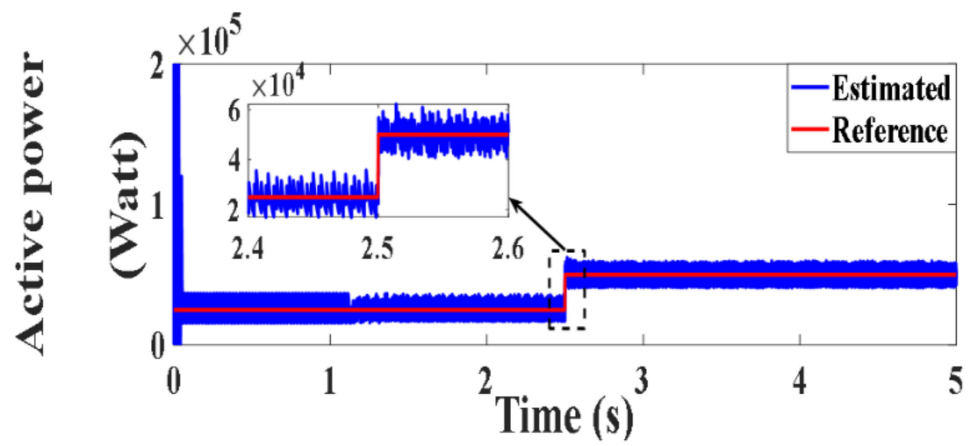

Figure 59. Active power under PVC (Watt). 


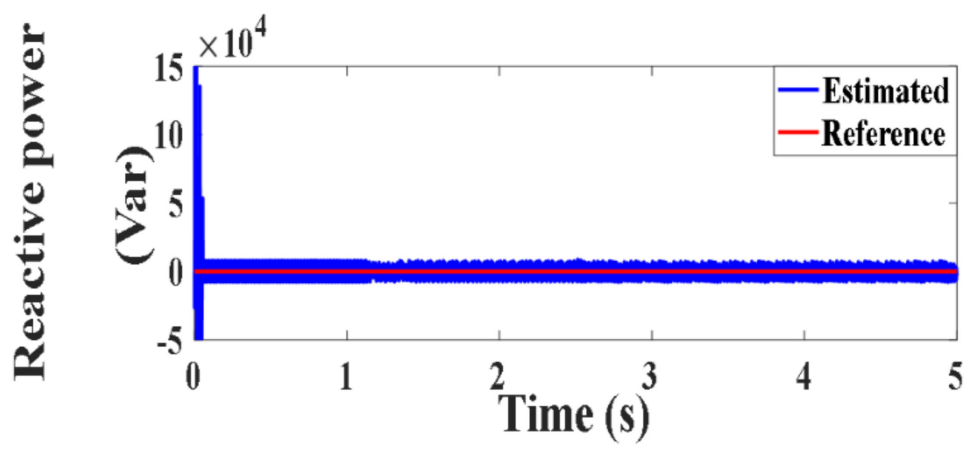

Figure 60. Reactive power under PVC (var).

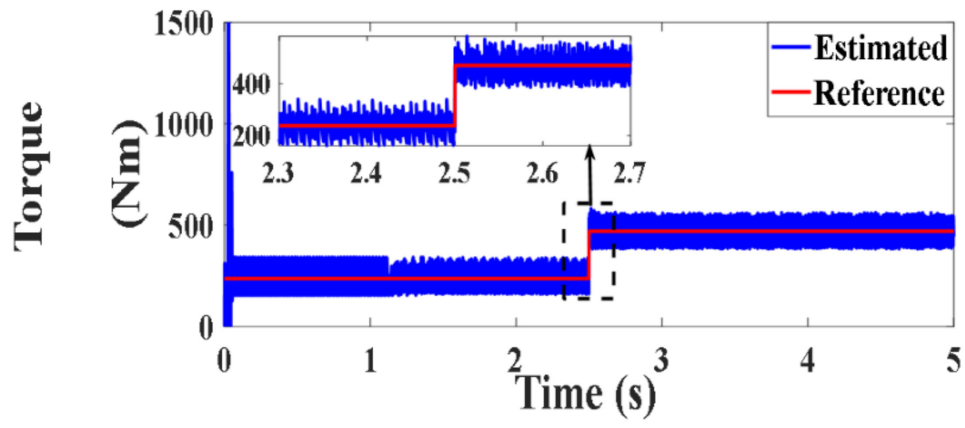

Figure 61. Developed torque under PVC (Nm).

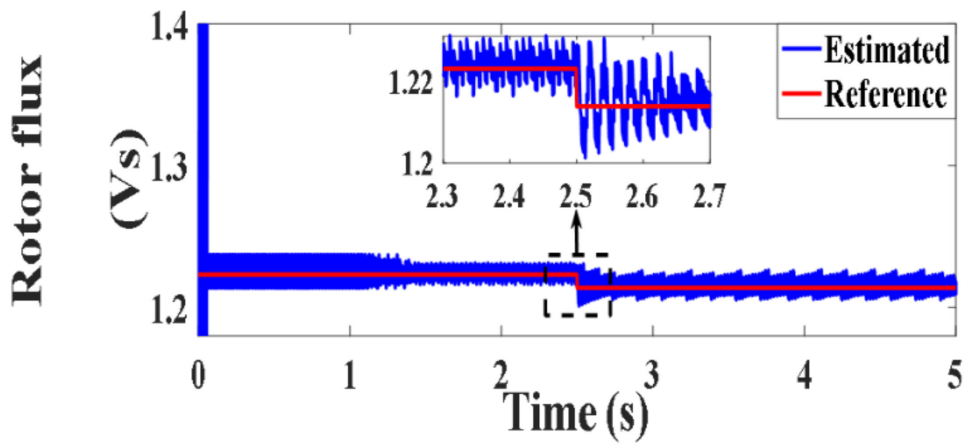

Figure 62. Rotor flux under PVC (Vs).

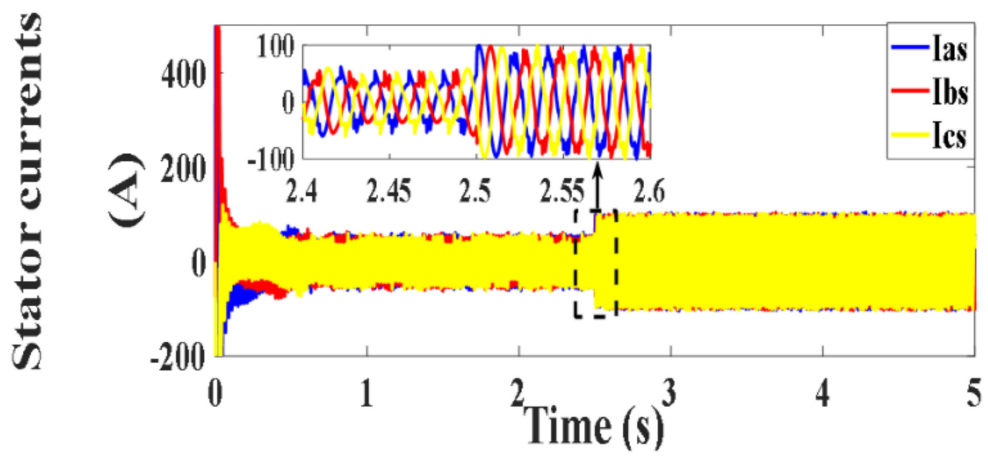

Figure 63. Stator currents under PVC (A). 


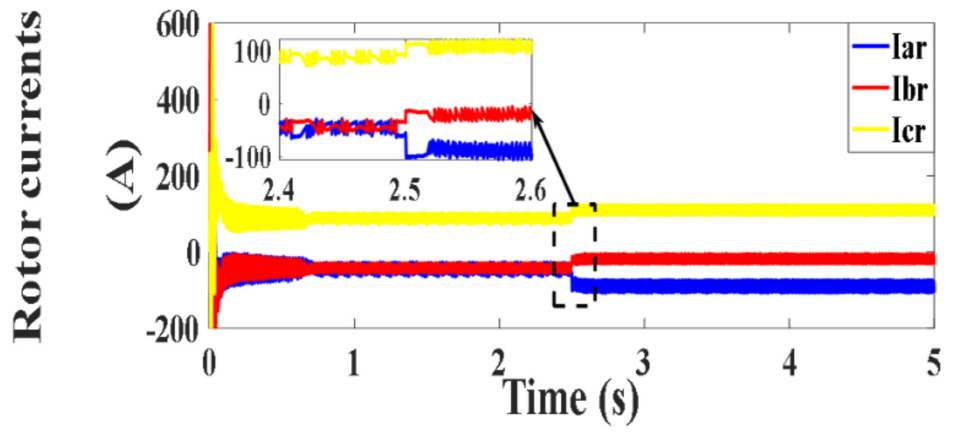

Figure 64. Rotor currents under PVC (A).

\subsection{Testing under Proposed PVC with Parameter Variation}

In this section, a robustness test for the proposed PVC and another control scheme recently introduced in [55-58] which adopts a similar operation mechanism is introduced. The purpose of this is to visualize the superiority of the proposed PVC in terms of system robustness.

\subsubsection{Testing under Proposed PVC with 20\% Variation of $R_{S}$}

In order to visualize the performance of the designed PVC under parameter mismatch, the following tests were performed. For the variable speed operation shown in Figure 65, a mismatch in stator resistance of $20 \%$ was applied at time $t=4 \mathrm{~s}$ (Figure 66). The obtained results reveal that the designed PVC succeeded in maintaining the proper operation under the resistance variation. This was confirmed by the maintained actual values of active and reactive powers, torque and rotor flux (Figures 67-70) for variable speed operation. The same robust behavior is also maintained for fixed speed operation (Figure 71) under a resistance variation of $20 \%$ applied at time $t=2.5 \mathrm{~s}$ (Figure 72 ). The obtained results for active and reactive powers (Figures 73 and 74) and for torque, and rotor flux (Figures 75 and 76) are confirming the robust dynamic behavior of the DFIG.

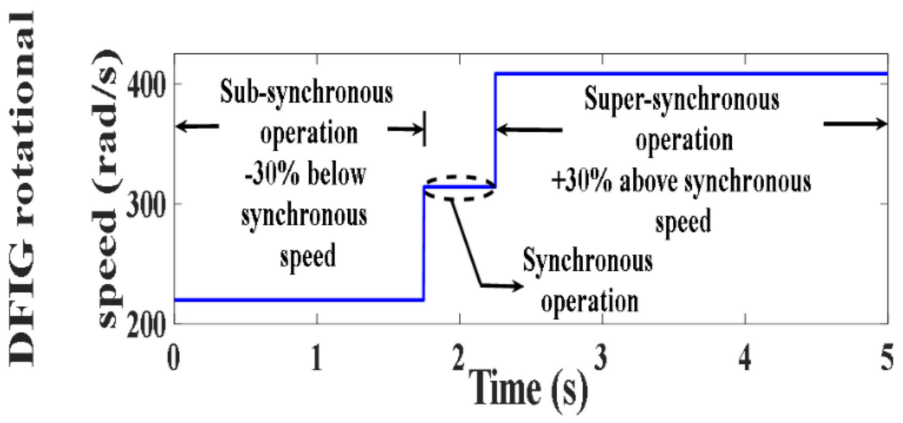

Figure 65. Prime mover operating speeds ( $\mathrm{rad} / \mathrm{s})$.

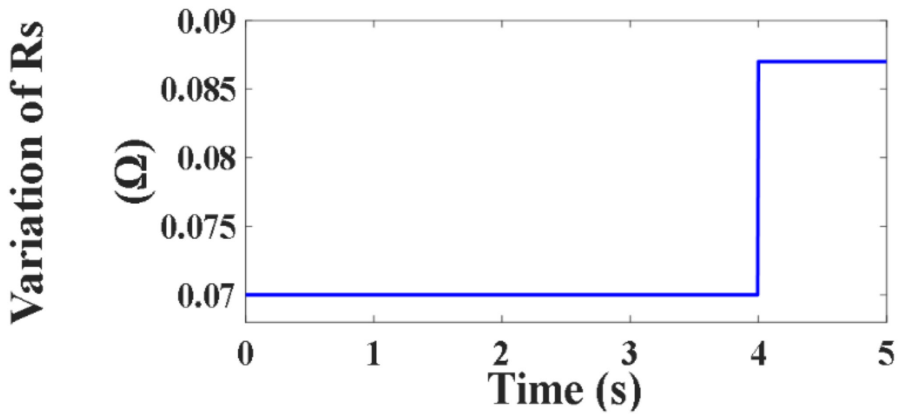

Figure 66. Variation of $R_{s}(\Omega)$. 


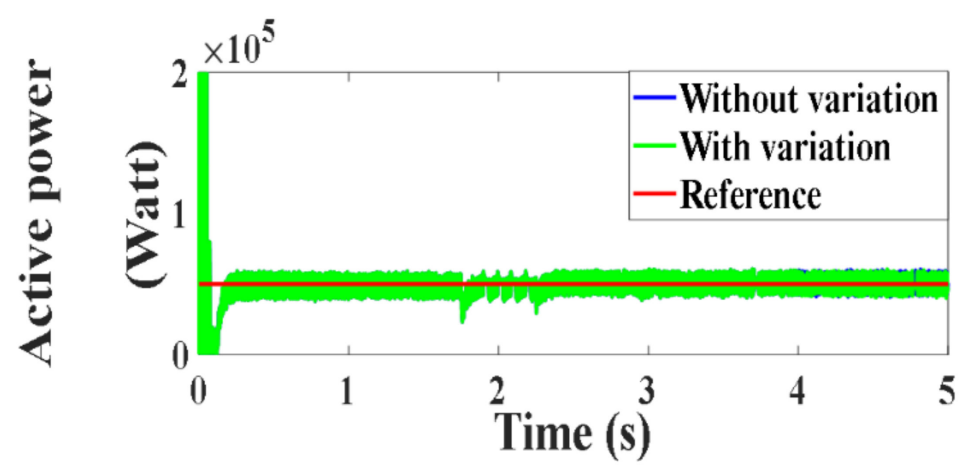

Figure 67. Active power under PVC (Watt).

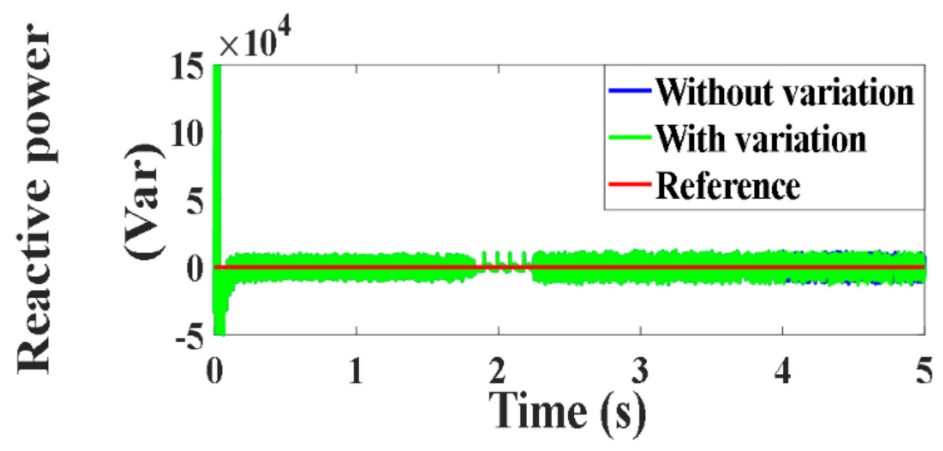

Figure 68. Reactive power under PVC (var).

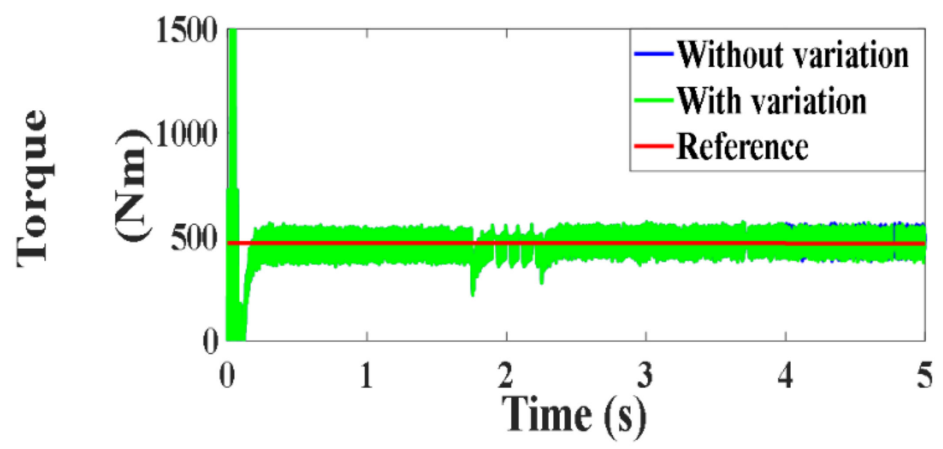

Figure 69. Developed torque under PVC (Nm).

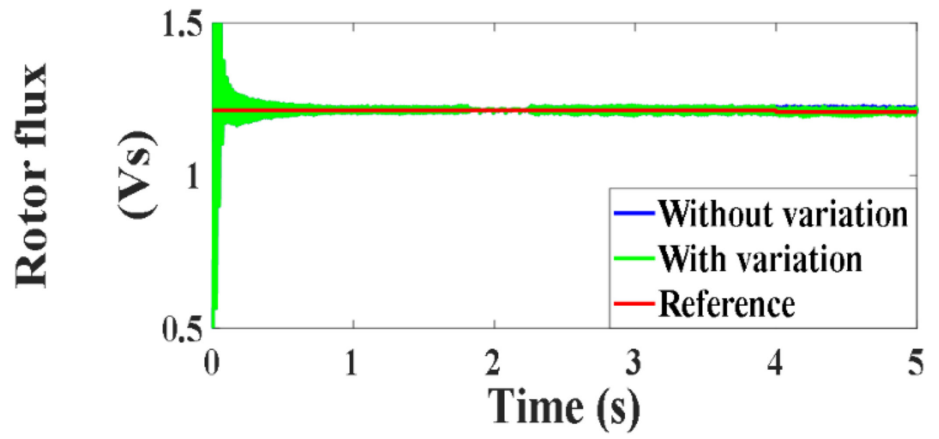

Figure 70. Rotor flux under PVC (Vs). 


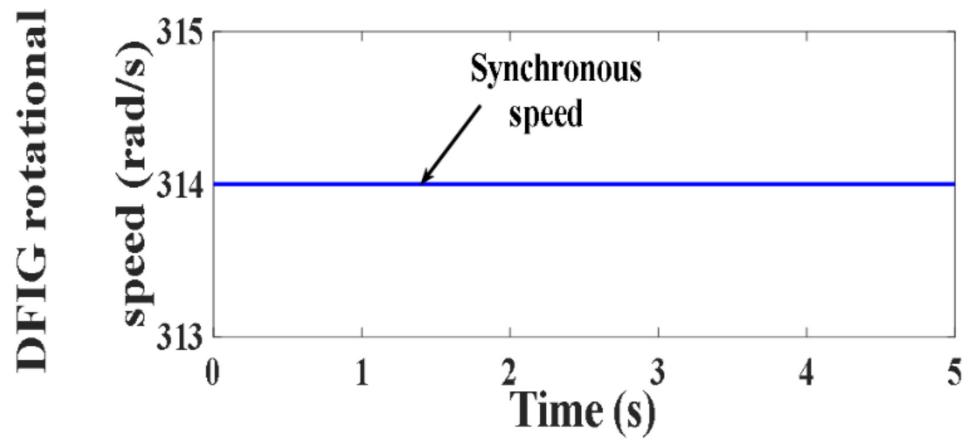

Figure 71. Prime mover operating speeds ( $\mathrm{rad} / \mathrm{s})$.

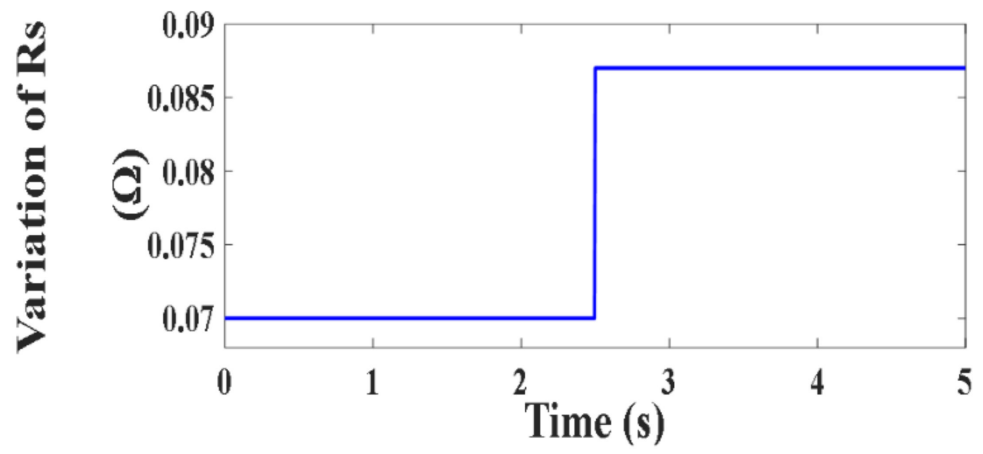

Figure 72. Variation of $R_{S}(\Omega)$.

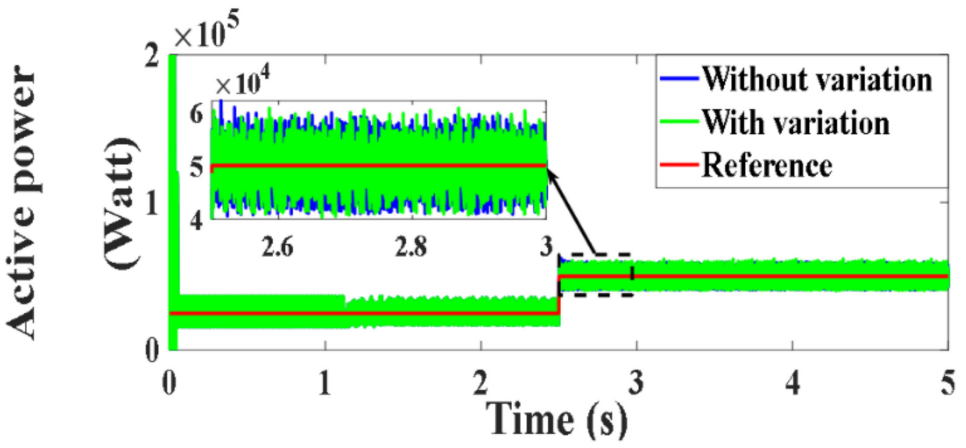

Figure 73. Active power under PVC (Watt).

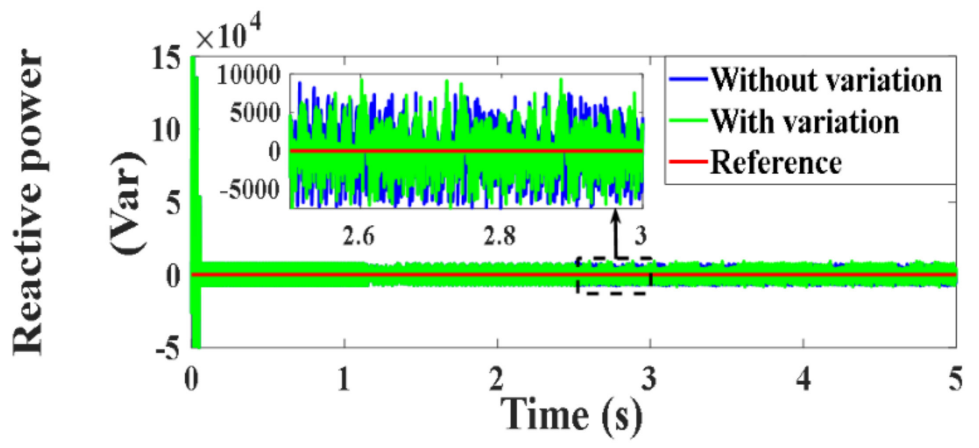

Figure 74. Reactive power under PVC (var). 


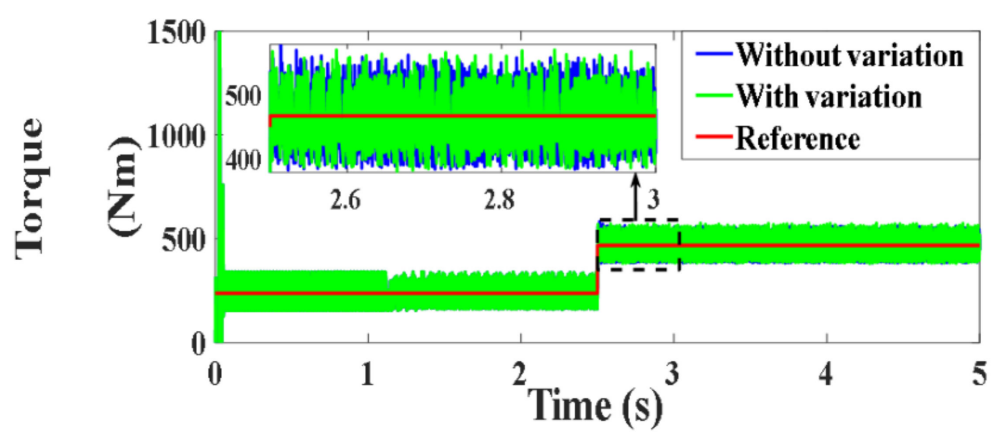

Figure 75. Developed torque under PVC (Nm).

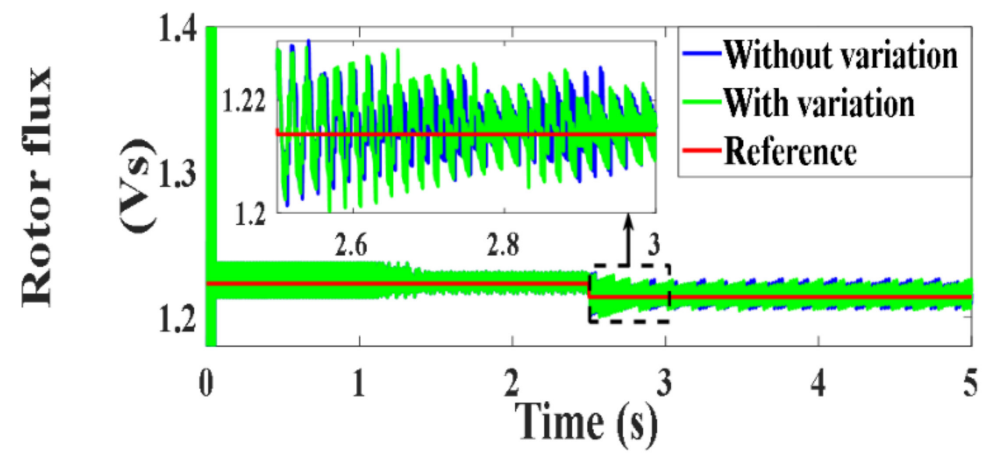

Figure 76. Rotor flux under PVC (Vs).

4.5.2. Testing under Proposed PVC with $20 \%$ Variation of $R_{r}$

The second parameter variation was made with the rotor resistance value with an increase of $20 \%$. The values of active and reactive powers, torque and rotor flux for variable wind speed shown in Figure 77 with $R_{s}$ variation (Figure 78) are presented in Figures 79 82, respectively. Similarly, for the fixed speed operation (Figure 83) with $R_{s}$ variation (Figure 84), the results are illustrated for the same variables in Figures 85-88, respectively. The obtained results present an adequate performance under the resistance variation, which again confirms the robustness of the designed PVC scheme.

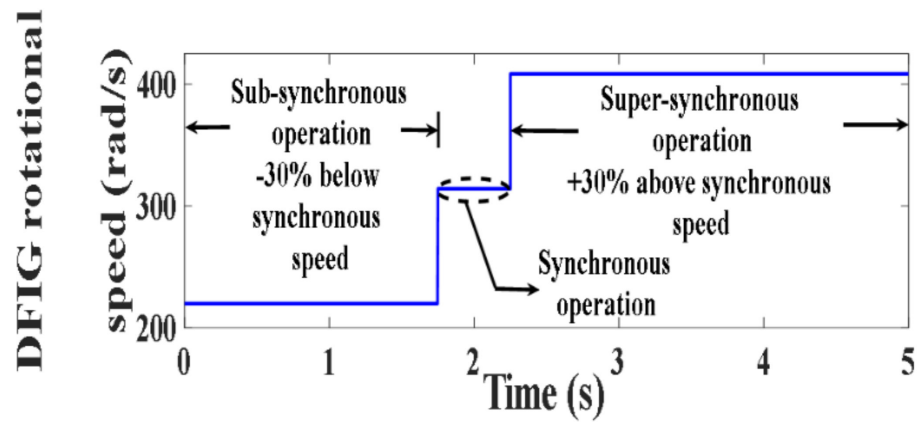

Figure 77. Prime mover operating speeds ( $\mathrm{rad} / \mathrm{s})$. 


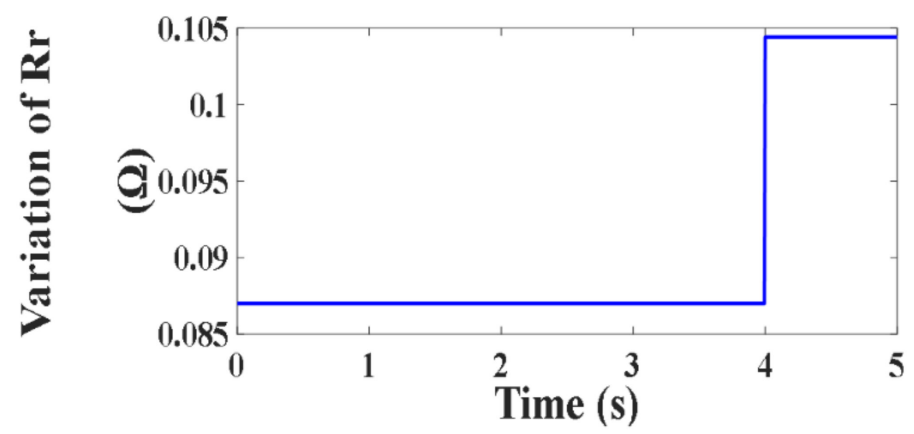

Figure 78. Variation of $R_{r}(\Omega)$.

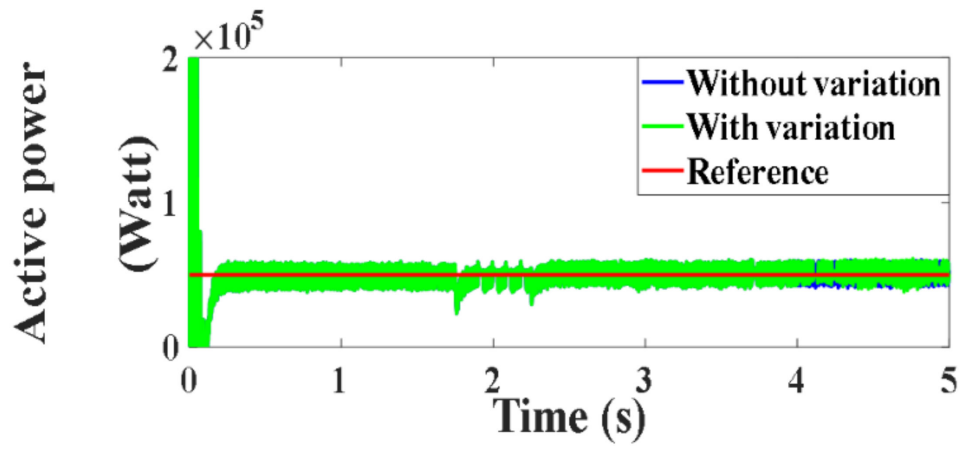

Figure 79. Active power under PVC (Watt).

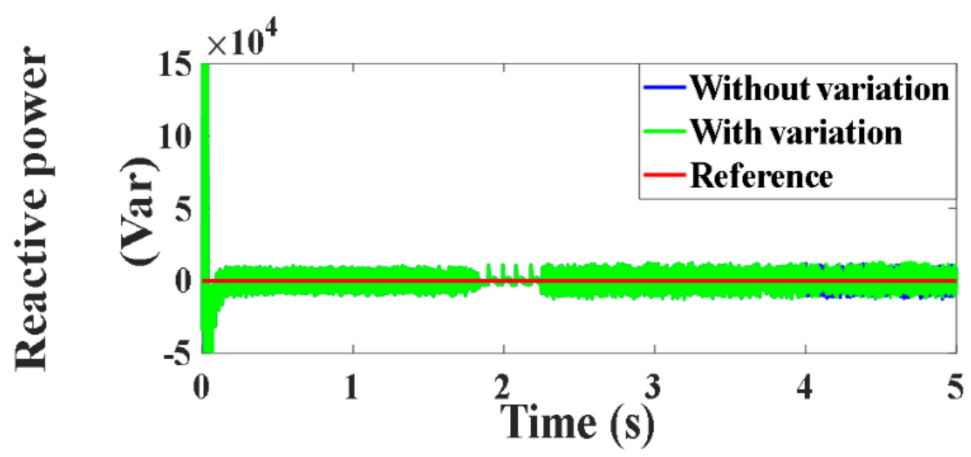

Figure 80. Reactive power under PVC (var).

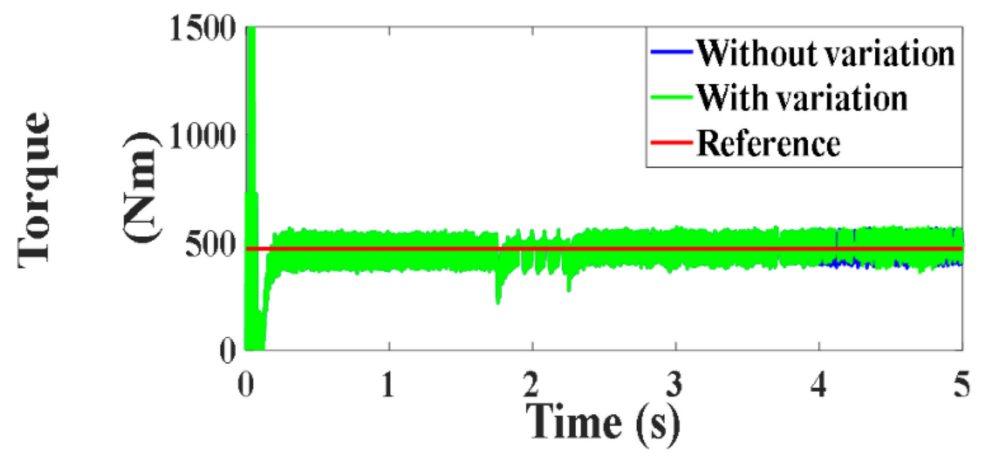

Figure 81. Developed torque under PVC (Nm). 


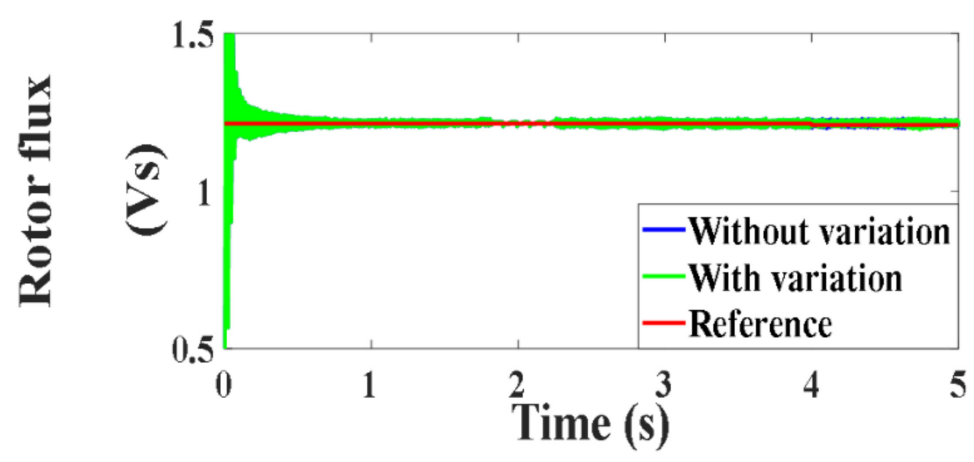

Figure 82. Rotor flux under PVC (Vs).

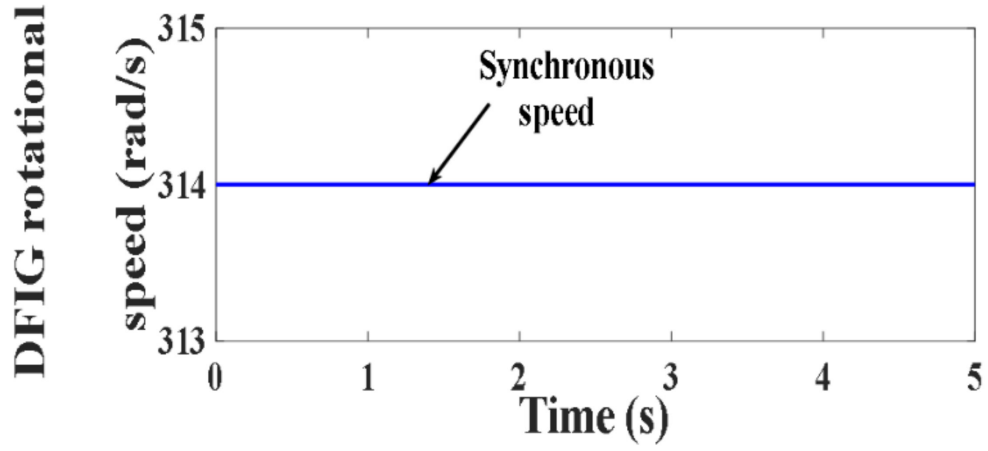

Figure 83. Prime mover operating speeds ( $\mathrm{rad} / \mathrm{s})$.

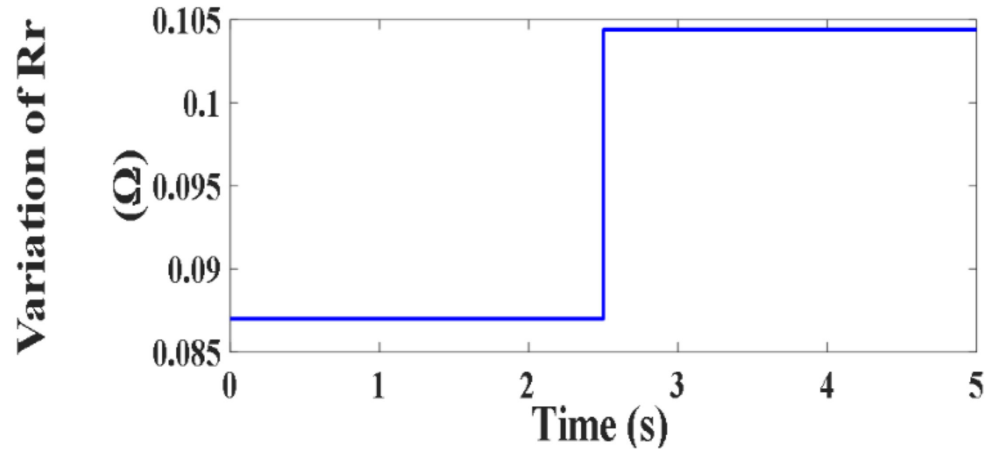

Figure 84. Variation of $R_{r}(\Omega)$.

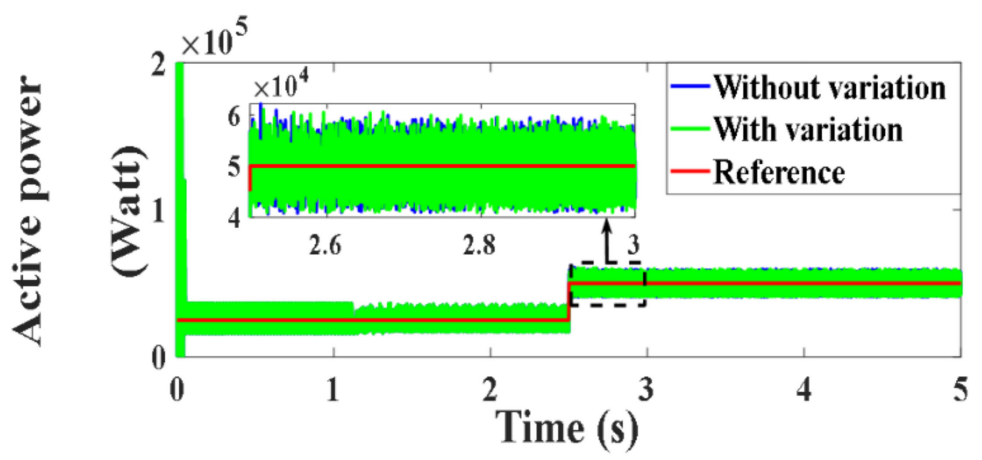

Figure 85. Active power under PVC (Watt). 


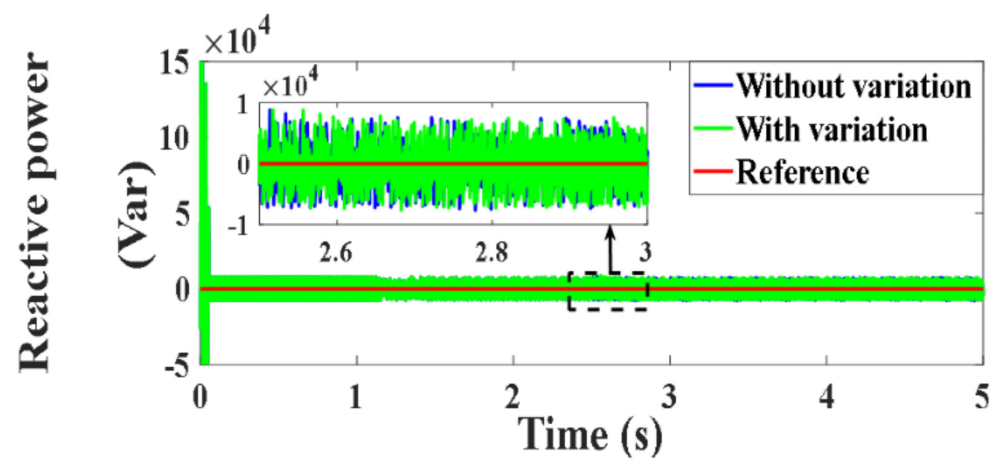

Figure 86. Reactive power under PVC (var).

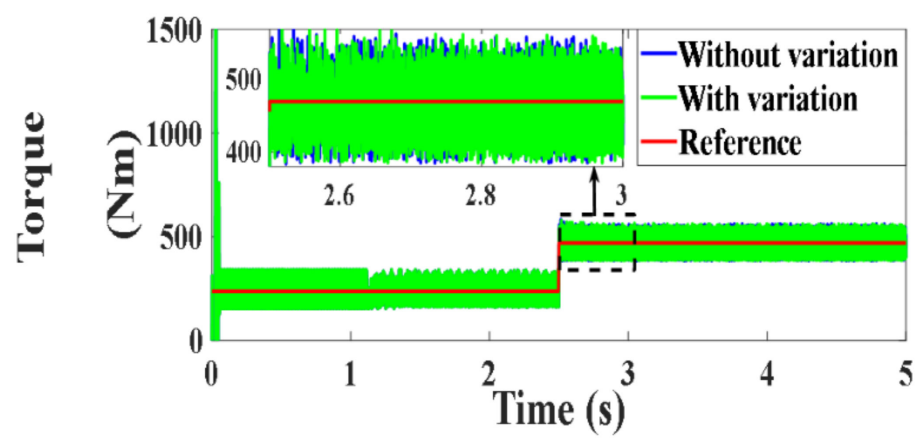

Figure 87. Developed torque under PVC (Nm).

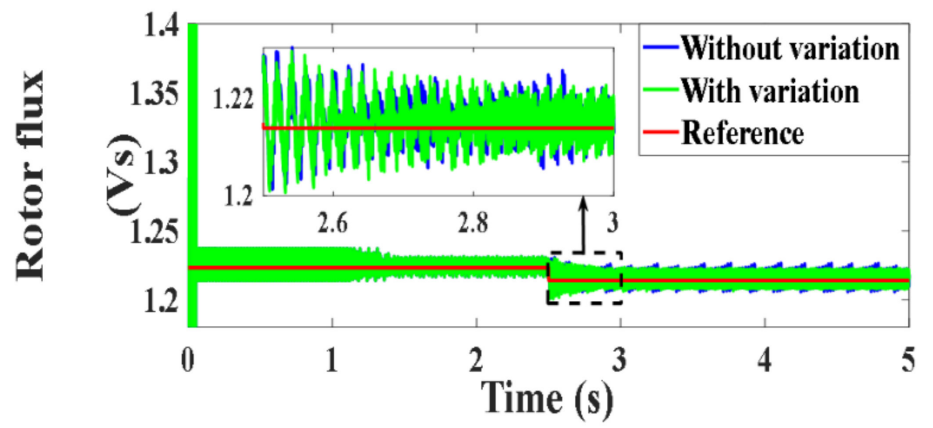

Figure 88. Rotor flux under PVC (Vs).

4.5.3. Testing under Proposed PVC with $15 \%$ Variation of $\mathrm{L}_{\mathrm{s}}$

The performance of the DFIG under PVC was also tested for the variable speed operation (Figure 89 ) while considering a mismatch of $15 \%$ in the stator inductance $\left(\mathrm{L}_{\mathrm{s}}\right)$ value (Figure 90). The obtained results for the active and reactive powers, torque and rotor flux are presented in Figures 91-94. A similar test is applied under the fixed speed operation (Figure 95) with a $L_{s}$ variation (Figure 96), and the results are presented in Figures 97-100, respectively. The obtained results reveal that the DFIG maintains an appropriate operation even under the inductance variation. 


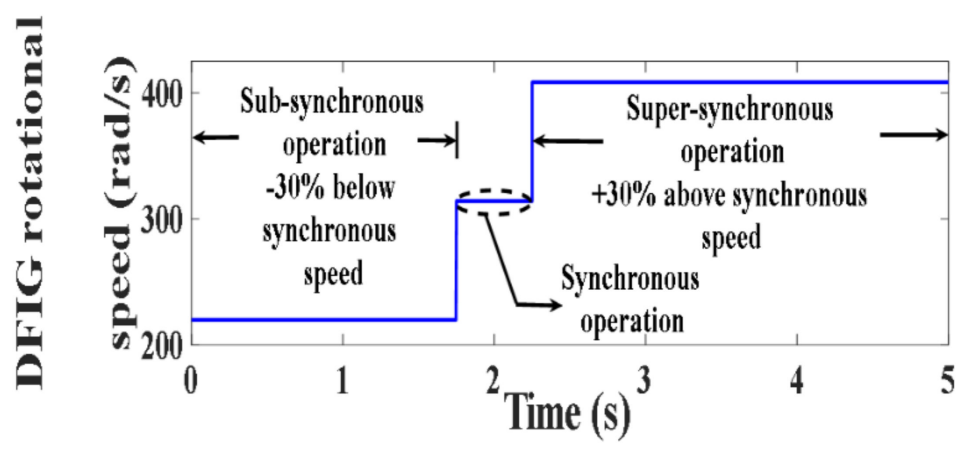

Figure 89. Prime mover operating speeds ( $\mathrm{rad} / \mathrm{s})$.

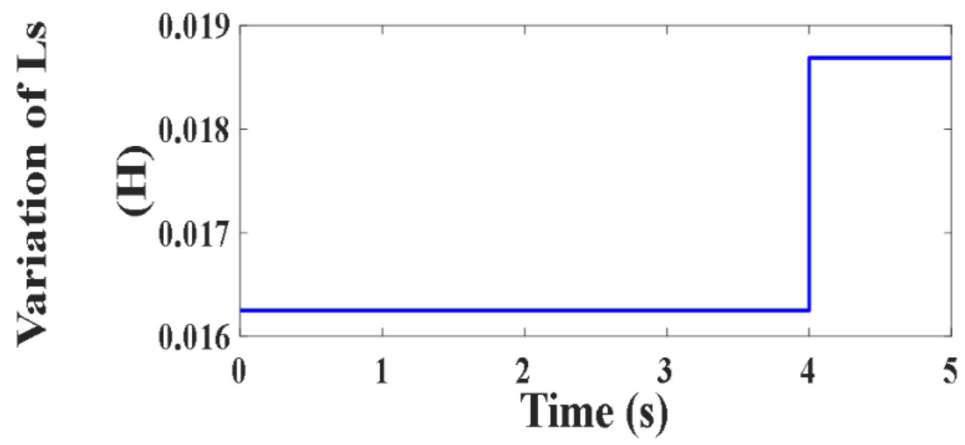

Figure 90. Variation of $\mathrm{L}_{\mathrm{s}}(\mathrm{H})$.

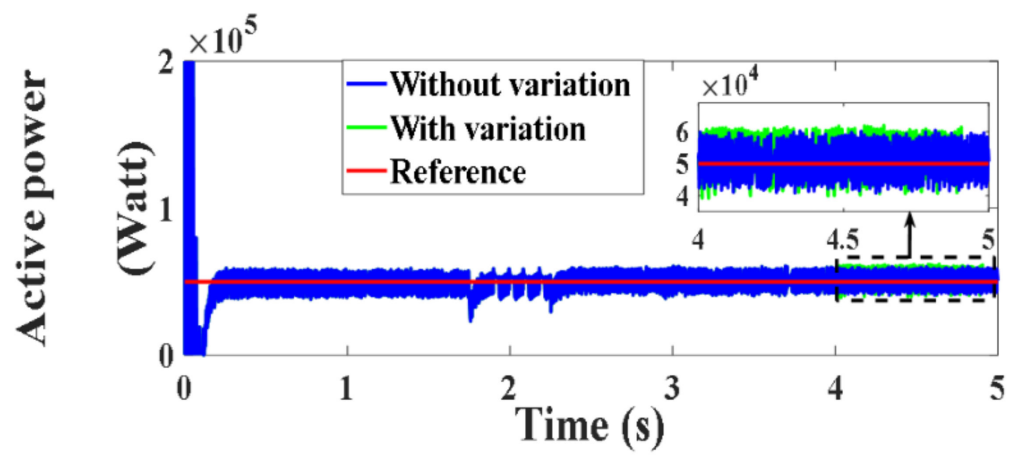

Figure 91. Active power under PVC (Watt).

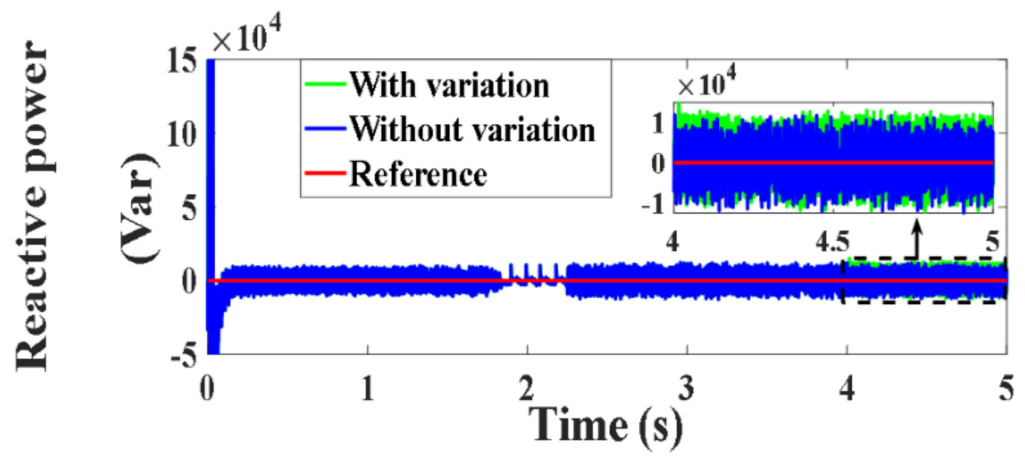

Figure 92. Reactive power under PVC (var). 


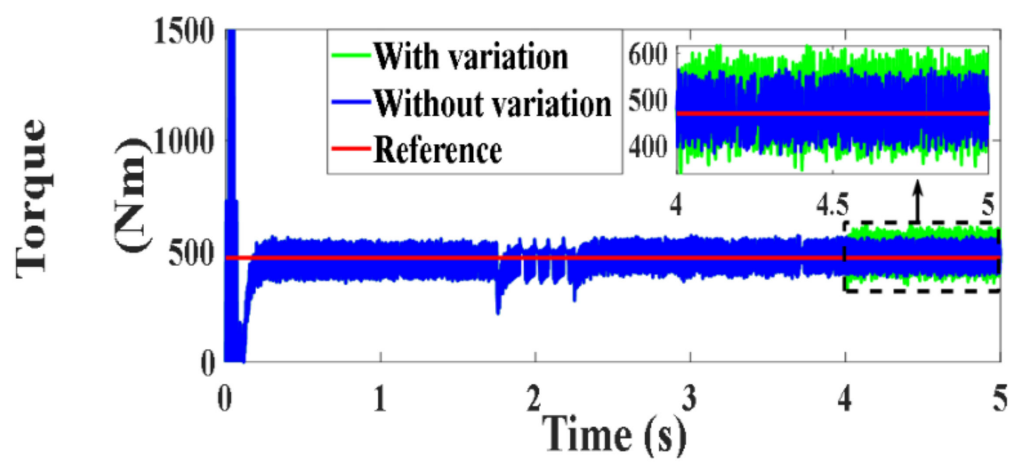

Figure 93. Developed torque under PVC (Nm).

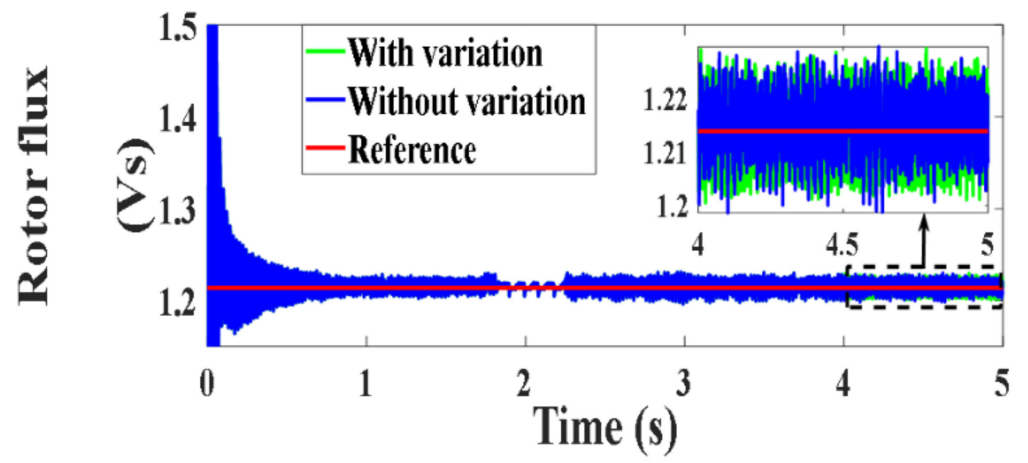

Figure 94. Rotor flux under PVC (Vs).

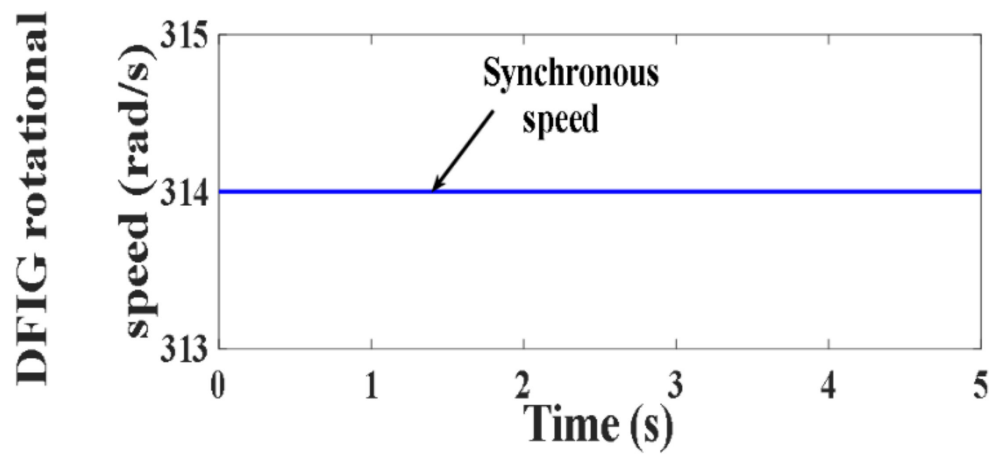

Figure 95. Prime mover operating speeds ( $\mathrm{rad} / \mathrm{s})$.

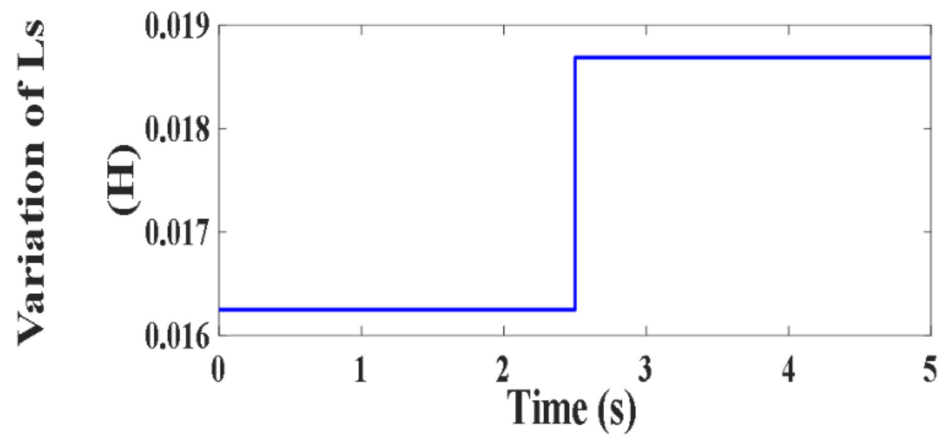

Figure 96. Variation of $\mathrm{L}_{\mathrm{S}}(\mathrm{H})$. 


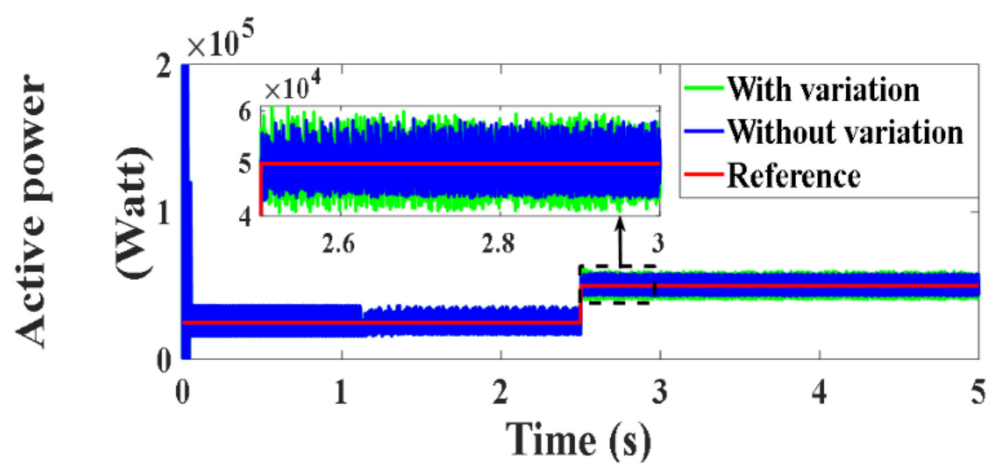

Figure 97. Active power under PVC (Watt).

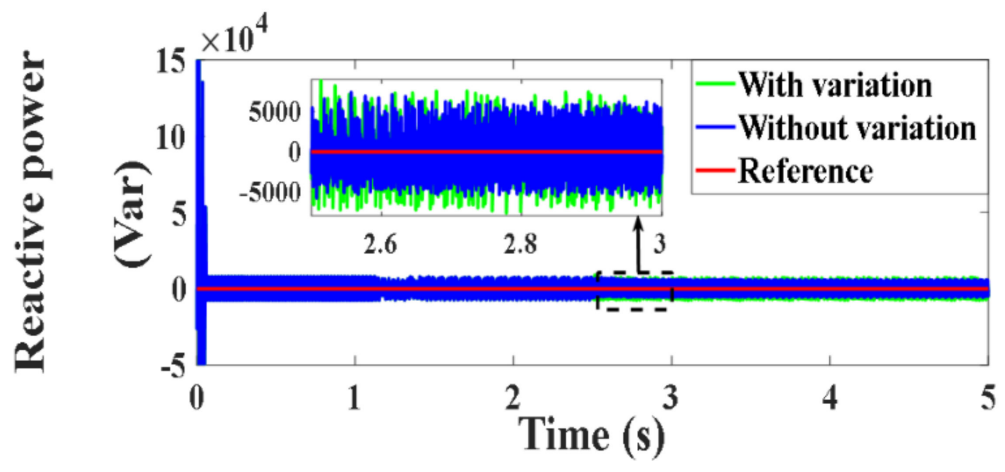

Figure 98. Reactive power under PVC (var).

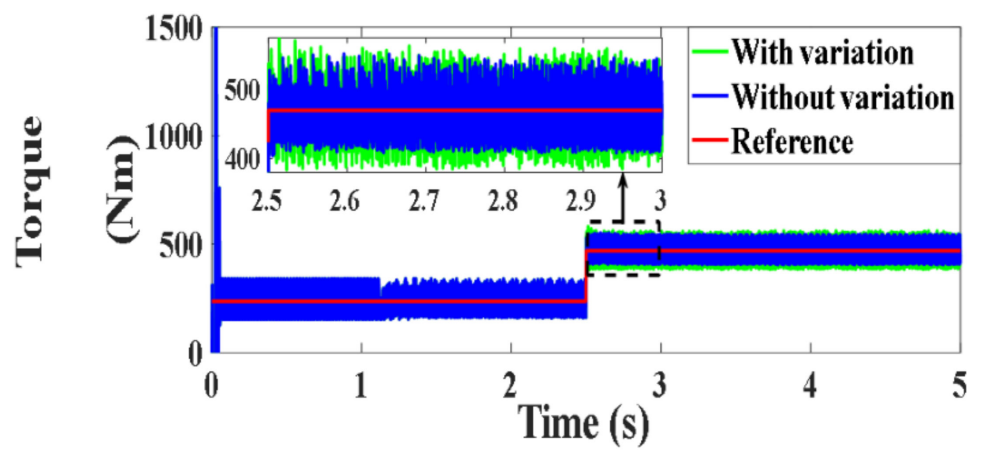

Figure 99. Developed torque under PVC (Nm).

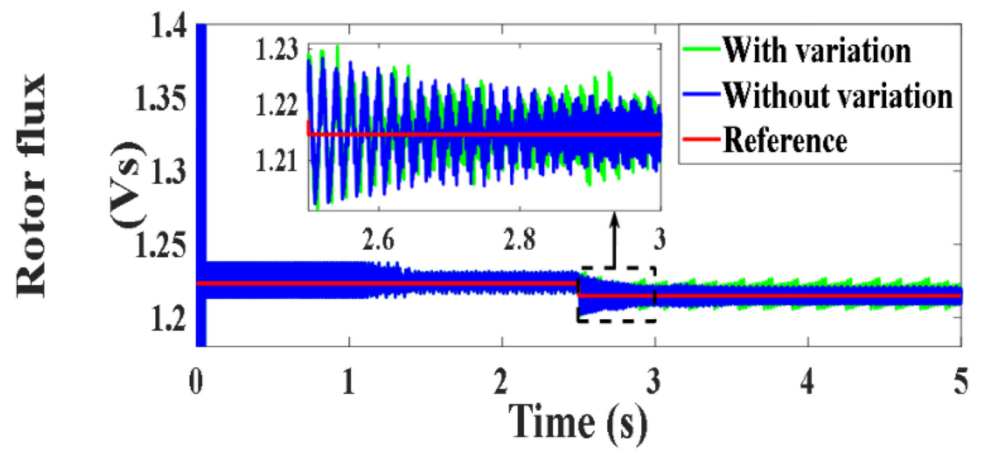

Figure 100. Rotor flux under PVC (Vs).

4.5.4. Testing under Proposed PVC with $15 \%$ Variation of $\mathrm{L}_{\mathrm{r}}$

The performance of the DFIG under PVC was also tested for the variable speed operation (Figure 101) while considering a mismatch of $15 \%$ in the stator inductance $\left(\mathrm{L}_{\mathrm{r}}\right)$ 
value (Figure 102). The obtained results for the active and reactive powers, torque and rotor flux are presented in Figures 103-106. A similar test is applied under the fixed speed operation (Figure 107) with a $\mathrm{L}_{\mathrm{r}}$ variation (Figure 108), and the results are presented in Figures 109-112, respectively. The captured figures confirm the ability of the designed PVC to keep the actual values within their predefined references.

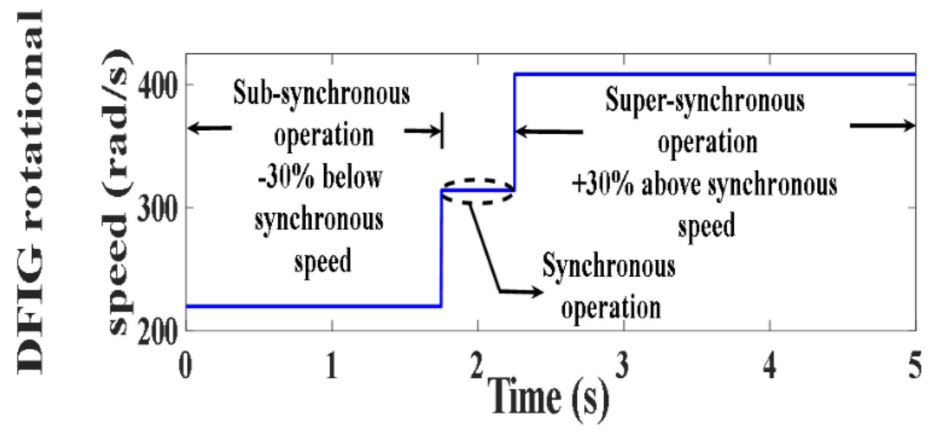

Figure 101. Prime mover operating speeds ( $\mathrm{rad} / \mathrm{s})$.

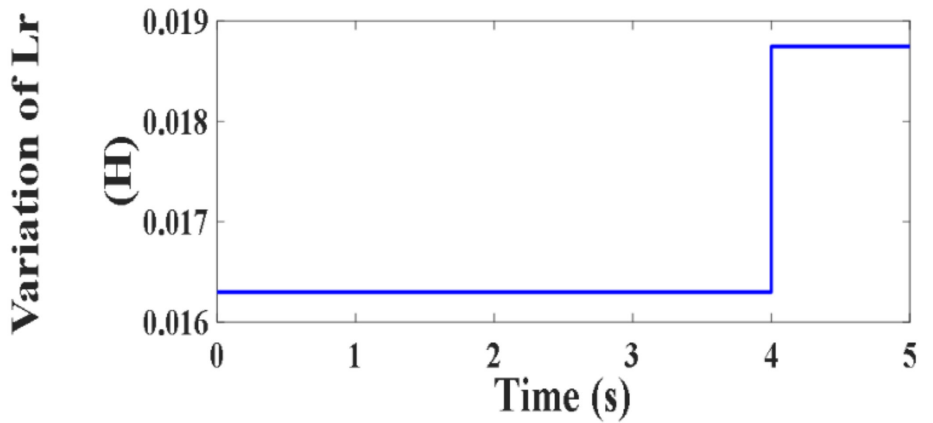

Figure 102. Variation of $L_{r}(H)$.

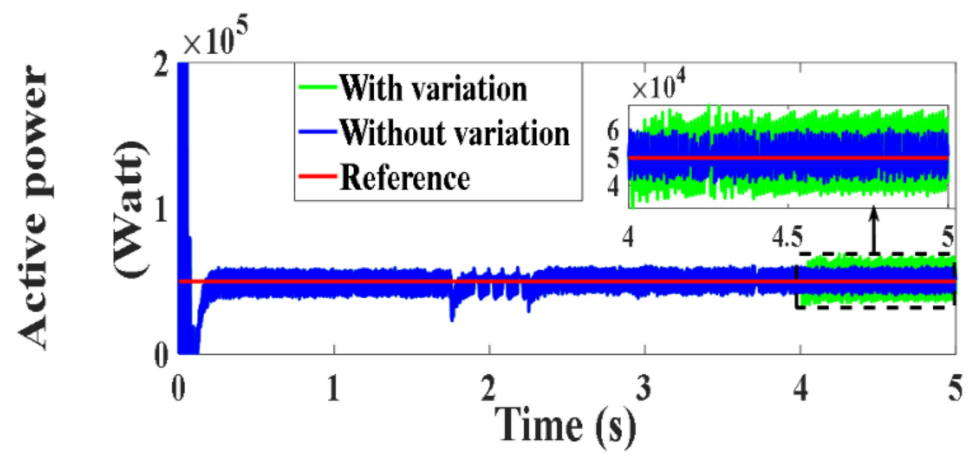

Figure 103. Active power under PVC (Watt).

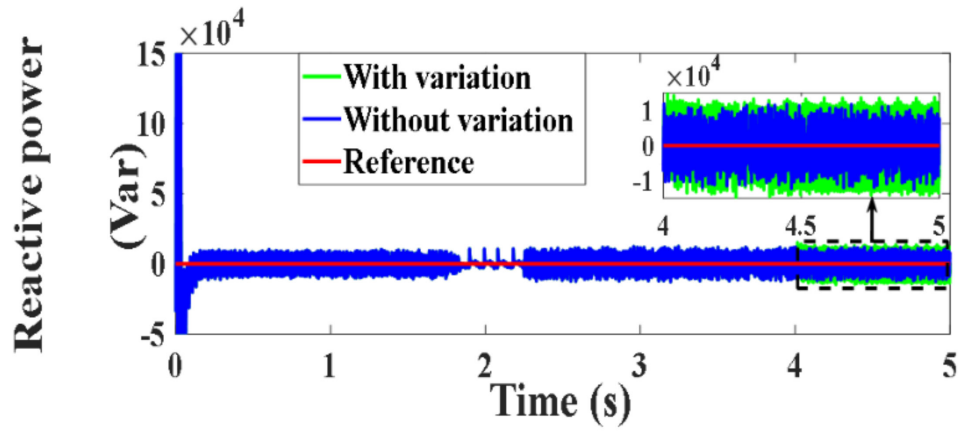

Figure 104. Reactive power under PVC (var). 


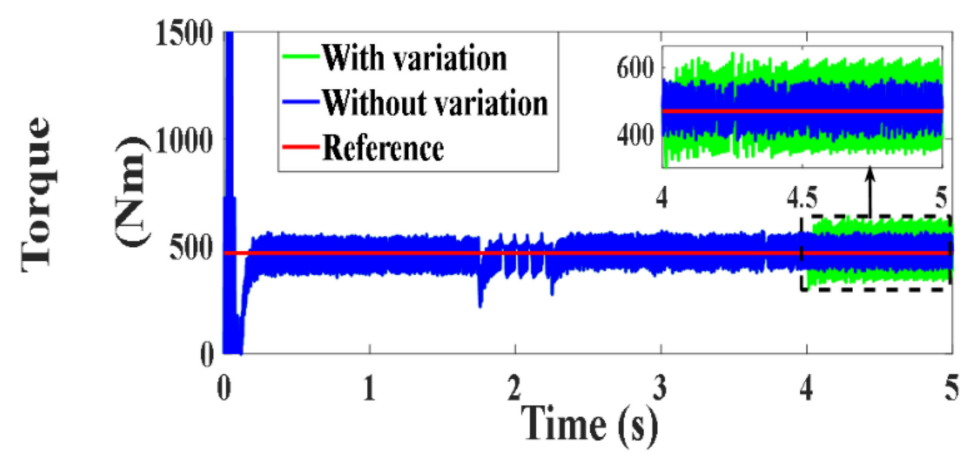

Figure 105. Developed torque under PVC (Nm).

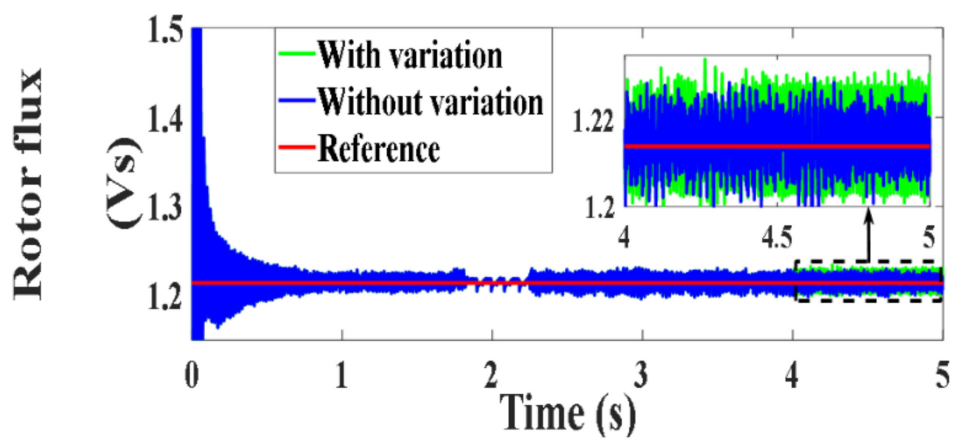

Figure 106. Rotor flux under PVC (Vs).

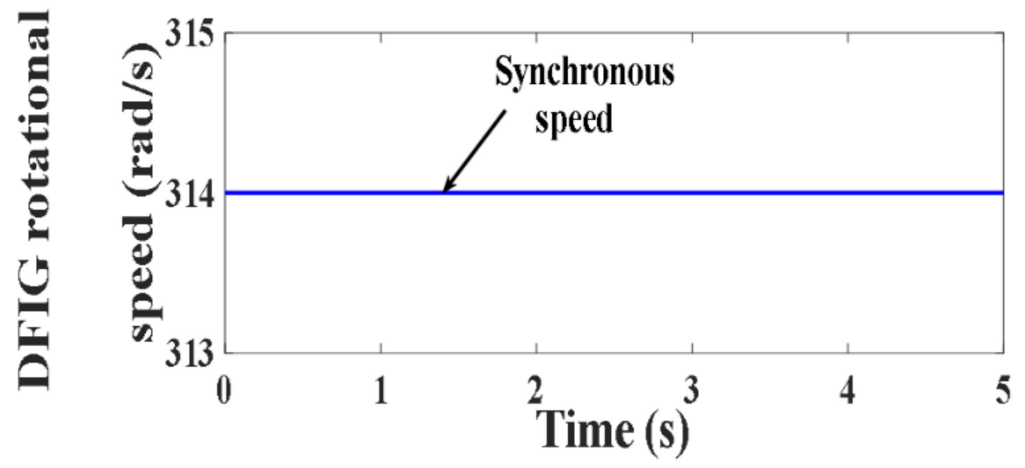

Figure 107. Prime mover operating speeds ( $\mathrm{rad} / \mathrm{s})$.

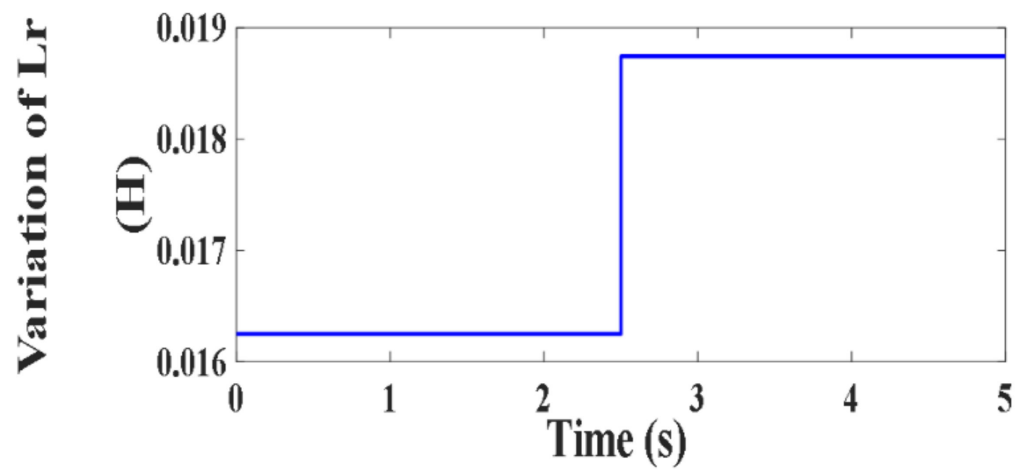

Figure 108. Variation of $L_{r}(H)$. 


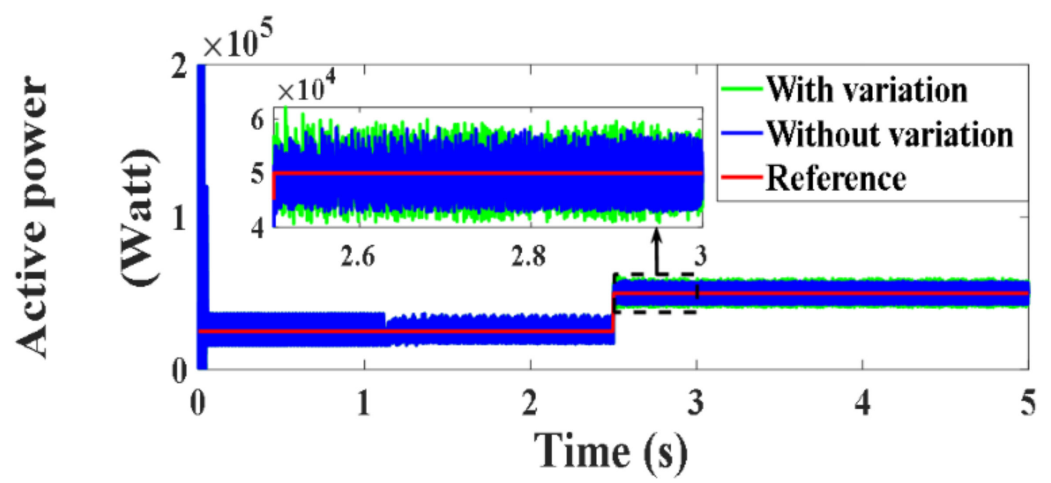

Figure 109. Active power under PVC (Watt).

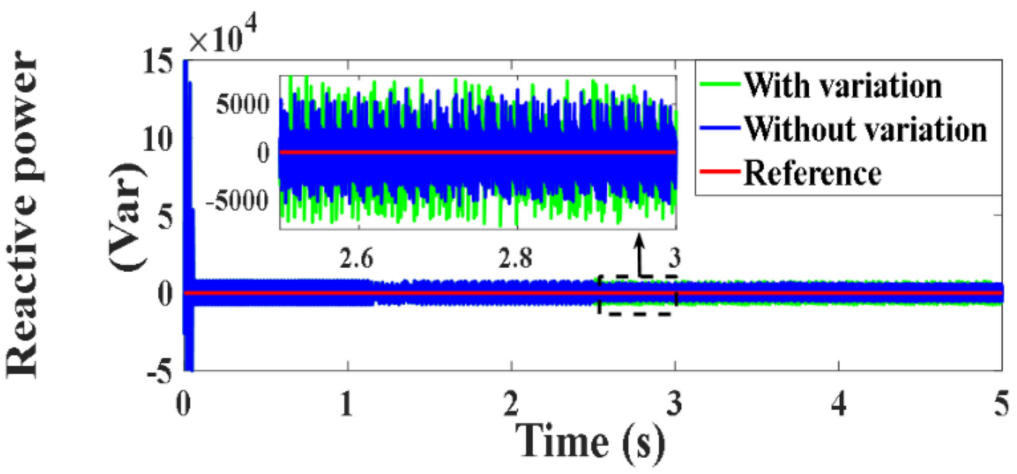

Figure 110. Reactive power under PVC (var).

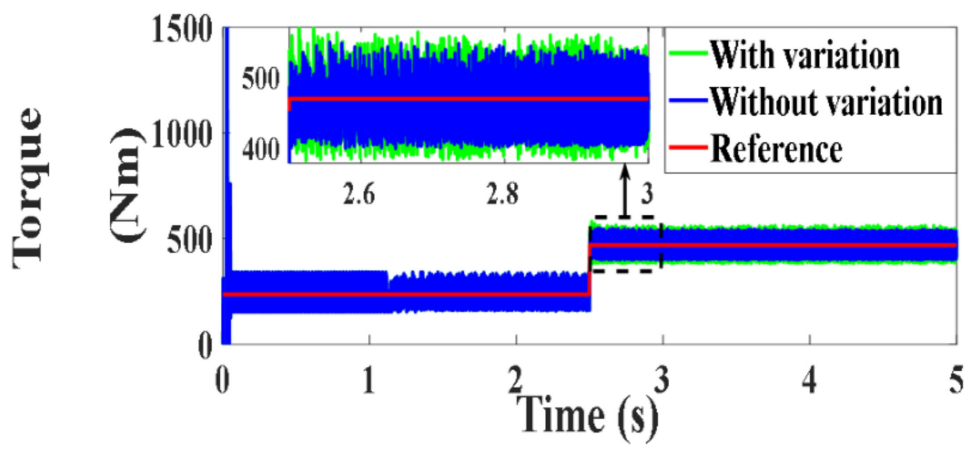

Figure 111. Developed torque under PVC (Nm).

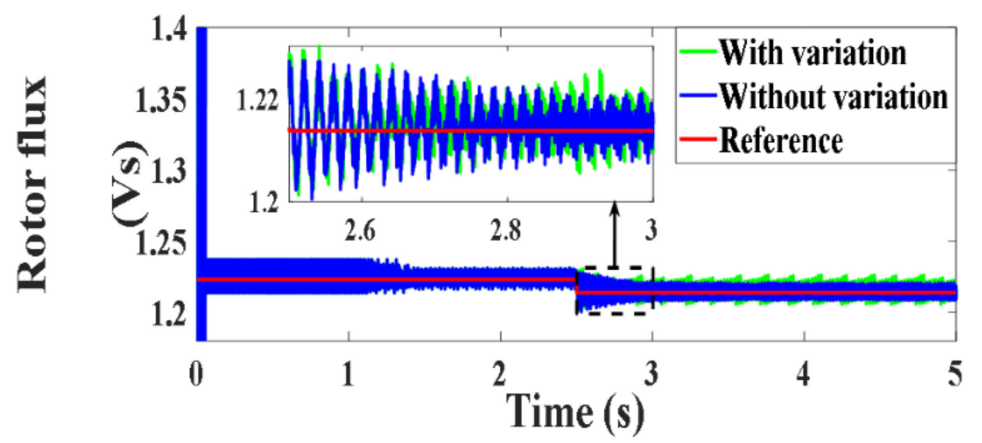

Figure 112. Rotor flux under PVC (Vs).

\subsubsection{Testing under Proposed PVC with $15 \%$ Variation of $\mathrm{L}_{\mathrm{m}}$}

The last performance test of the DFIG for the variable speed operation (Figure 113) while considering a mismatch of $15 \%$ in the magnetizing inductance $\left(\mathrm{L}_{\mathrm{m}}\right)$ value (Figure 114). 
The obtained results for the active and reactive powers, torque and rotor flux are presented in Figures 115-118. A similar test is applied under the fixed speed operation (Figure 119) with a $\mathrm{L}_{\mathrm{m}}$ variation (Figure 120), and the results are presented in Figures 121-124, respectively. The results reveal that the actual variables still stayed within their relevant reference ranges, which validates the effectiveness of the designed PVC.

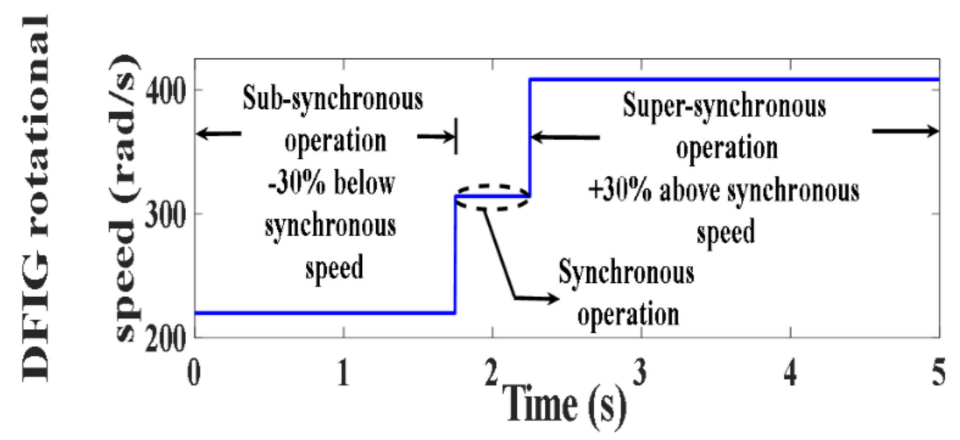

Figure 113. Prime mover operating speeds (rad/s).

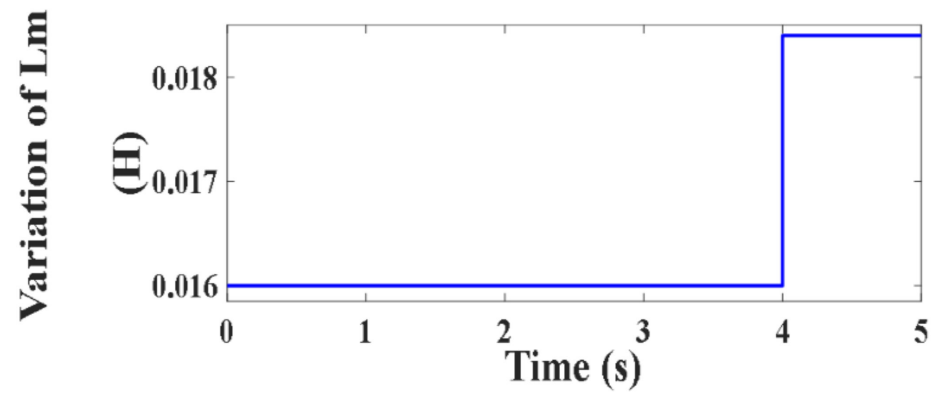

Figure 114. Variation of $\mathrm{L}_{\mathrm{m}}(\mathrm{H})$.

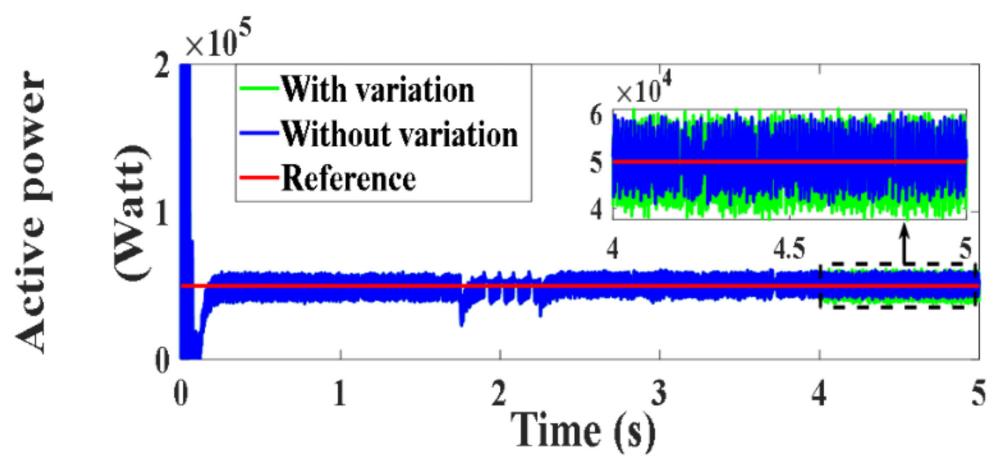

Figure 115. Active power under PVC (Watt).

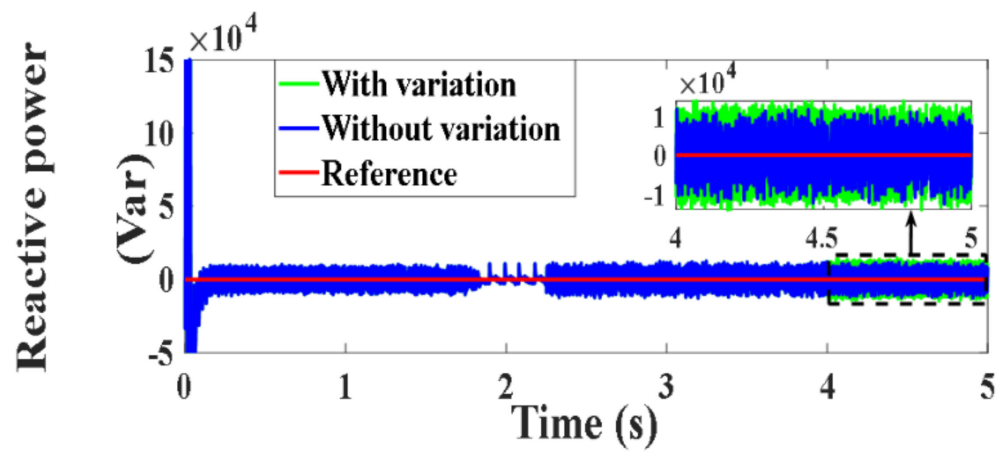

Figure 116. Reactive power under PVC (var). 


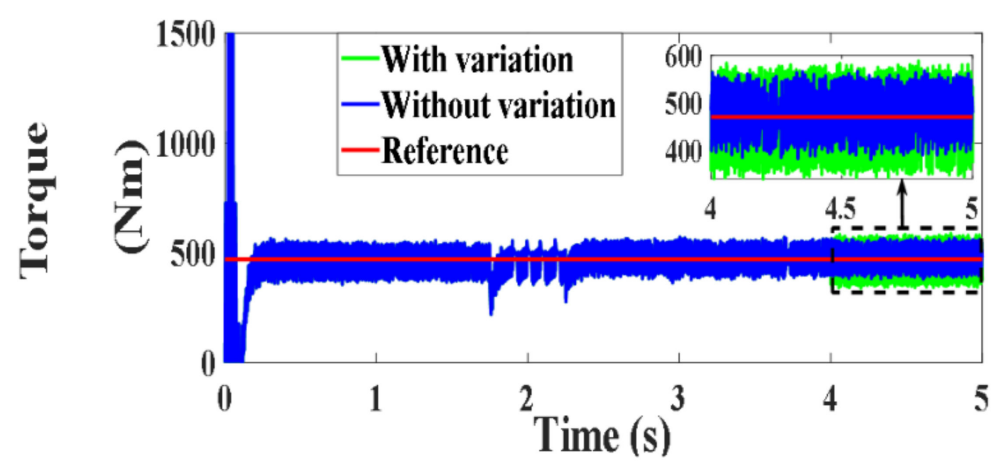

Figure 117. Developed torque under PVC (Nm).

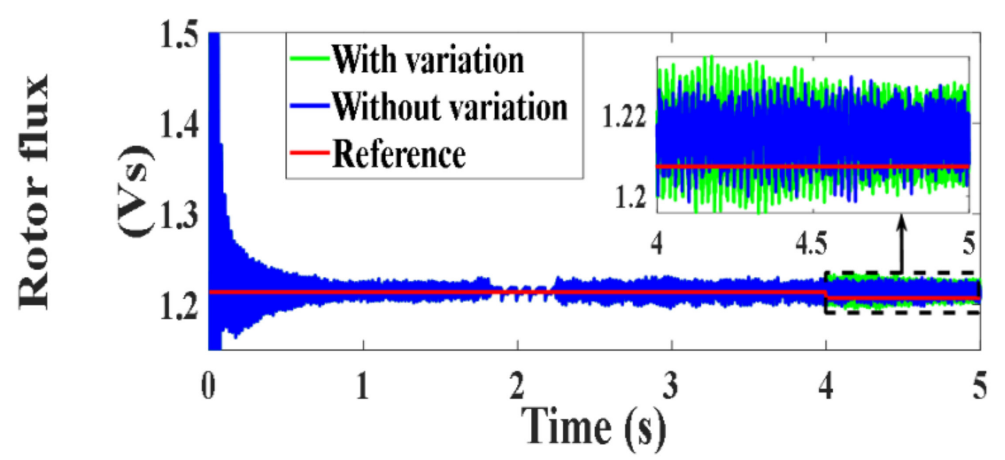

Figure 118. Rotor flux under PVC (Vs).

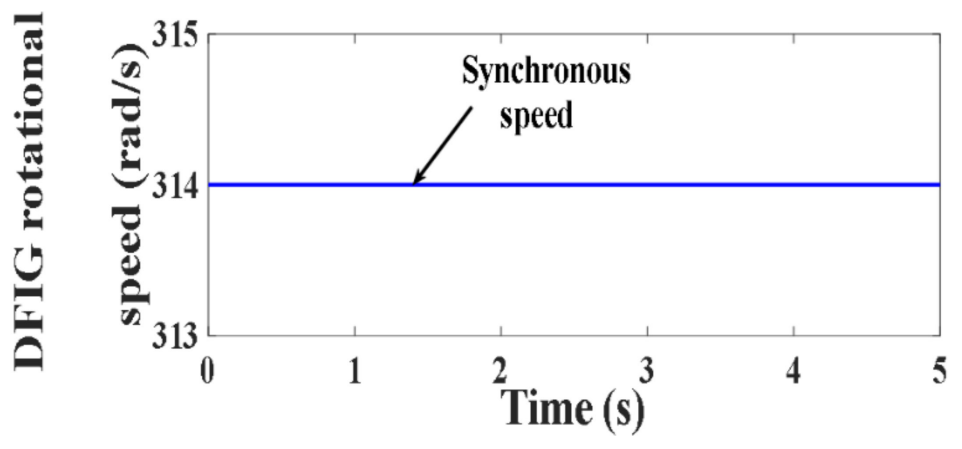

Figure 119. Prime mover operating speeds ( $\mathrm{rad} / \mathrm{s})$.

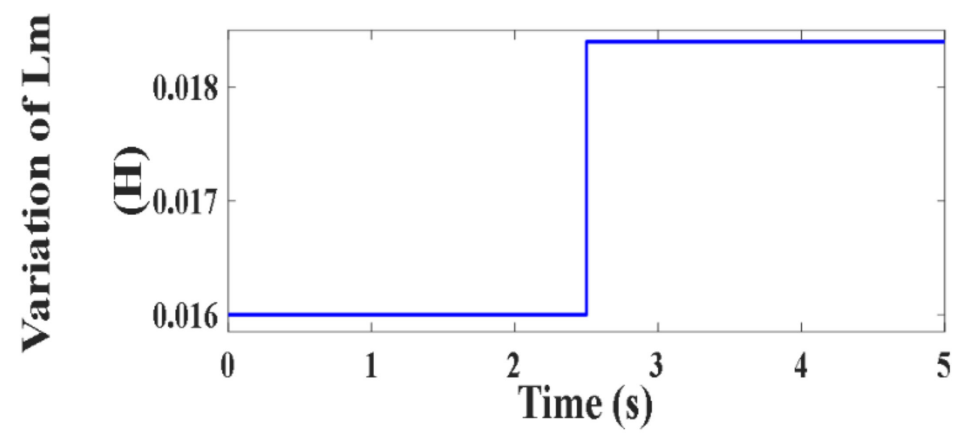

Figure 120. Variation of $L_{m}(H)$. 


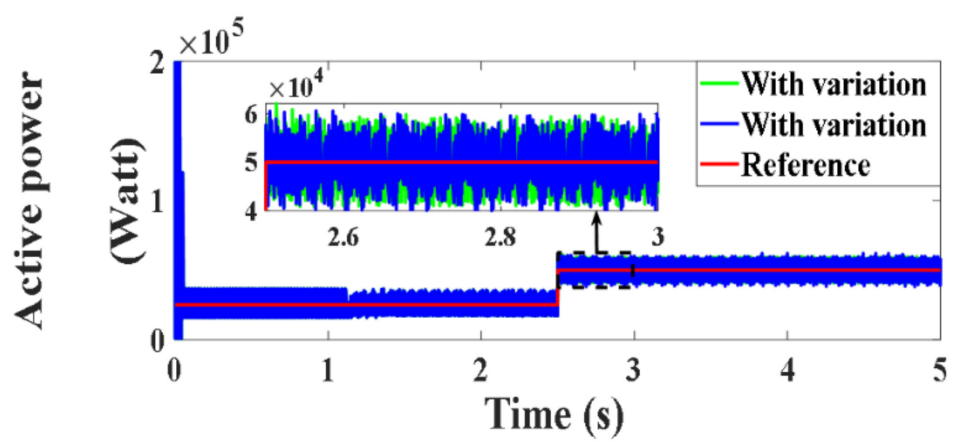

Figure 121. Active power under PVC (Watt).

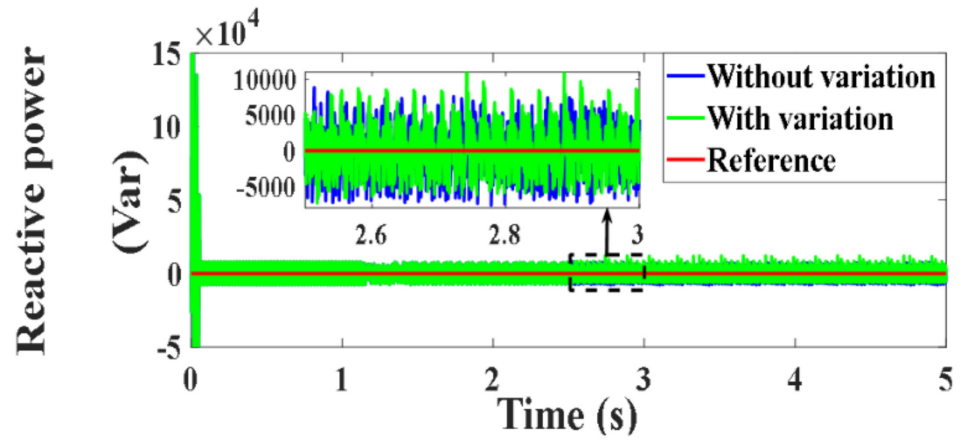

Figure 122. Reactive power under PVC (var).

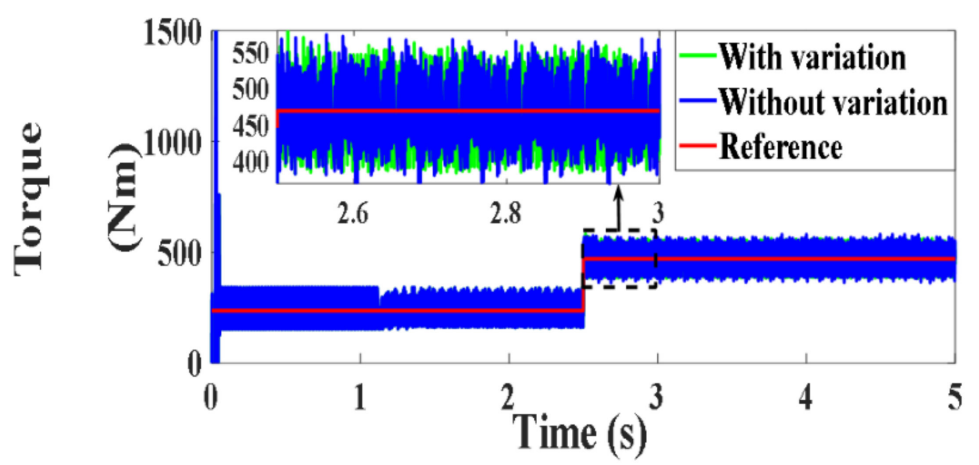

Figure 123. Developed torque under PVC (Nm).

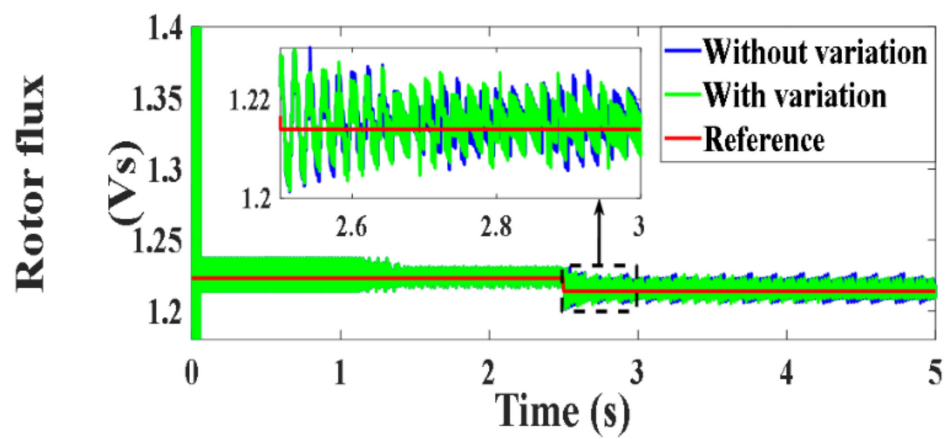

Figure 124. Rotor flux under PVC (Vs).

4.6. Testing Using Deadbeat Based Predictive Control (DBPC) Scheme with Parameter Variation 4.6.1. Testing the DBPC Scheme with $20 \%$ Variation of $R_{s}$

In order to visualize the performance of the DFIG under the PVC technique, which uses the deadbeat principle [55-58] for generating the reference voltages under parameter mismatch, the following tests were performed. Section 4.6.1 presents the dynamic 
performance of the DFIG for variable speed operation (Figure 125) when a mismatch in stator resistance of $20 \%$ was applied at time $t=4 \mathrm{~s}$ (Figure 126). The obtained results reveal that this scheme of PVC failed in maintaining the proper operation under the resistance variation. This fact can be confirmed by following up the deviation of the actual values of active and reactive powers, torque and rotor flux (Figures 127-130, respectively). A similar test under fixed speed operation (Figure 131) is applied with a resistance variation at time $t=2.5 \mathrm{~s}$ (Figure 132). The obtained results in Figures 133-136 reveal the obvious deviation of the actual values from their references. As a result, it is confirmed that the validity and robustness of our designed PVC against parameter change compared with this scheme is ensured.

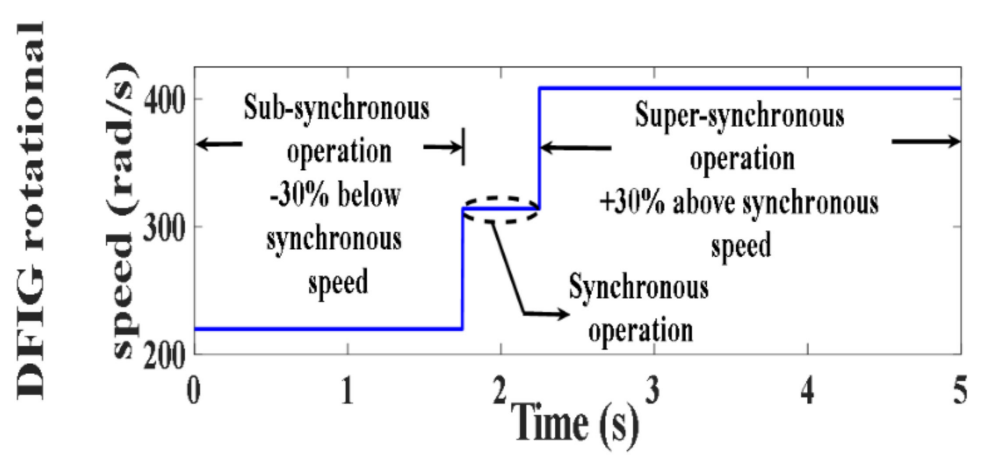

Figure 125. Prime mover operating speeds ( $\mathrm{rad} / \mathrm{s})$.

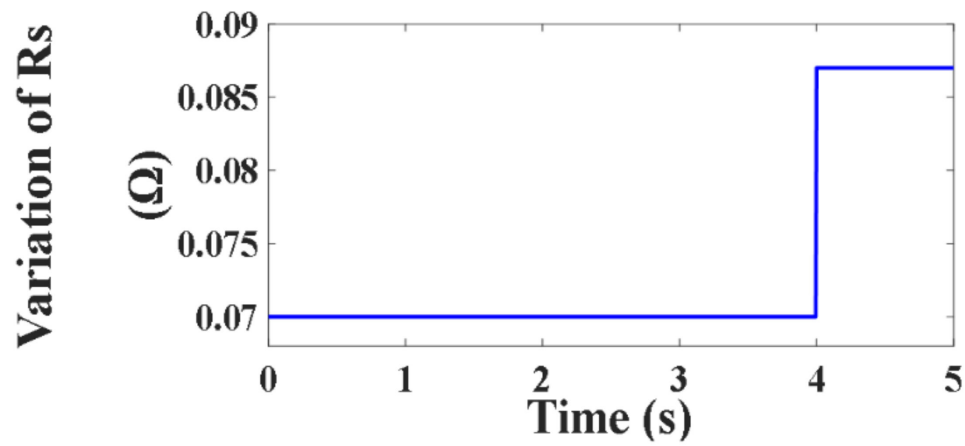

Figure 126. Variation of $R_{s}(\Omega)$.

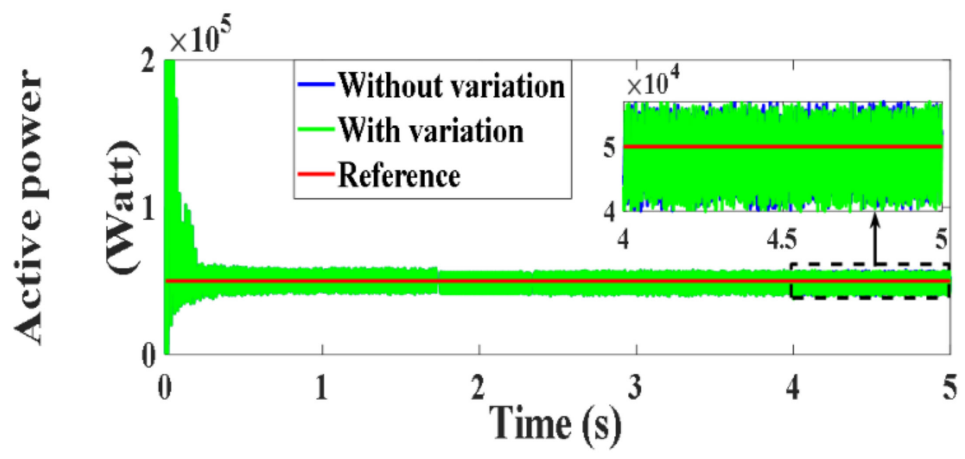

Figure 127. Active power under PVC (Watt). 


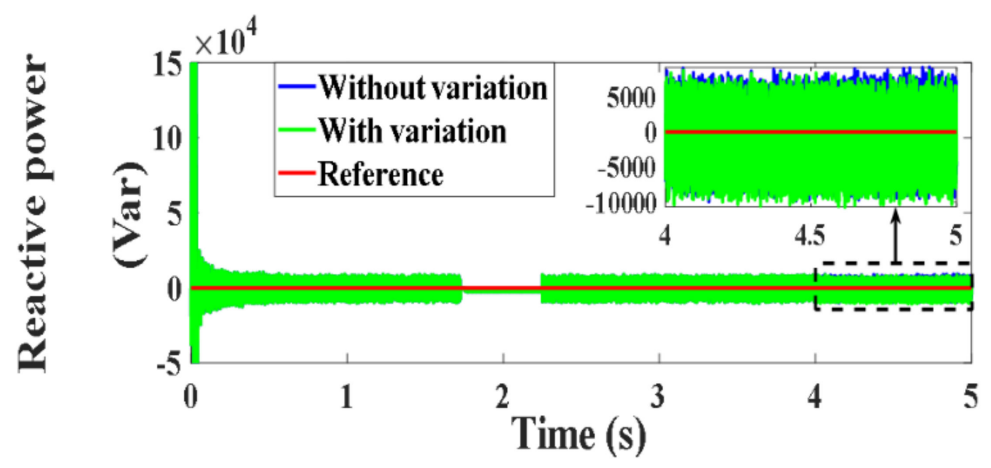

Figure 128. Reactive power under PVC (var).

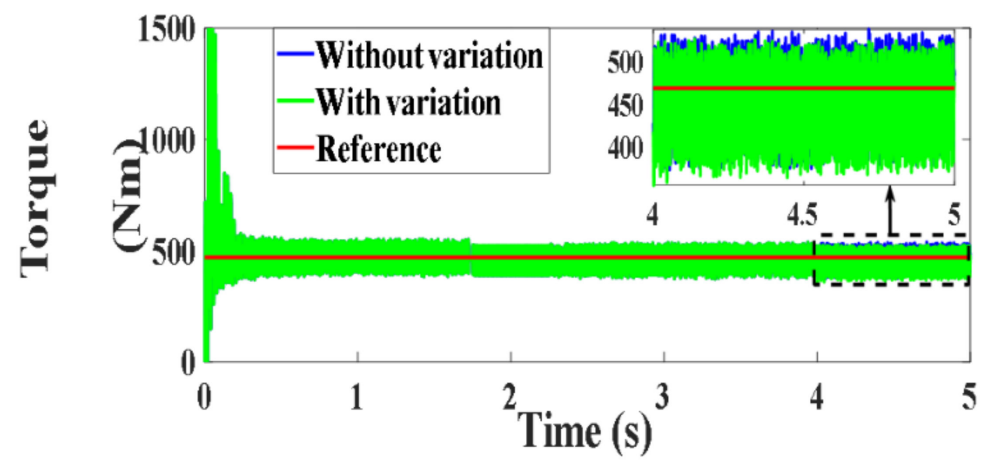

Figure 129. Developed torque under PVC (Nm).

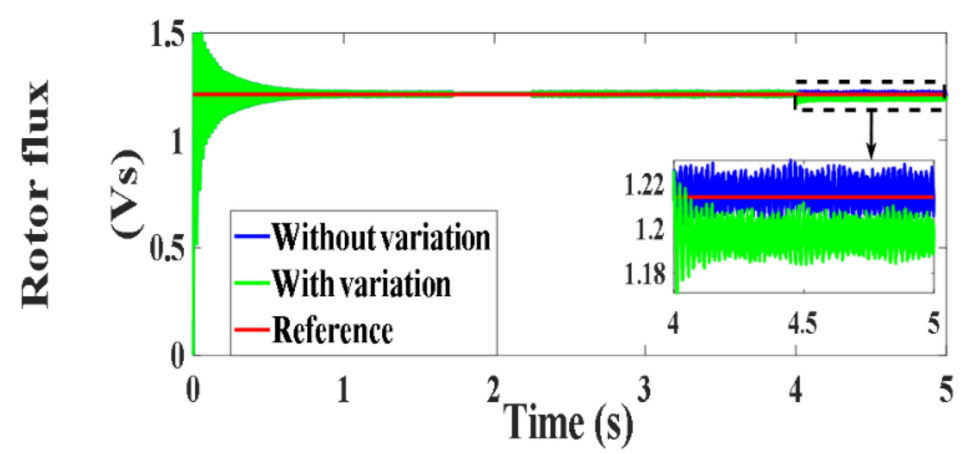

Figure 130. Rotor flux under PVC (Vs).

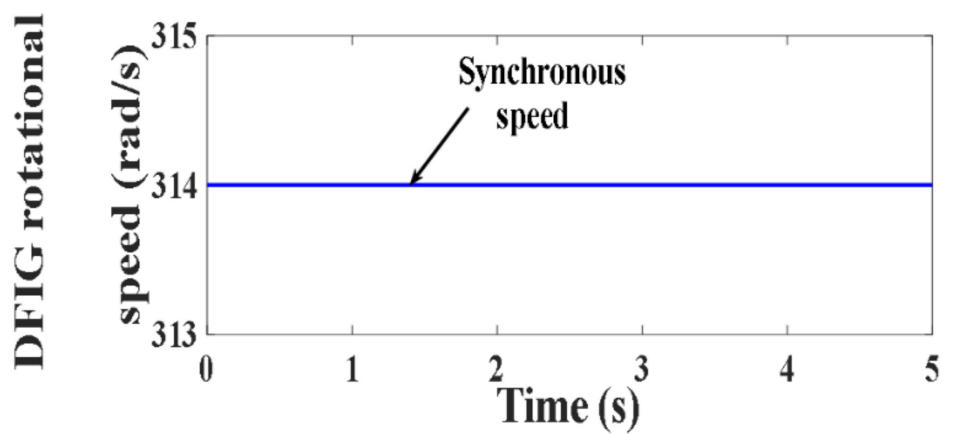

Figure 131. Prime mover operating speeds ( $\mathrm{rad} / \mathrm{s})$. 


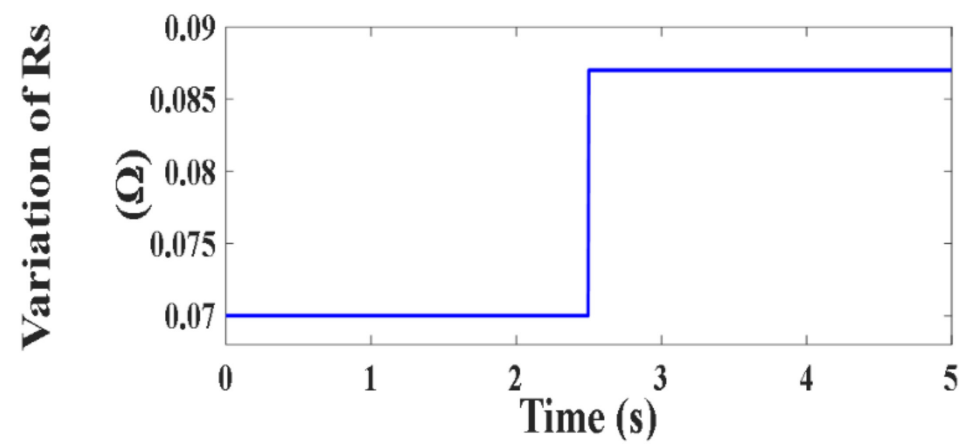

Figure 132. Variation of $R_{S}(\Omega)$.

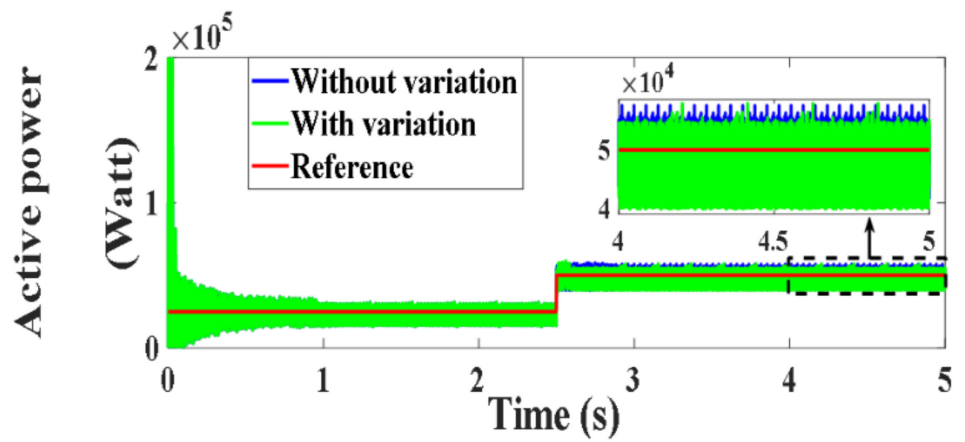

Figure 133. Active power under PVC (Watt).

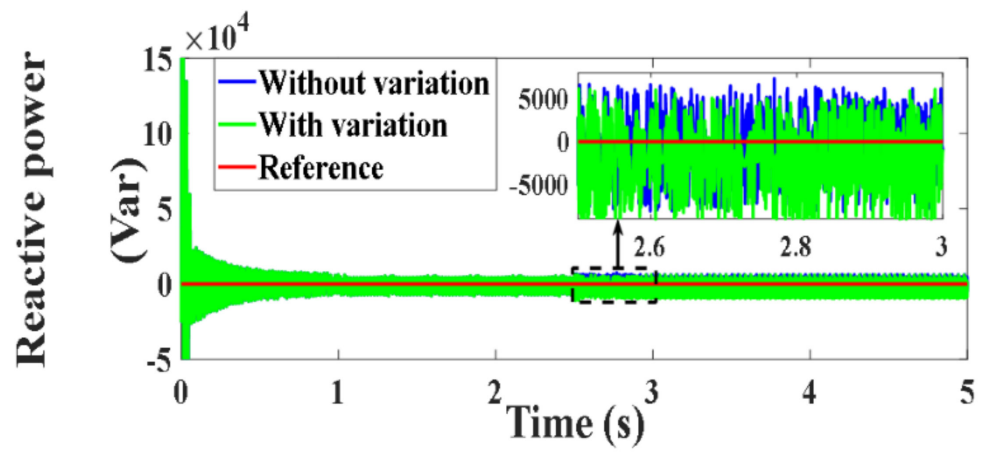

Figure 134. Reactive power under PVC (var).

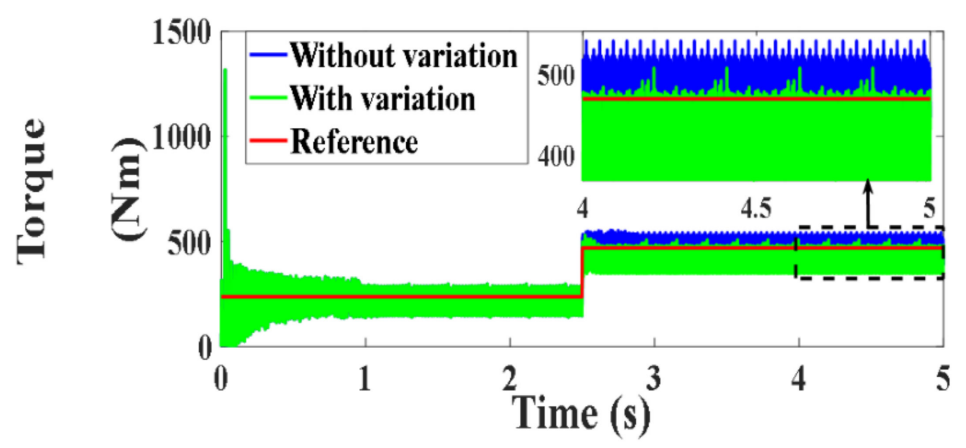

Figure 135. Developed torque under PVC (Nm). 


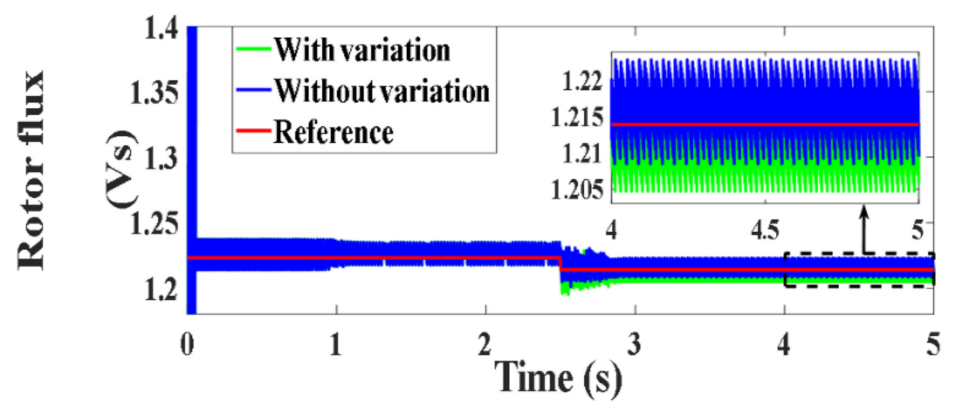

Figure 136. Rotor flux under PVC (Vs).

4.6.2. Testing the DBPC Scheme with $20 \%$ Variation of $R_{r}$

The dynamic performance of the DFIG for variable speed operation (Figure 137) when a mismatch in rotor resistance of $20 \%$ was applied (Figure 138). The obtained results reveal that DBPC scheme failed in maintaining the proper operation under the resistance variation. This fact can be confirmed by following up the deviation of the actual values of active and reactive powers, torque and rotor flux (Figures 139-142, respectively). A similar test under fixed speed operation (Figure 143) is applied with a resistance variation at time $t=2.5 \mathrm{~s}$ (Figure 144). The obtained results in Figures 145-148 reveal the obvious deviation of the actual values from their references.

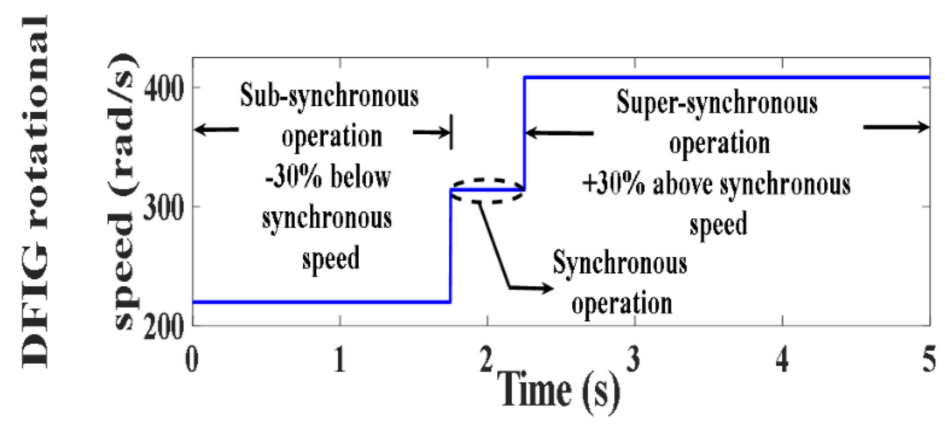

Figure 137. Prime mover operating speeds ( $\mathrm{rad} / \mathrm{s})$.

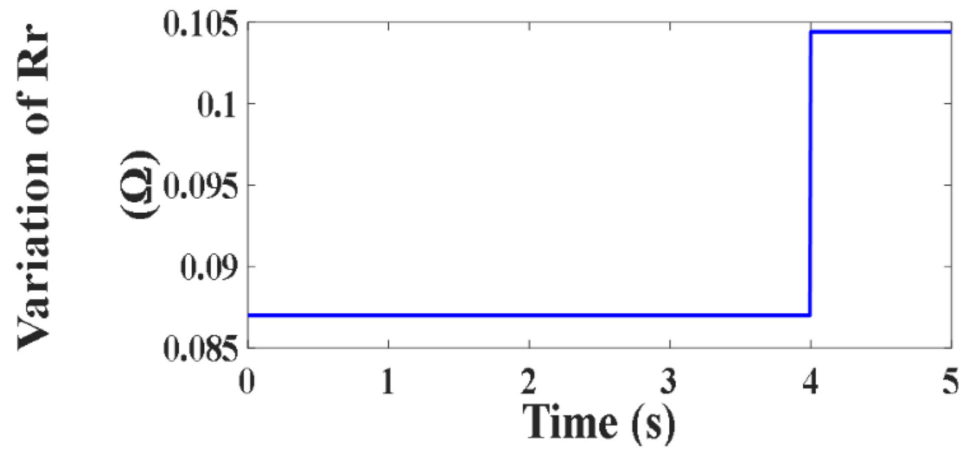

Figure 138. Variation of $R_{r}(\Omega)$. 


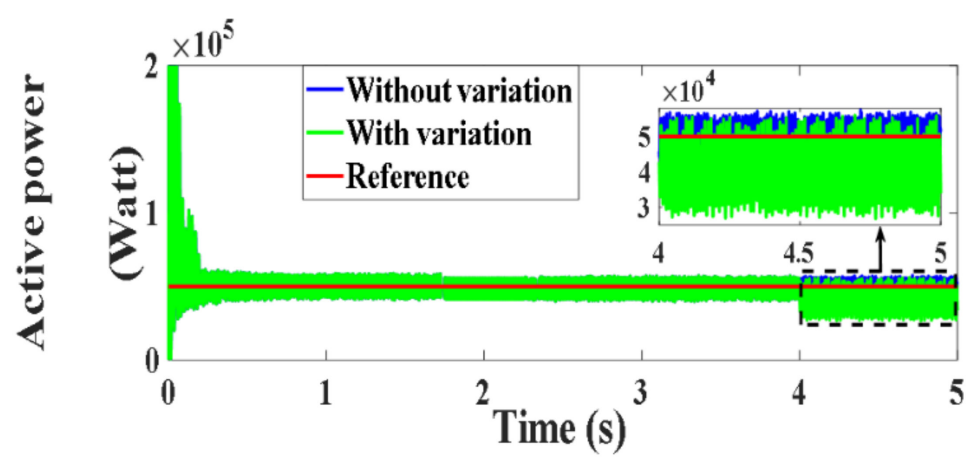

Figure 139. Active power under PVC (Watt).

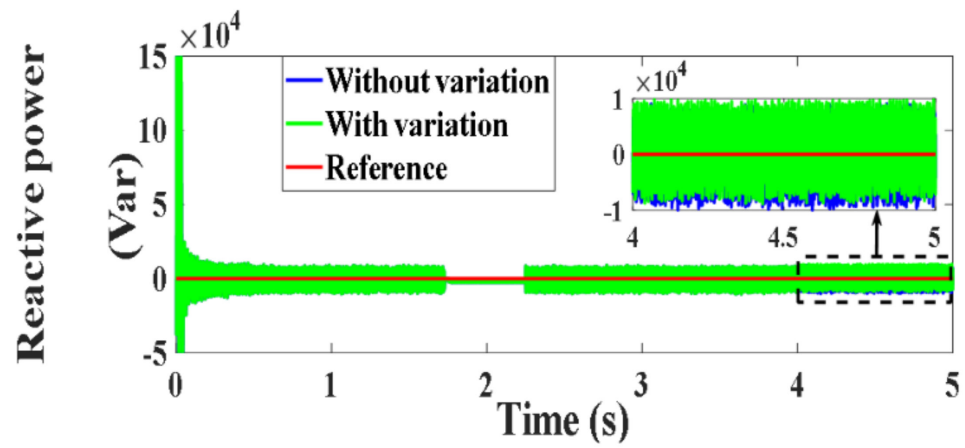

Figure 140. Reactive power under PVC (var).

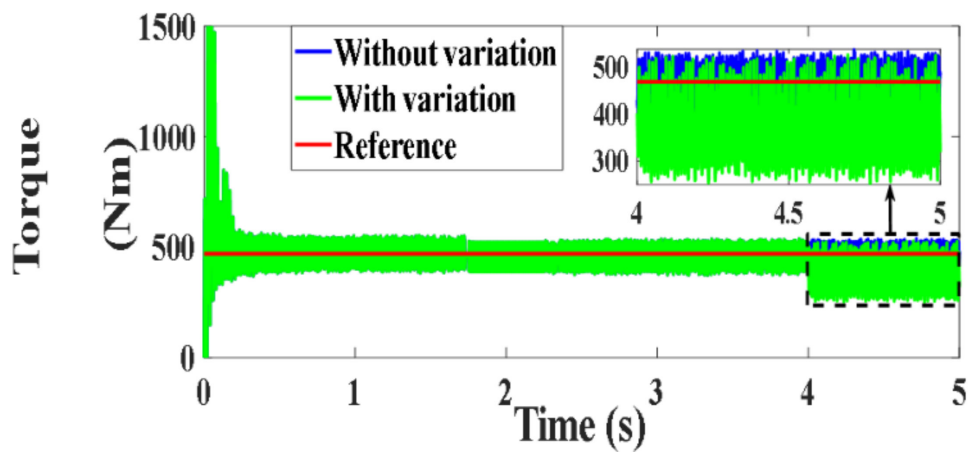

Figure 141. Developed torque under PVC (Nm).

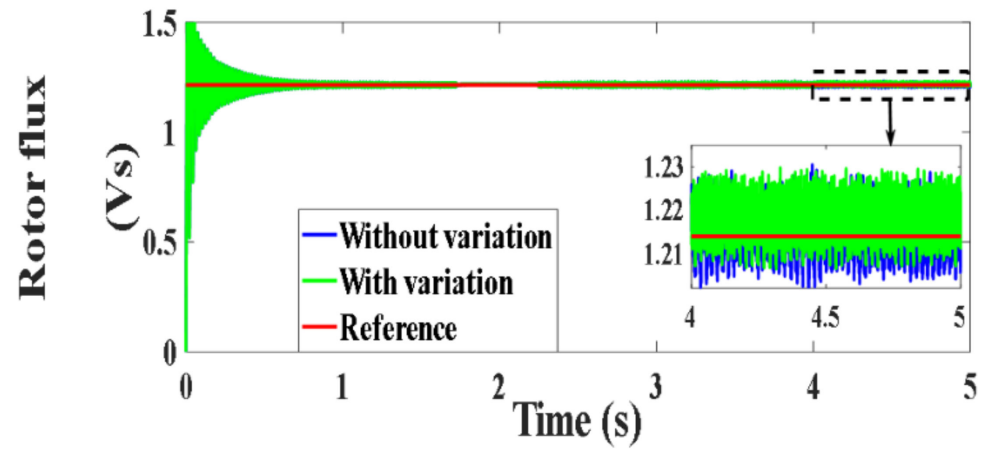

Figure 142. Rotor flux under PVC (Vs). 


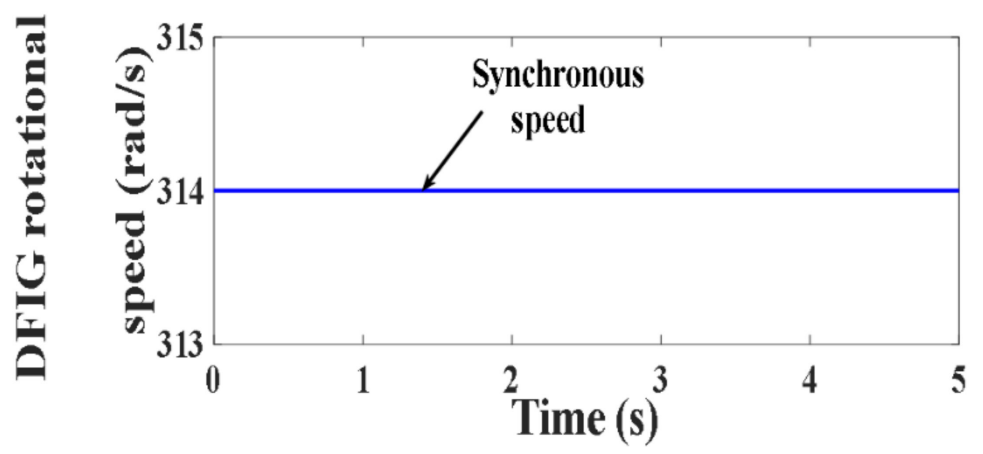

Figure 143. Prime mover operating speeds ( $\mathrm{rad} / \mathrm{s})$.

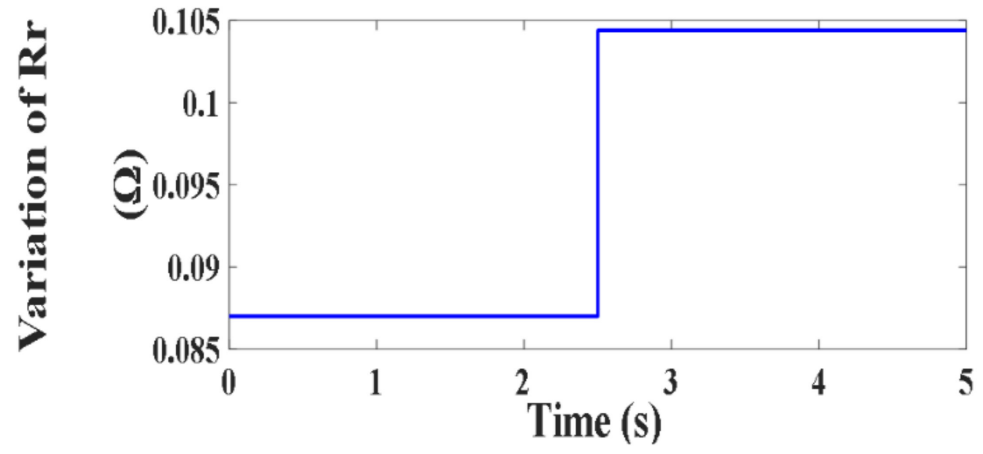

Figure 144. Variation of $R_{r}(\Omega)$.

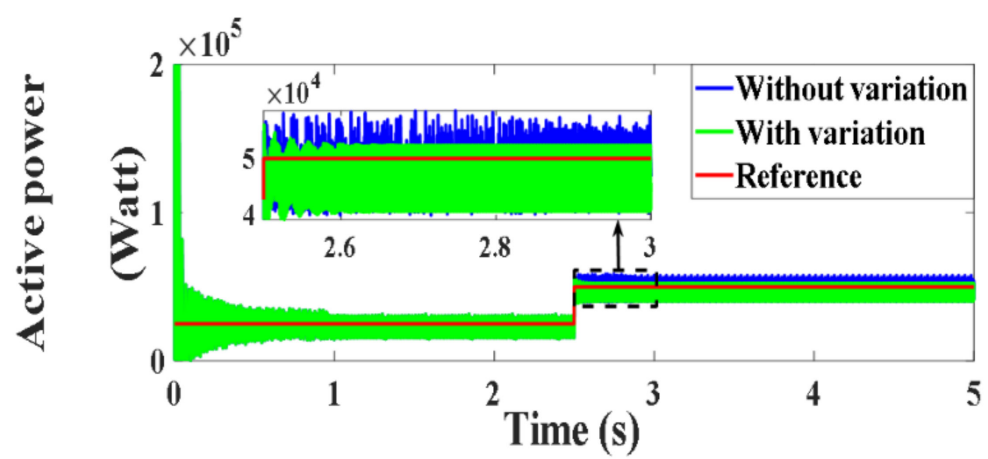

Figure 145. Active power under PVC (Watt).

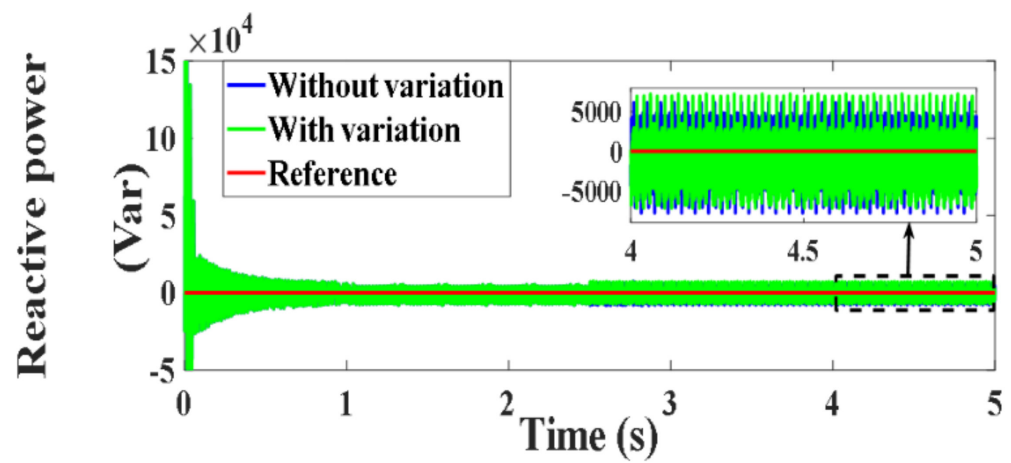

Figure 146. Reactive power under PVC (var). 


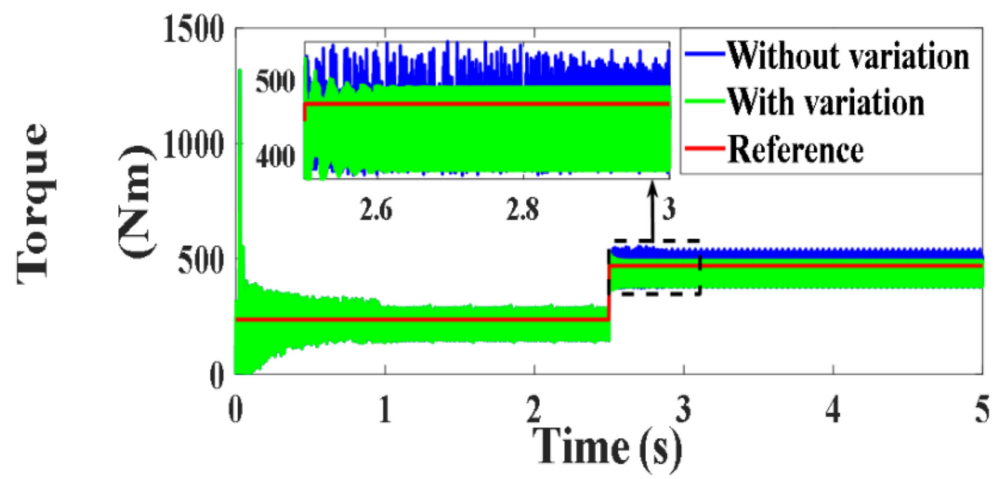

Figure 147. Developed torque under PVC (Nm).

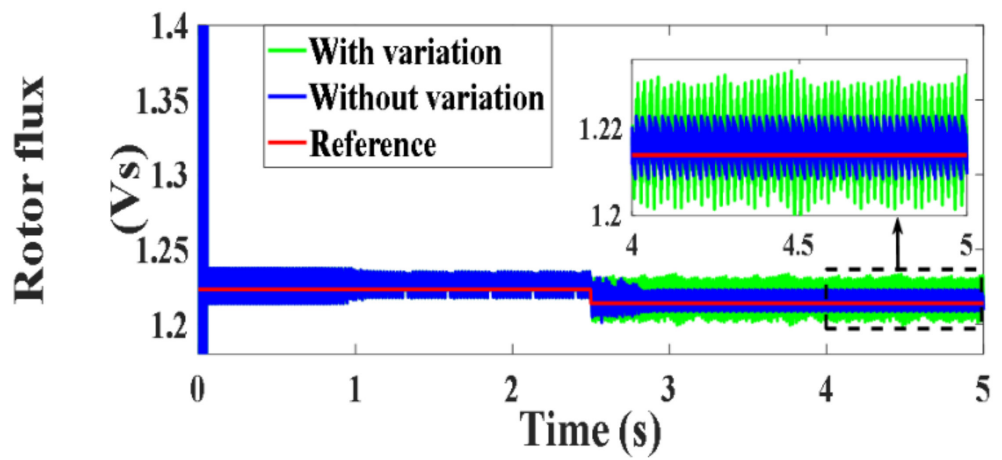

Figure 148. Rotor flux under PVC (Vs).

4.6.3. Testing the DBPC Scheme with $15 \%$ Variation of $\mathrm{L}_{\mathrm{s}}$

The performance of the DFIG under the DBPC scheme was also tested while considering a mismatch of $15 \%$ in the stator inductance $\left(\mathrm{L}_{\mathrm{S}}\right)$ value. For the variable speed operation (Figure 149) when a mismatch in $\mathrm{L}_{\mathrm{s}}$ of $15 \%$ was applied (Figure 150). The obtained results reveal that DBPC scheme failed in maintaining the proper operation under the inductance variation. This fact can be confirmed by following up the deviation of the actual values of active and reactive powers, torque and rotor flux (Figures 151-154, respectively). A similar test under fixed speed operation (Figure 155) is applied with an inductance variation at time $t=2.5 \mathrm{~s}$ (Figure 156). The test results in Figures 157-160 prove the effectiveness and robustness of our designed PVC against parameter change compared with the DBPC scheme.

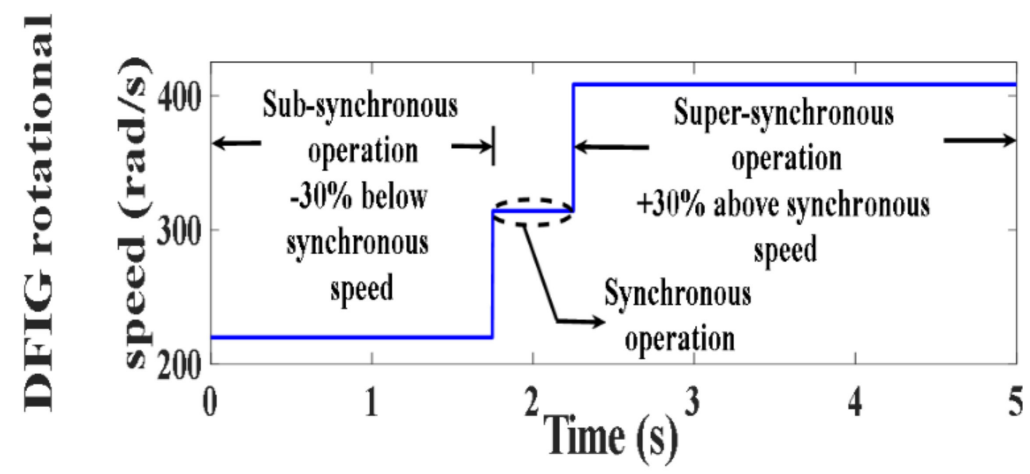

Figure 149. Prime mover operating speeds ( $\mathrm{rad} / \mathrm{s})$. 


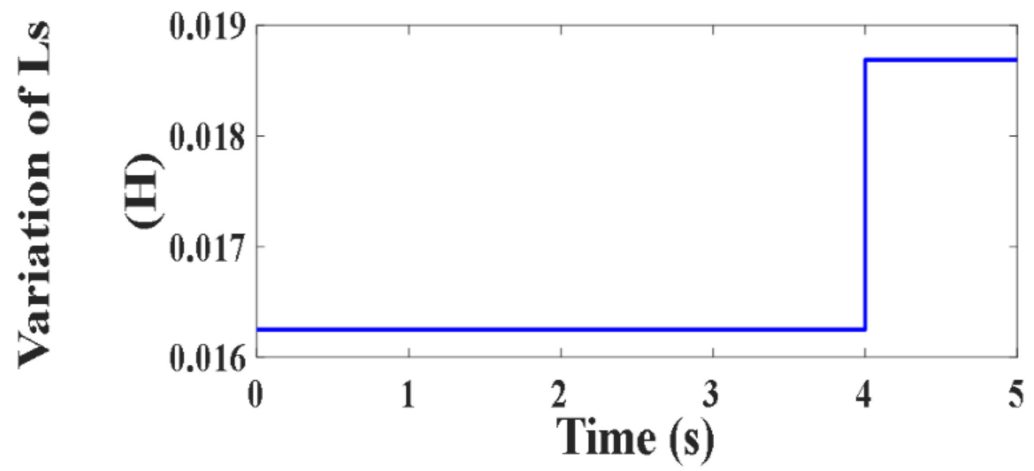

Figure 150. Variation of $L_{s}(H)$.

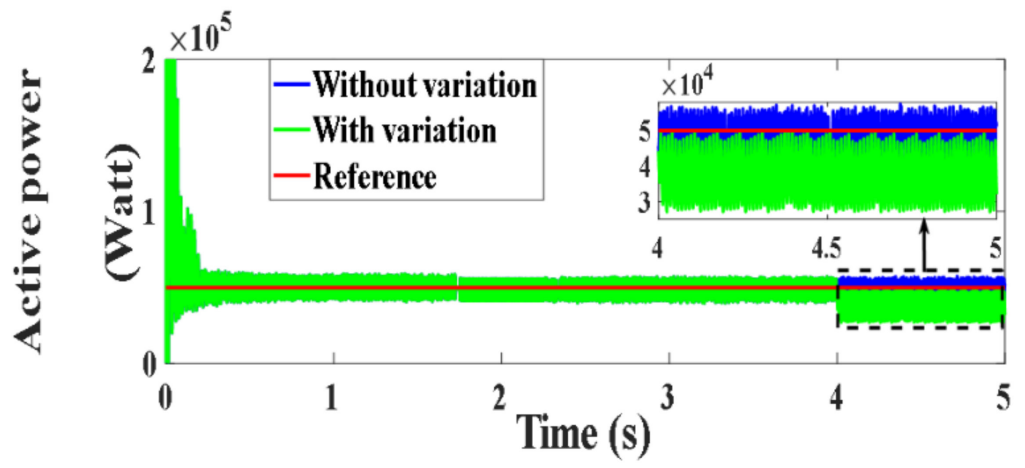

Figure 151. Active power under PVC (Watt).

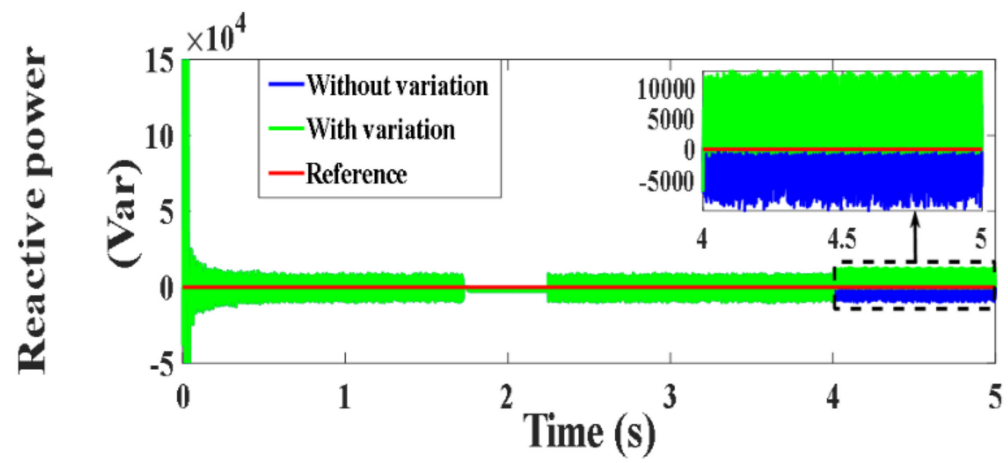

Figure 152. Reactive power under PVC (var).

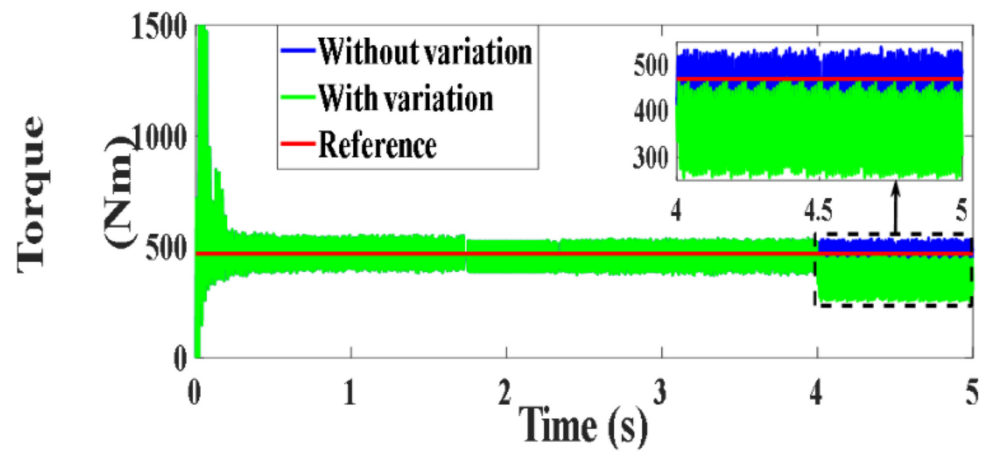

Figure 153. Developed torque under PVC (Nm). 


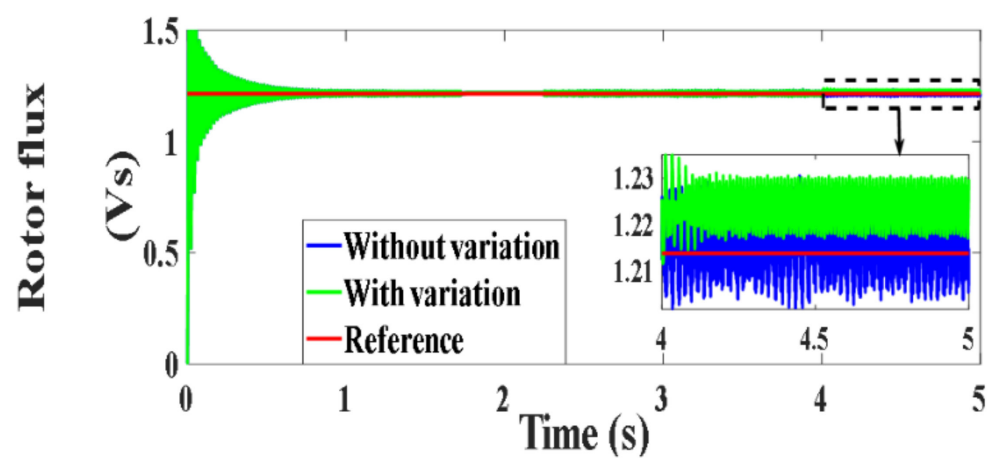

Figure 154. Rotor flux under PVC (Vs).

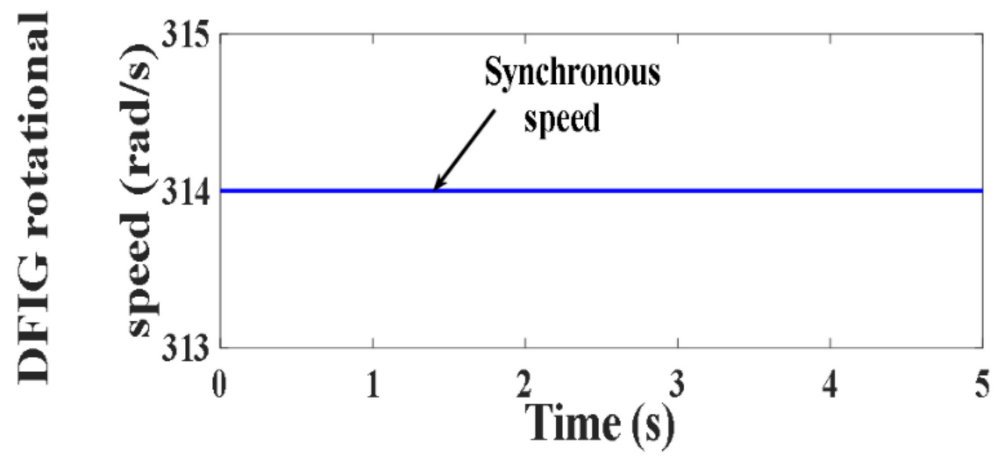

Figure 155. Prime mover operating speeds ( $\mathrm{rad} / \mathrm{s})$.

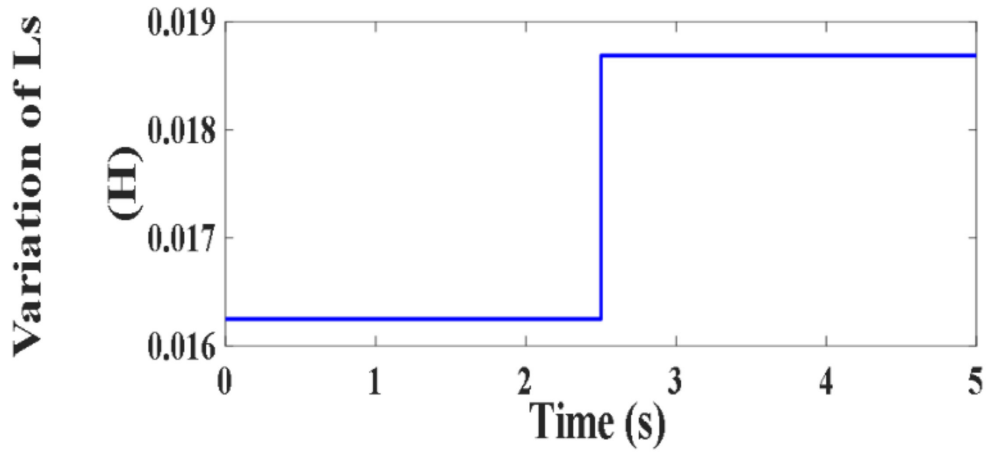

Figure 156. Variation of $L_{s}(H)$.

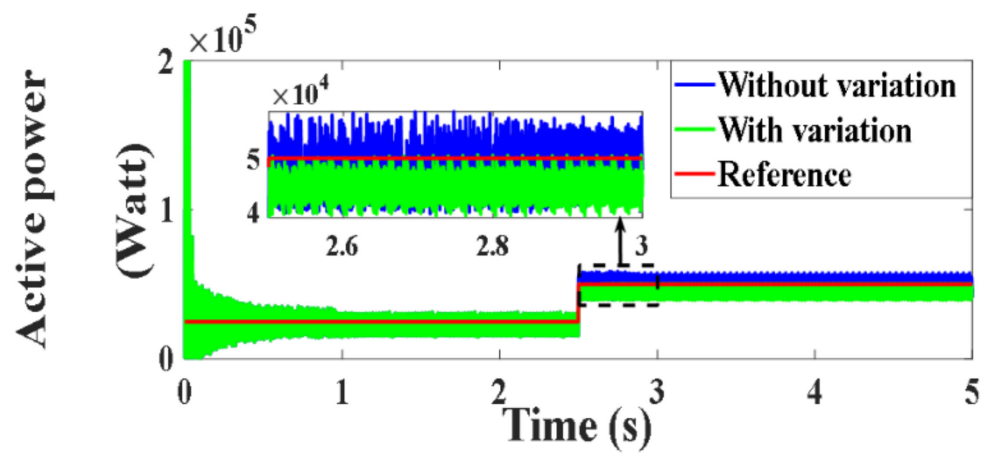

Figure 157. Active power under PVC (Watt). 


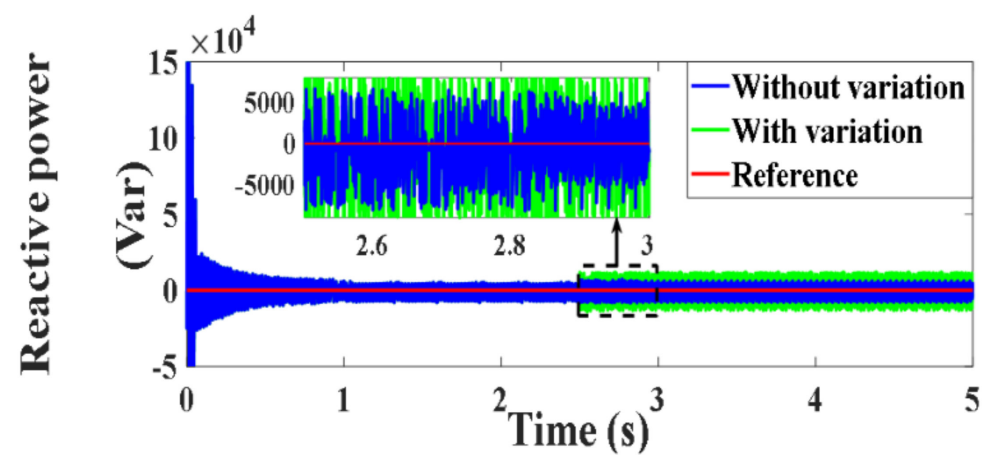

Figure 158. Reactive power under PVC (var).

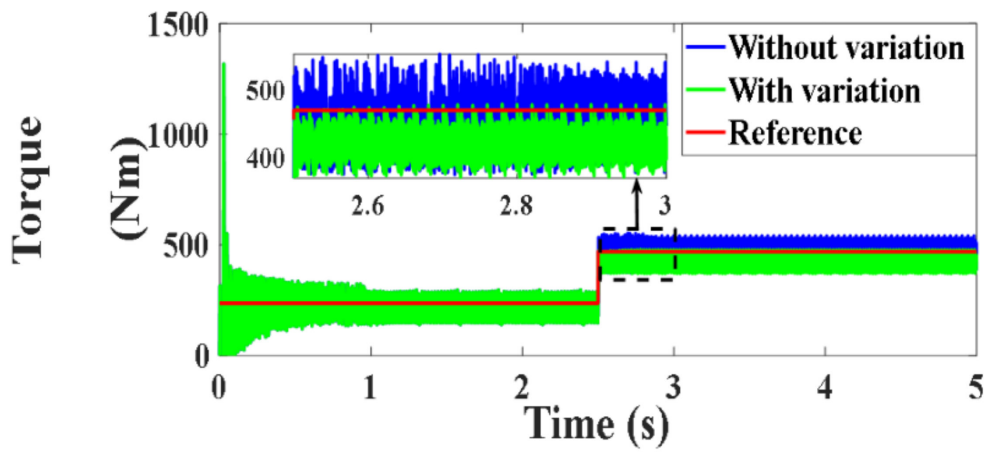

Figure 159. Developed torque under PVC (Nm).

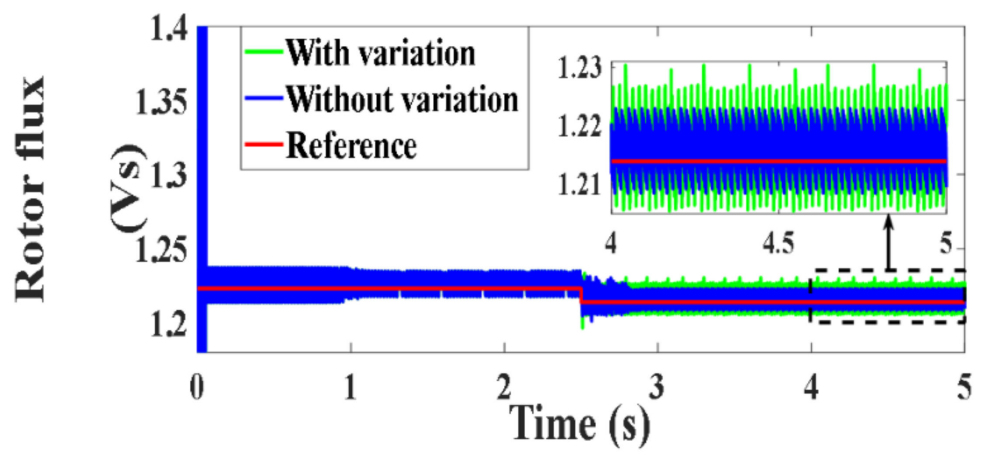

Figure 160. Rotor flux under PVC (Vs).

4.6.4. Testing the DBPC Scheme with $15 \%$ Variation of $\mathrm{L}_{r}$

For the variable speed operation (Figure 161), a mismatch in $\mathrm{L}_{r}$ of $15 \%$ was applied (Figure 162). The obtained results reveal that DBPC scheme failed in maintaining the proper operation under the inductance variation. This fact is illustrated via checking the deviation of the actual values of active and reactive powers, torque and rotor flux (Figures 163-166, respectively). A similar test under fixed speed operation (Figure 167) is applied with a $\mathrm{L}_{\mathrm{r}}$ variation at time $t=2.5 \mathrm{~s}$ (Figure 168). The results in Figures 169-172 reveal the deficiency of the DBPC in handling the system uncertainties. 


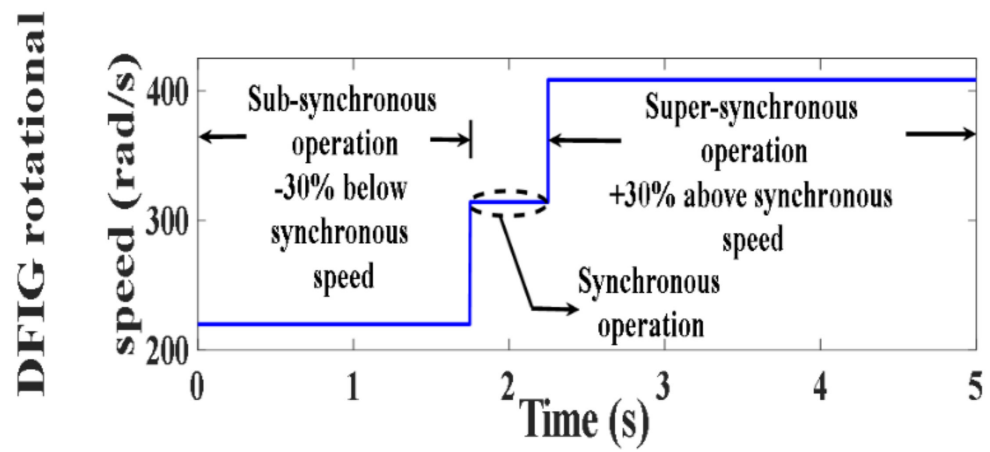

Figure 161. Prime mover operating speeds (rad/s).

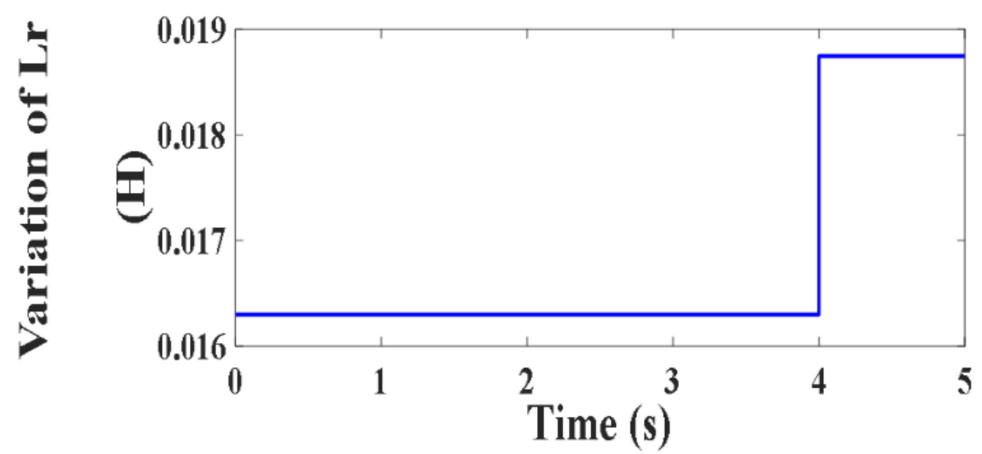

Figure 162. Variation of $L_{r}(H)$.

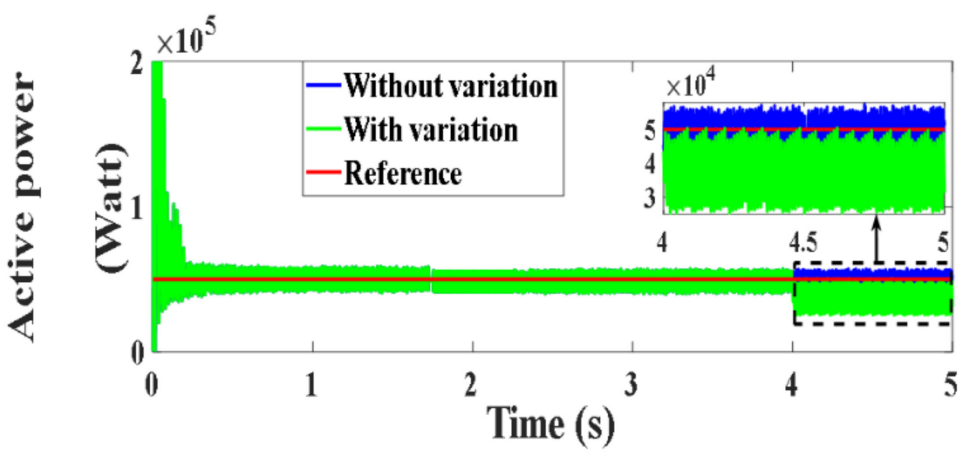

Figure 163. Active power under PVC (Watt).

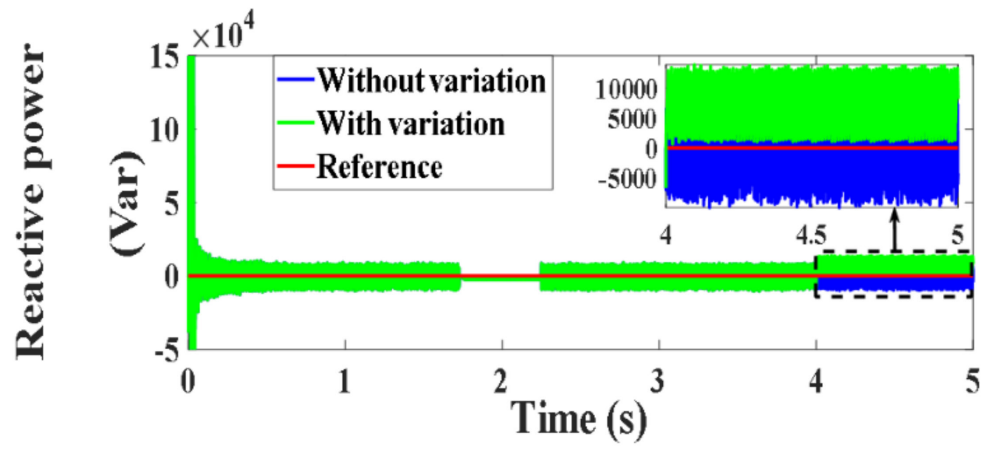

Figure 164. Reactive power under PVC (var). 


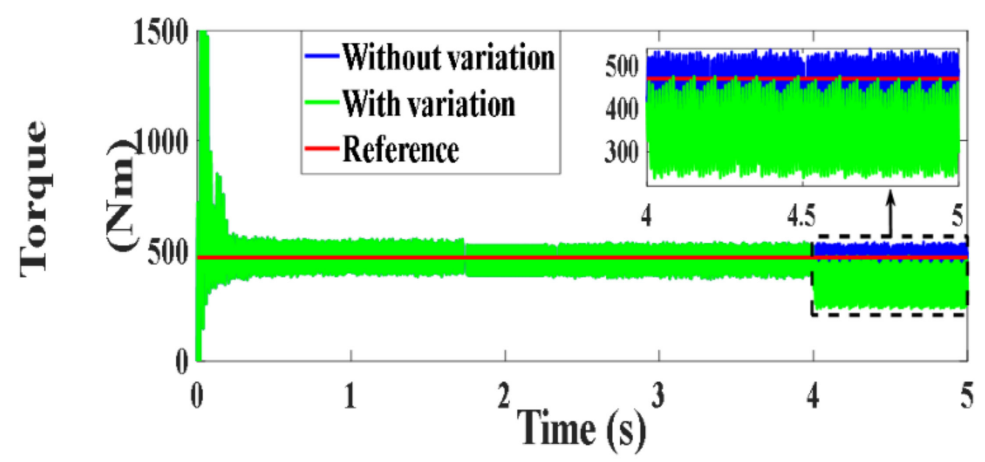

Figure 165. Developed torque under PVC (Nm).

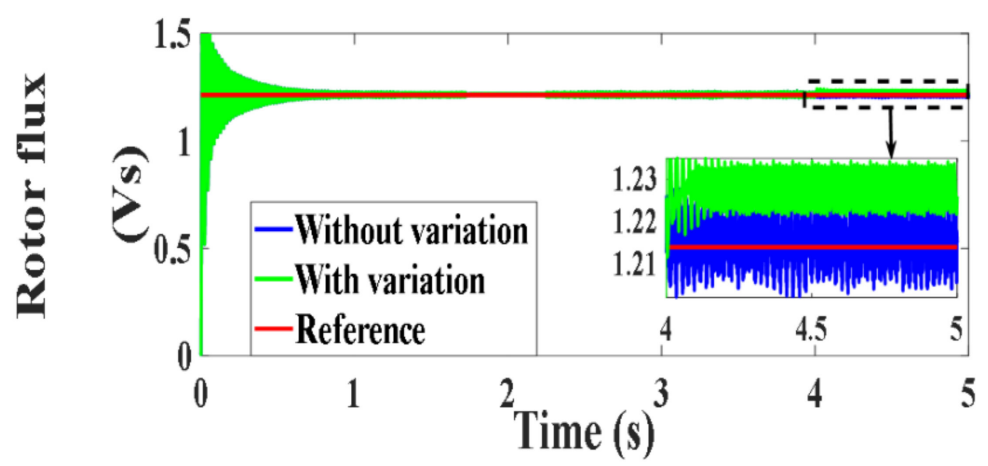

Figure 166. Rotor flux under PVC (Vs).

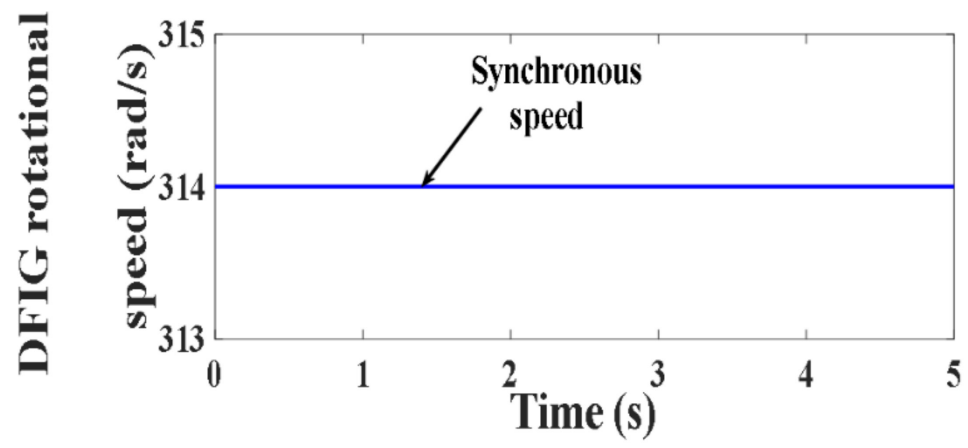

Figure 167. Prime mover operating speeds (rad/s).

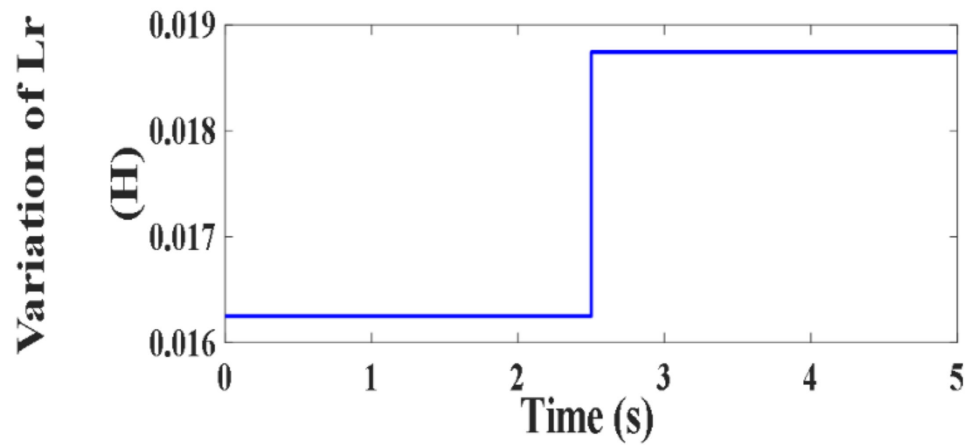

Figure 168. Variation of $L_{r}(H)$. 


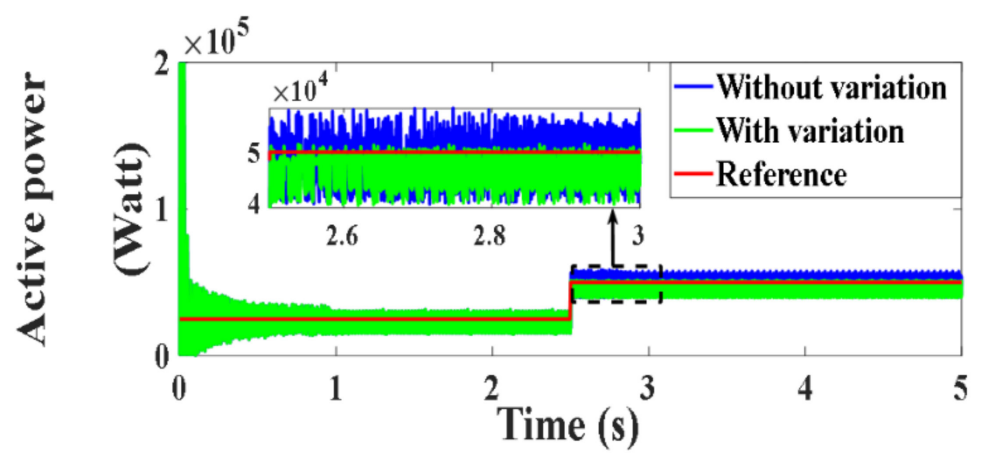

Figure 169. Active power under PVC (Watt).

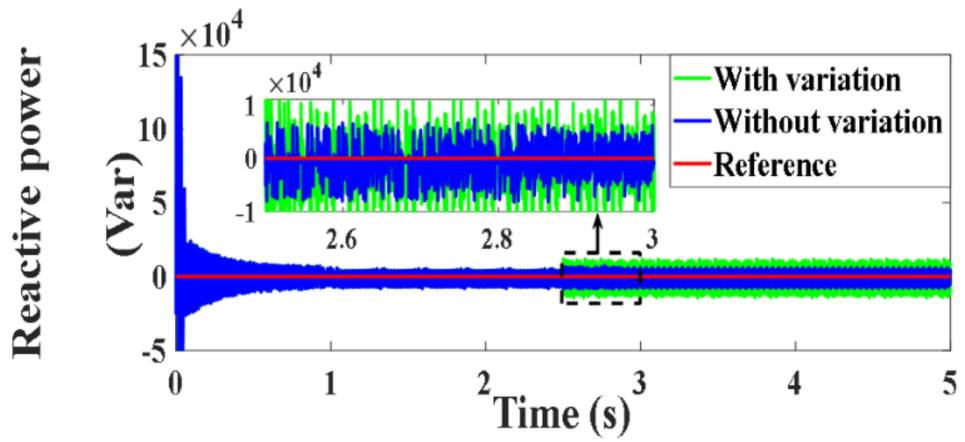

Figure 170. Reactive power under PVC (var).

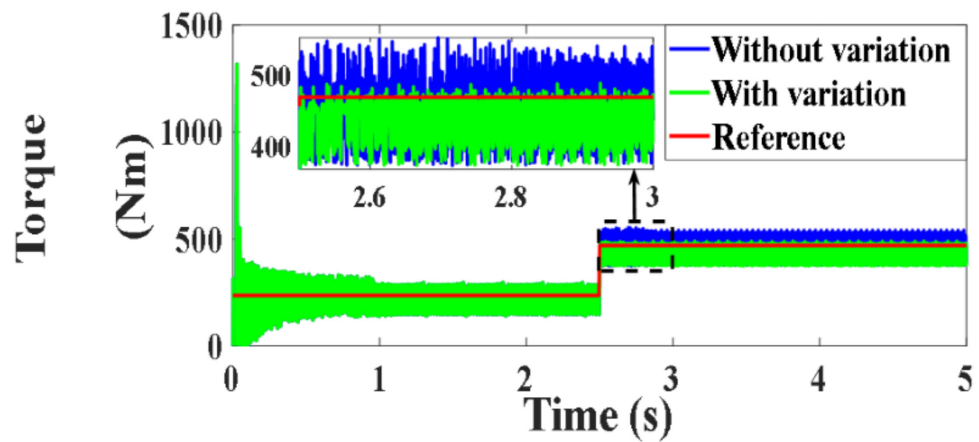

Figure 171. Developed torque under PVC (Nm).

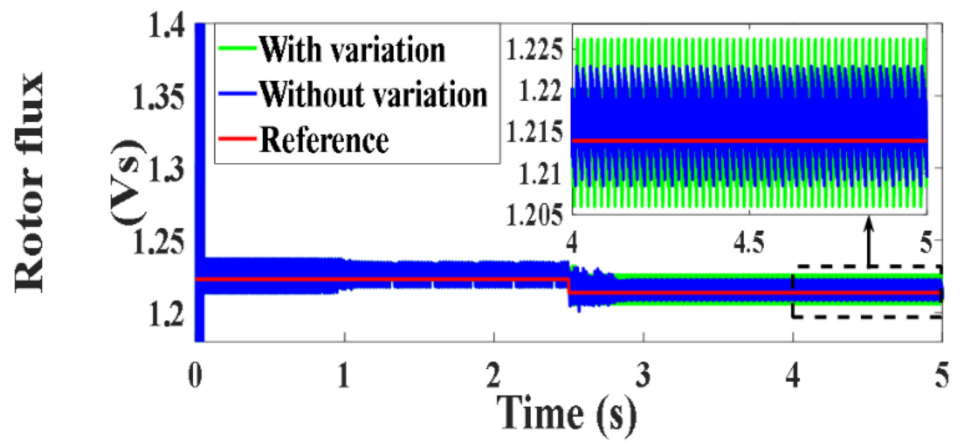

Figure 172. Rotor flux under PVC (Vs).

4.6.5. Testing the DBPC Scheme with $15 \%$ Variation of $\mathrm{L}_{\mathrm{m}}$

The last performance test of the DFIG for the variable speed operation (Figure 173) while considering a mismatch of $15 \%$ in the magnetizing inductance $\left(\mathrm{L}_{\mathrm{m}}\right)$ value (Figure 174). The obtained results for the active and reactive powers, torque and rotor flux are presented 
in Figures 175-178. A similar test is applied under the fixed speed operation (Figure 179) with a $\mathrm{L}_{\mathrm{m}}$ variation (Figure 180), and the results are presented in Figures 181-184, respectively. The results reveal that the actual variables are still deviated from their relevant reference ranges under the mutual inductance variation, which validates the robustness and superiority of our proposed PVC.

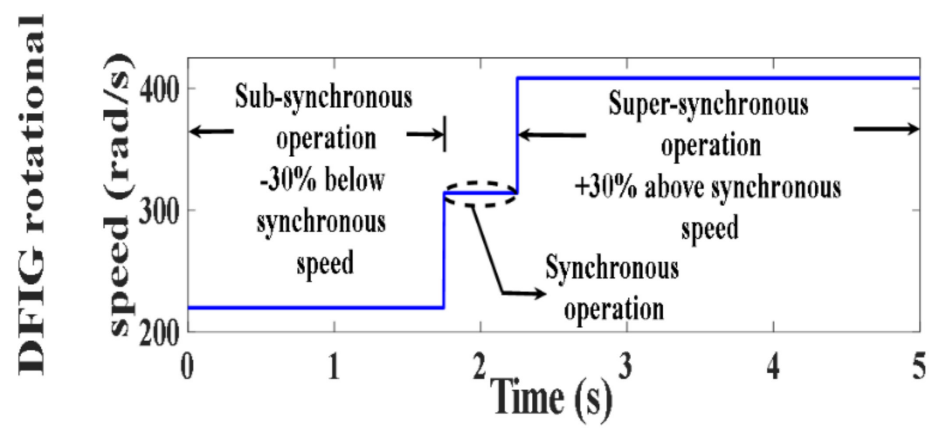

Figure 173. Prime mover operating speeds ( $\mathrm{rad} / \mathrm{s})$.

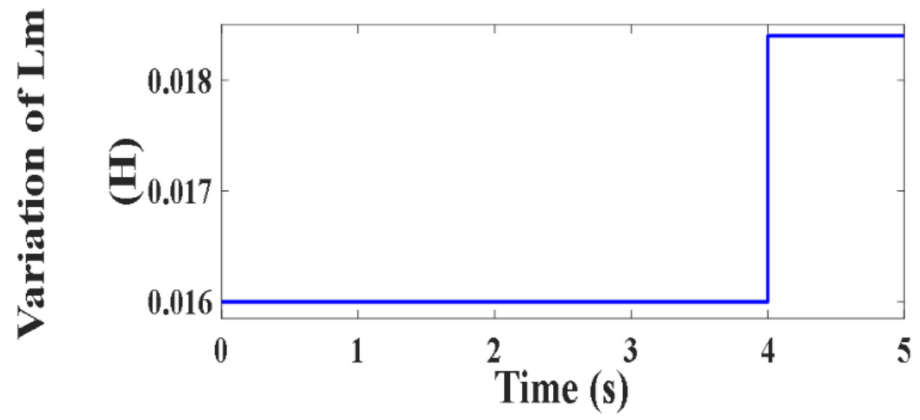

Figure 174. Variation of $\mathrm{L}_{\mathrm{m}}(\mathrm{H})$.

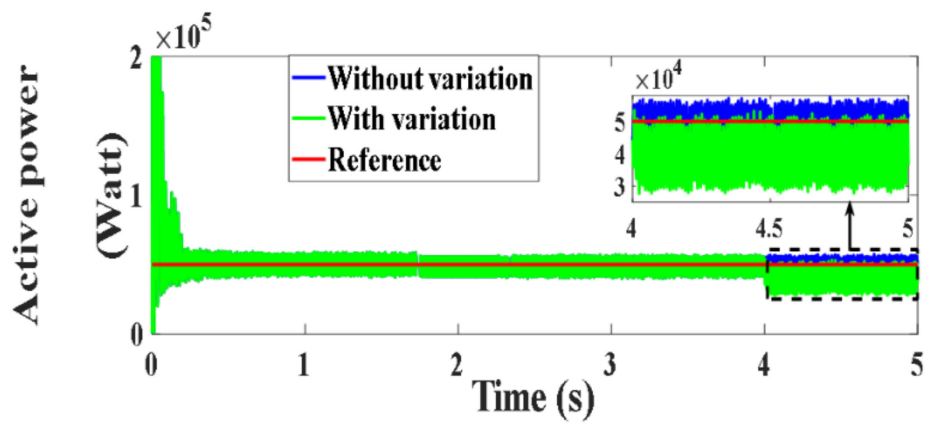

Figure 175. Active power under PVC (Watt).

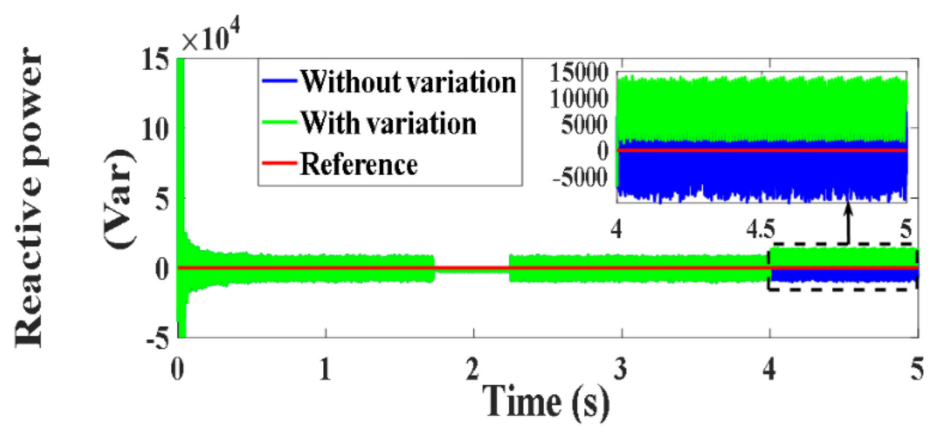

Figure 176. Reactive power under PVC (var). 


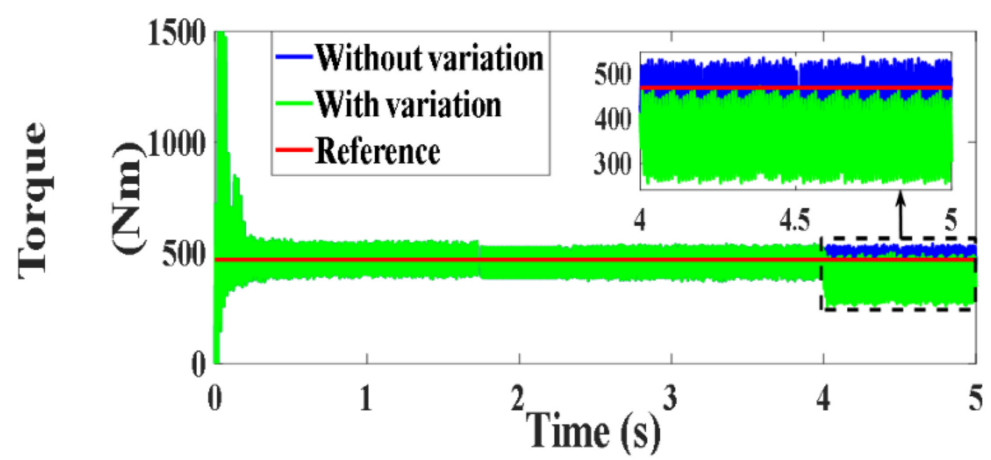

Figure 177. Developed torque under PVC (Nm).

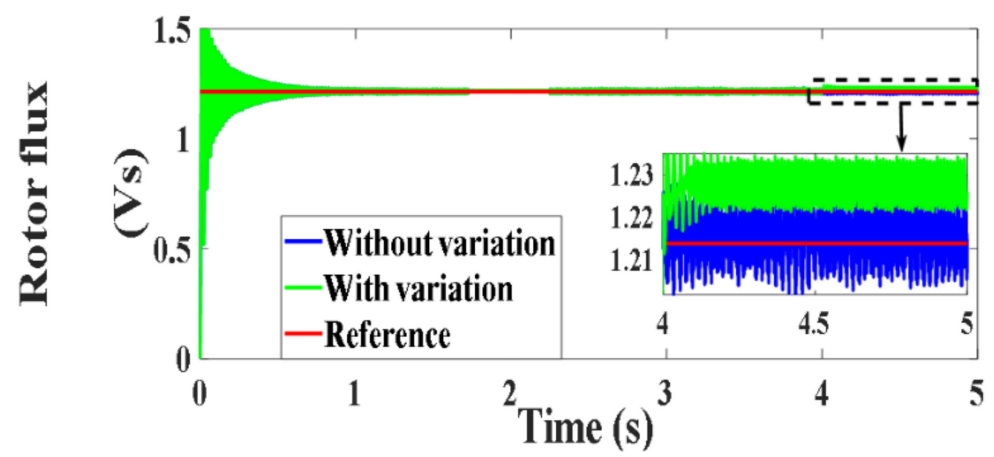

Figure 178. Rotor flux under PVC (Vs).

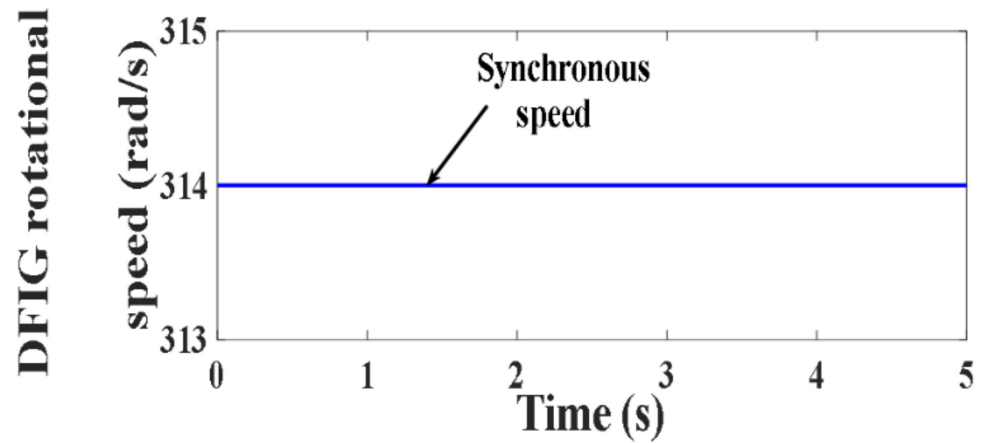

Figure 179. Prime mover operating speeds ( $\mathrm{rad} / \mathrm{s})$.

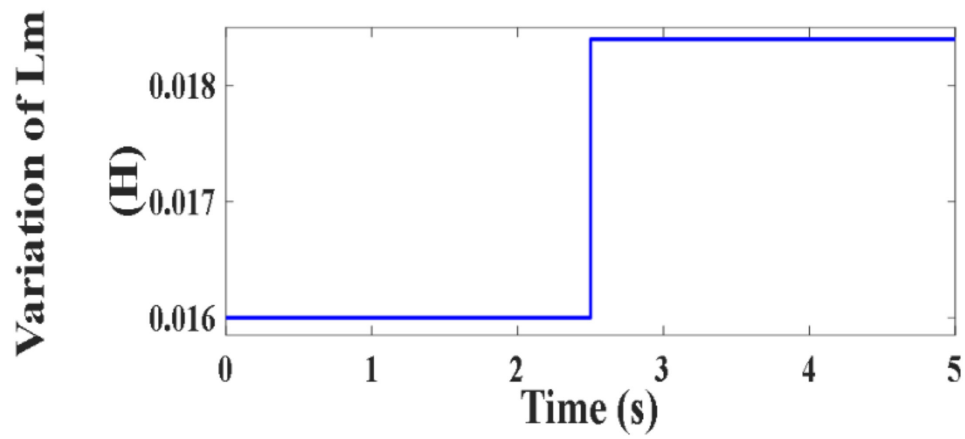

Figure 180. Variation of $\mathrm{L}_{\mathrm{m}}(\mathrm{H})$. 


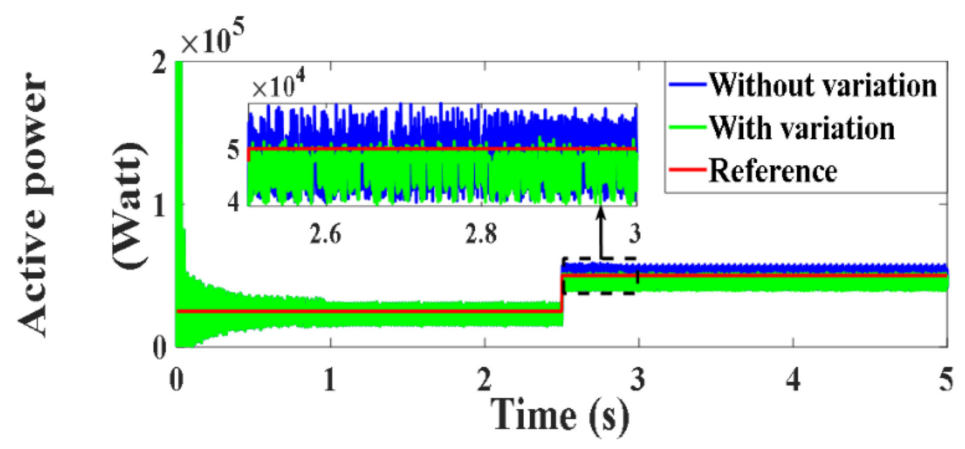

Figure 181. Active power under PVC (Watt).

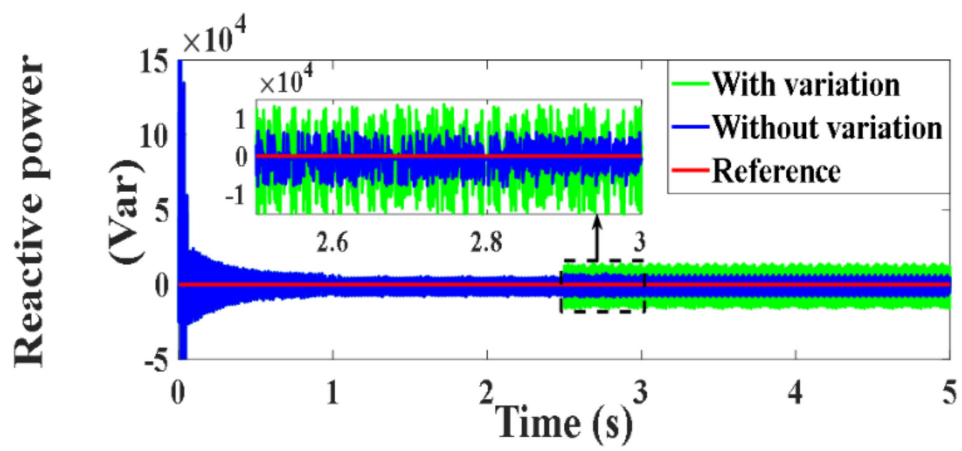

Figure 182. Reactive power under PVC (var).

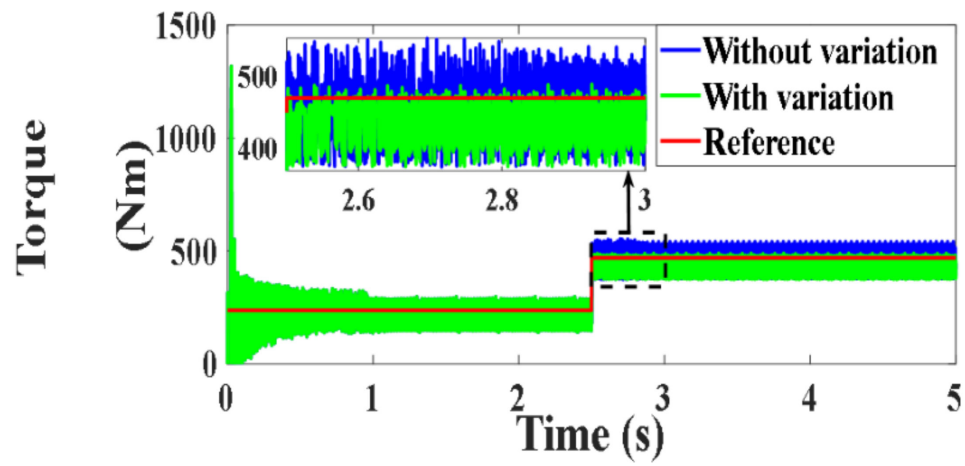

Figure 183. Developed torque under PVC (Nm).

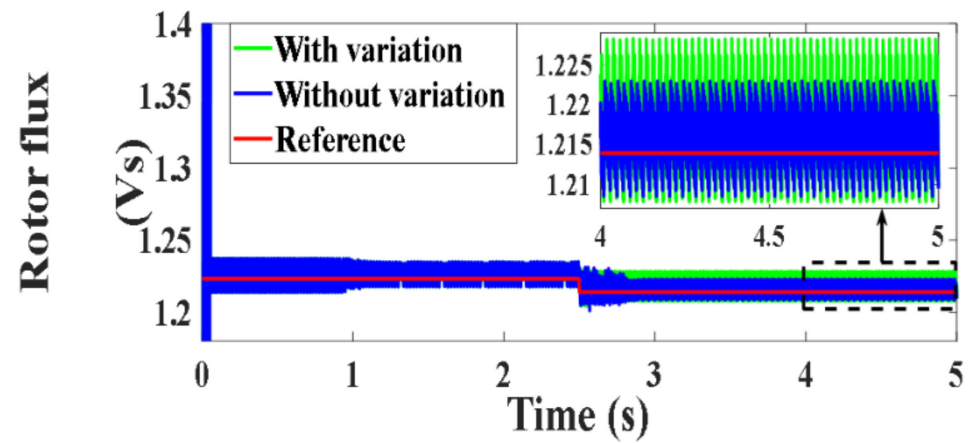

Figure 184. Rotor flux under PVC (Vs).

\subsection{Comparison Study}

Finally, a comparison was performed to study the dynamic performance of the DFIG under the four control techniques to enable the selection of the most appropriate technique to be used with the DFIG. The control effectiveness was measured in terms of ripples 
content, dynamic response time, and computational burden. The results are shown in Figures 185-189, which outline the active power, reactive power, developed torque, and rotor flux magnitude for the variable speed operation, and illustrated in Figures 190-194 the fixed speed operation, respectively. Table 1 introduces a comparison of the response time for each technique to clarify, with the aid of the results, which technique has a shorter response time and consequently possesses the fastest dynamic response. As noted in Table 1, the actual values under the proposed PVC technique show a shorter response time in comparison with the other control approaches, as the controlled variables in PVC are the voltage vectors, which are the nearest electrical value applied to the machine windings. Table 2 presents a comparison of the ripples content in the four principles and proves, with the help of the results, that the ripples content of the PVC technique is lower than that of the MPCC approach. It can thus be concluded that the proposed PVC technique is the most appropriate control scheme to be used with the DFIG for the following reasons: it achieves system simplicity; its dynamic response is the fastest compared to that of the MPCC, MPDTC, and SVOC principles; and its ripples content is lower than that of the MPCC and MPDTC approaches.

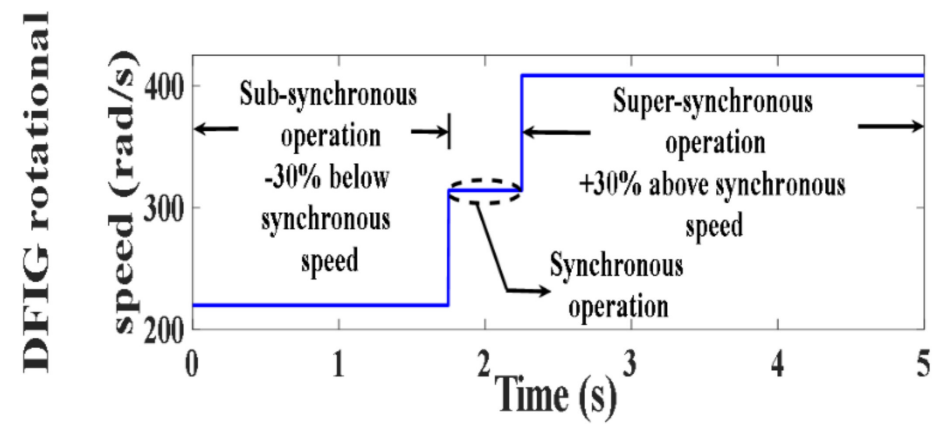

Figure 185. Prime mover operating speeds ( $\mathrm{rad} / \mathrm{s})$.

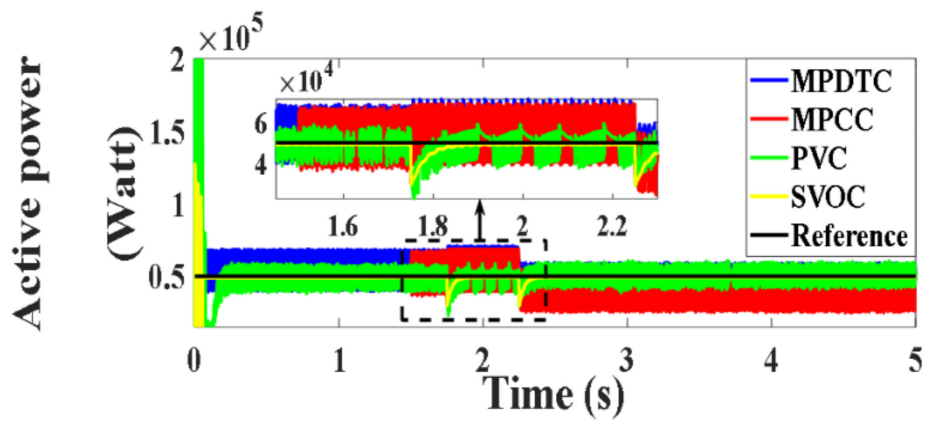

Figure 186. Comparison between active powers of four techniques (Watt).

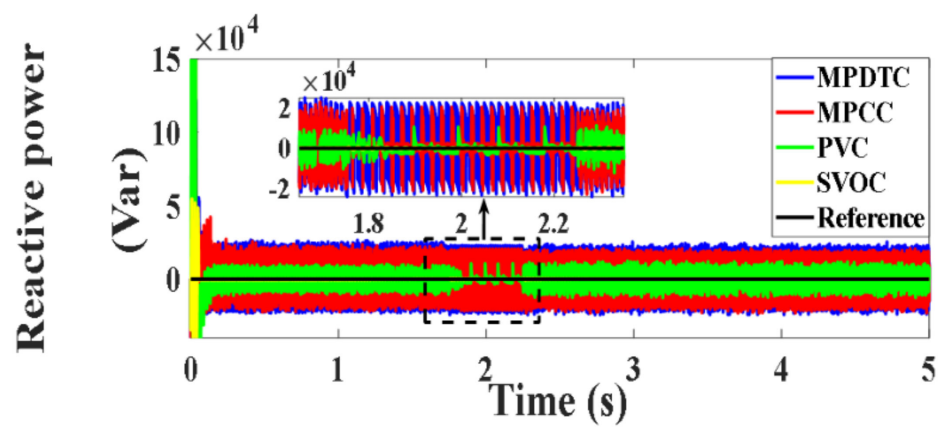

Figure 187. Comparison between reactive powers of four techniques (var). 


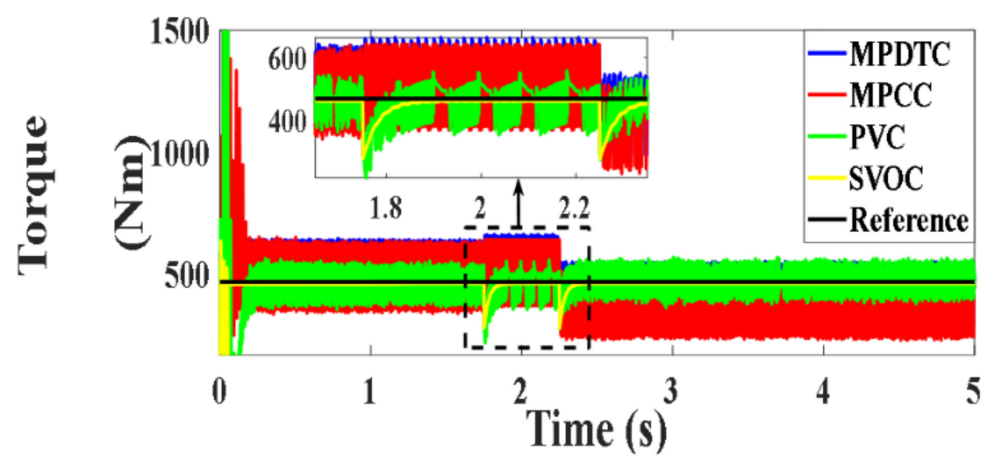

Figure 188. Comparison between torques of four techniques (Nm).

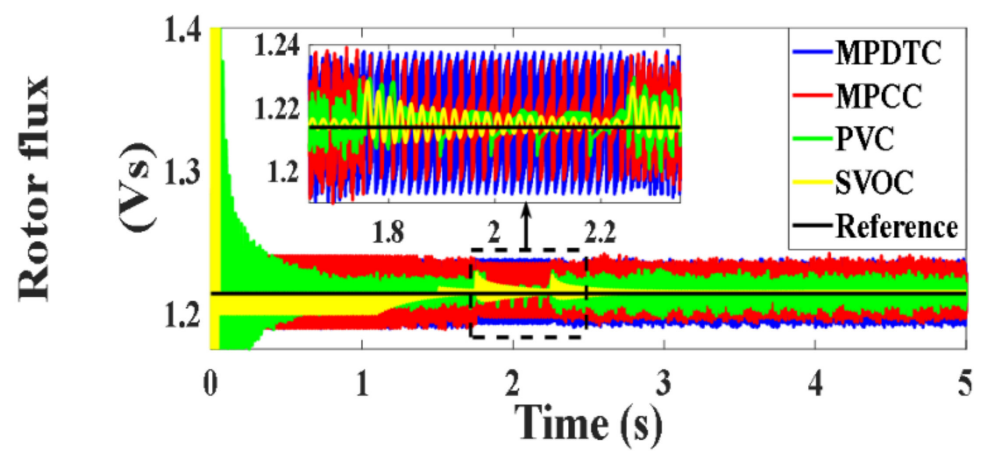

Figure 189. Comparison between rotor fluxes of four techniques (Vs).

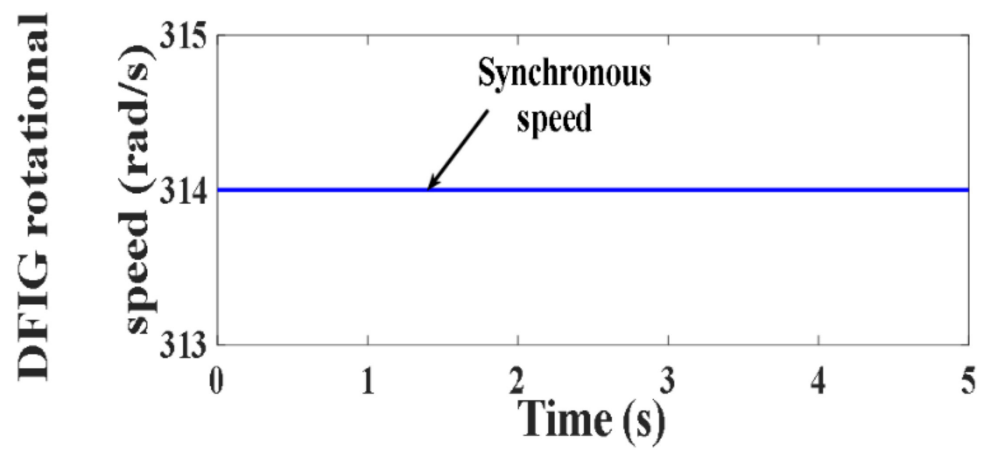

Figure 190. Prime mover operating speed ( $\mathrm{rad} / \mathrm{s})$.

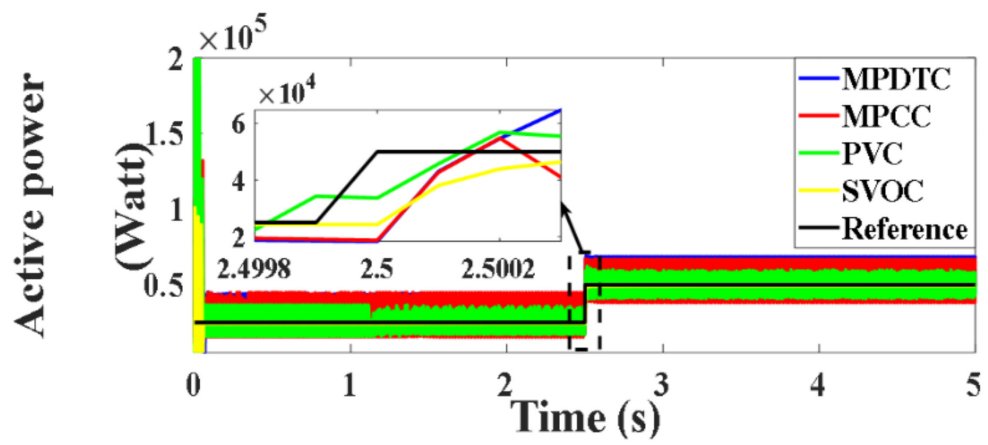

Figure 191. Comparison between active powers of four techniques (Watt). 


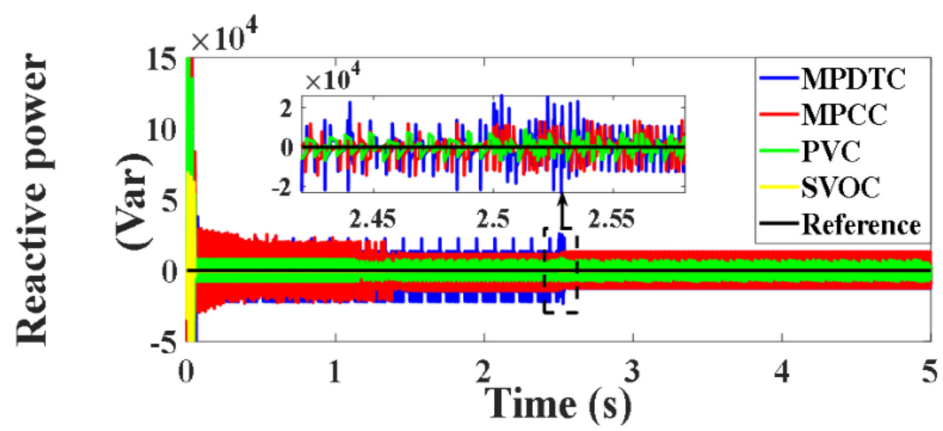

Figure 192. Comparison between reactive powers of four techniques (var).

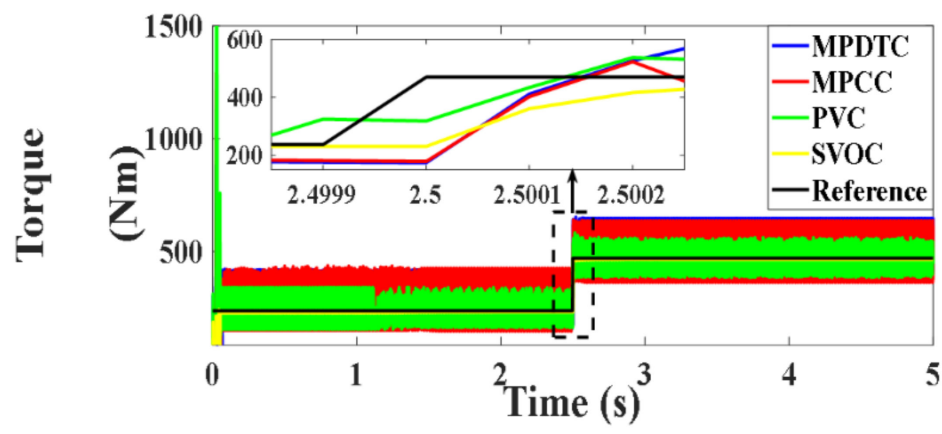

Figure 193. Comparison between torques of four techniques (Nm).

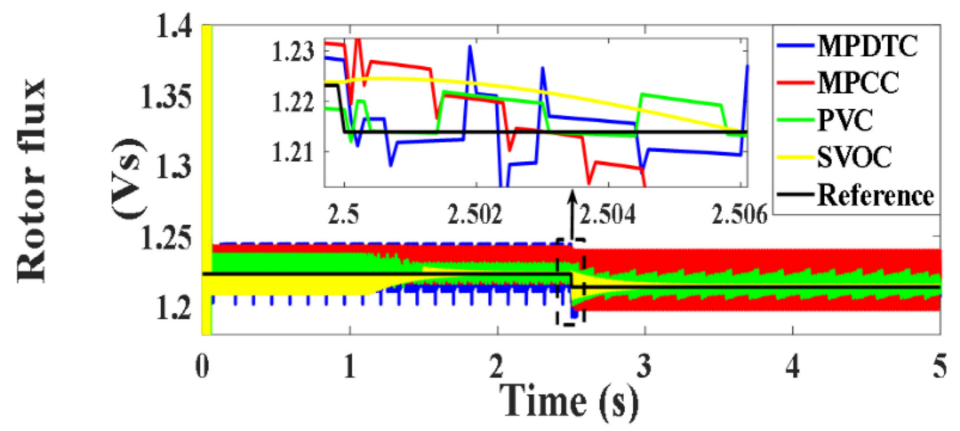

Figure 194. Comparison between rotor fluxes of four techniques (Vs).

The computation time for predictive control schemes is a critical issue, as it is known that model predictive controllers are time-consuming. For this reason, a comparison was also made between the three presented predictive controllers (MPDTC, MPCC, and designed PVC) in terms of number of performed commutations during the code execution. As we know, the switching states of the inverter switches are changed as the voltage index (i) is varied, so we could identify the number of commutations using the voltage index as follows. In the beginning, for each of the three inverter legs ( $a, b$, and $c)$, we calculated the binary variance between each logical state and its previous one; then, we took the summation of the different resultant terms. Finally, we could easily estimate the number of performed commutations in each predictive control technique and performed a comparison between them, as illustrated in Table 3. From these analytics, it was revealed that the designed PVC has the lowest number of performed commutations and thus has a shorter computation time compared with the MPDTC and MPCC approaches, which reduces the switching losses of the inverter. The used embedded code for calculating the number of performed commutations is presented in Figure 195. 


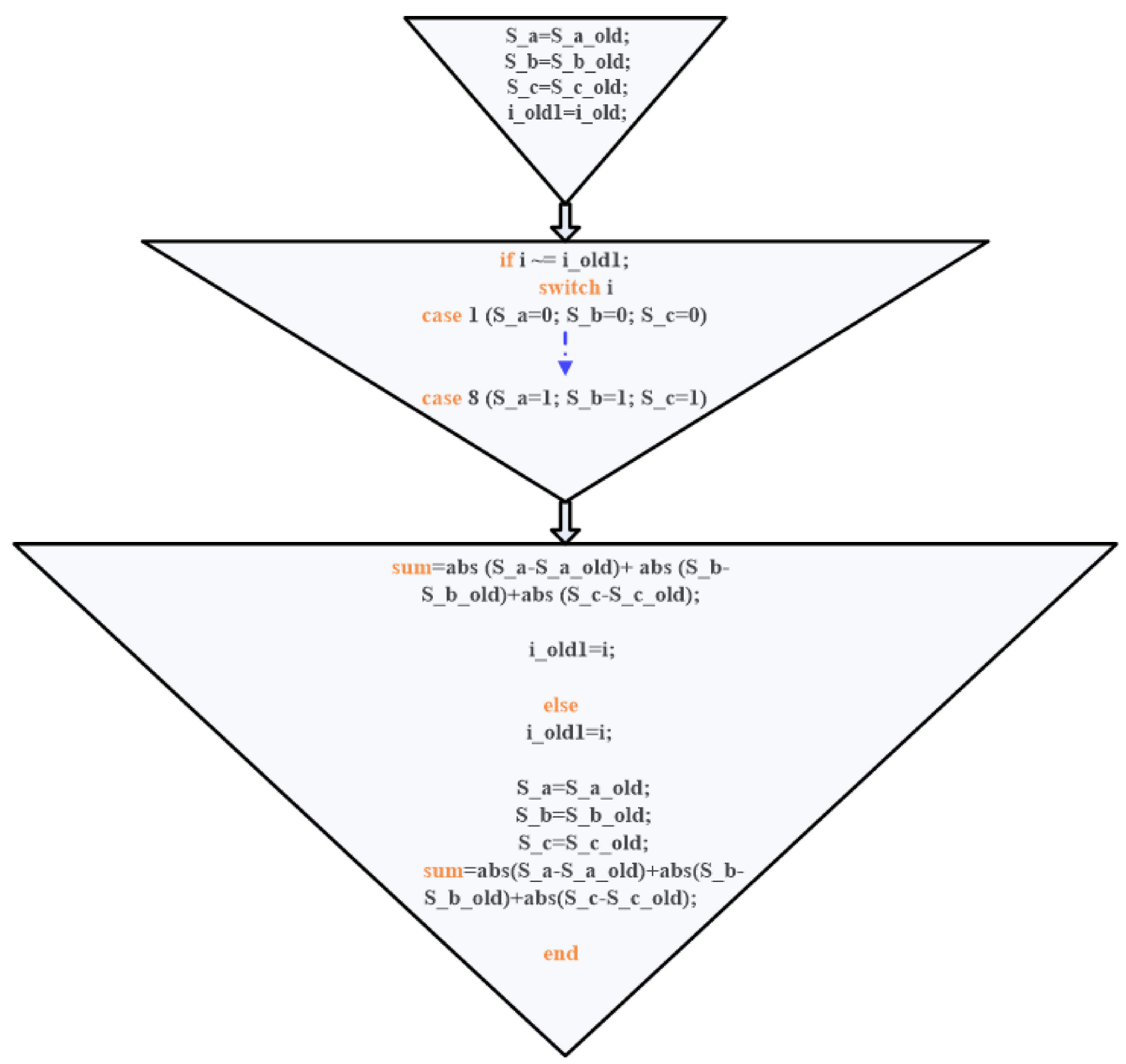

Figure 195. Embedded code for calculating the number of commutations for predictive controllers.

Table 1. Response time taken by the actual values to reach to their references values in 2nd condition.

\begin{tabular}{cccc}
\hline Technique & $\begin{array}{c}\text { Time Taken by } \\
\text { Active Power Profile }\end{array}$ & $\begin{array}{c}\text { Time Taken by } \\
\text { Torque Profile }\end{array}$ & $\begin{array}{c}\text { Time Taken by Rotor } \\
\text { Flux Profile }\end{array}$ \\
\hline SVOC & $0.55 \mathrm{~ms}$ & $0.65 \mathrm{~ms}$ & $6.5 \mathrm{~ms}$ \\
\hline MPCC & $0.16065 \mathrm{~ms}$ & $0.156 \mathrm{~ms}$ & $2.4 \mathrm{~ms}$ \\
\hline MPDTC & $0.1604 \mathrm{~ms}$ & $0.151 \mathrm{~ms}$ & $0.14 \mathrm{~ms}$ \\
\hline PVC & $0.14 \mathrm{~ms}$ & $0.135 \mathrm{~ms}$ & $0.057 \mathrm{~ms}$ \\
\hline
\end{tabular}


Table 2. Ripples content of the actual values above their references values.

\begin{tabular}{|c|c|c|c|c|c|c|c|c|}
\hline \multirow{2}{*}{ Technique } & \multicolumn{2}{|c|}{$\begin{array}{c}\text { Ripples of } \\
\text { Active Power (Watt) }\end{array}$} & \multicolumn{2}{|c|}{$\begin{array}{c}\text { Ripples of } \\
\text { Reactive Power (var) }\end{array}$} & \multicolumn{2}{|c|}{$\begin{array}{c}\text { Ripples of Developed } \\
\text { Torque (Nm) }\end{array}$} & \multicolumn{2}{|c|}{$\begin{array}{c}\text { Ripples of } \\
\text { Rotor Flux (Vs) }\end{array}$} \\
\hline & $\begin{array}{c}\text { Case } \\
1\end{array}$ & $\begin{array}{c}\text { Case } \\
2 \\
\end{array}$ & $\begin{array}{c}\text { Case } \\
1 \\
\end{array}$ & $\begin{array}{c}\text { Case } \\
2\end{array}$ & $\begin{array}{c}\text { Case } \\
1\end{array}$ & $\begin{array}{c}\text { Case } \\
2\end{array}$ & $\begin{array}{c}\text { Case } \\
1\end{array}$ & $\begin{array}{c}\text { Case } \\
2 \\
\end{array}$ \\
\hline SVOC & 740 & 670 & 274 & 281 & 9.2 & 9.9 & 0.012 & 0.013 \\
\hline MPCC & 7040 & 7580 & 7865 & 7673 & 171.1 & 183.4 & 0.023 & 0.02 \\
\hline MPDTC & 7890 & 8140 & 10080 & 9846 & 193.3 & 185 & 0.024 & 0.022 \\
\hline PVC & 2980 & 3070 & 4043 & 3804 & 85 & 104.1 & 0.016 & 0.014 \\
\hline
\end{tabular}

Table 3. Comparison in terms of performed commutations by the predictive controllers.

\begin{tabular}{ccc}
\hline Technique & Variable Speed Operation & Fixed Speed Operation \\
\hline MPCC & 8830 & 3732 \\
\hline MPDTC & 8588 & 2461 \\
\hline PVC & 7057 & 1409 \\
\hline
\end{tabular}

\section{Conclusions}

The paper has presented a comprehensive dynamic performance analysis for a doubly fed induction generator using different control algorithms under different operating speeds. The control algorithms used are stator voltage-oriented control (SVOC), model predictive current control (MPCC), and model predictive direct torque control (MPDTC) as classic types and a newly formulated predictive voltage control (PVC) approach as an enhanced type. Compared with the classic predictive controllers, the cost function of the formulated PVC is very simple as it does not contain a weighting factor, in addition to not containing any variables that need to be estimated. This leads to limiting the ripples and minimizing the computation time under PVC. The finite control set (FCS) is used with the designed PVC to select the optimal voltages from a specified set of vectors, which leads to stopping the use of a PWM, thus making the system configuration simpler. The comparison results between the four controllers revealed that the proposed PVC approach succeeded in attaining the control targets and obviating the defects faced by the other control approaches. The designed PVC system improves the dynamic performance of the DFIG through presenting the fastest dynamic response, reducing the ripples content, and minimizing the number of commutations, which results in reducing the computation time. The designed PVC scheme also has a confirmed high robustness against parameter mismatch, which was illustrated through performing extensive performance evaluation tests.

Author Contributions: Conceptualization, M.A.M. and M.K.A.; methodology, M.A.M., N.B. and A.A.H.; software, M.A.M. and M.K.A.; validation, M.A.M., A.A.H. and N.B.; formal analysis, M.A.M., M.K.A. and N.B.; investigation, A.A.H., N.B. and M.A.M.; resources, M.A.M., M.K.A. and A.A.H.; data curation, M.A.M. and M.K.A.; writing—original draft preparation, M.A.M. and M.K.A.; writingreview and editing, M.K.A., M.A.M. and N.B.; visualization, M.A.M., A.A.H. and N.B.; supervision, M.A.M., A.A.H. and N.B.; project administration, M.A.M., A.A.H. and N.B.; funding acquisition, M.A.M. All authors have read and agreed to the published version of the manuscript.

Funding: This research was funded by the Egyptian Mission Sector, Ministry of Higher Education of the Arab Republic of Egypt.

Institutional Review Board Statement: Not applicable.

Informed Consent Statement: Not applicable.

Data Availability Statement: The data presented in this study are available upon request from the corresponding author. 
Acknowledgments: This work was made possible by a fellowship funded by the Egyptian Mission Sector at the Ministry of Higher Education of the Arab Republic of Egypt.

Conflicts of Interest: The authors declare no conflict of interest.

\section{Appendix A}

Table A1. DFIG and control system parameters.

\begin{tabular}{cccc}
\hline Parameters & Value & Parameters & Value \\
\hline Rated power & $55 \mathrm{~kW}$ & Pole pairs $(p)$ & 3 \\
\hline $\mathrm{R}_{\mathrm{s}}$ & $70 \mathrm{~m} \Omega$ & $\begin{array}{c}\mathrm{U}_{\text {sn }} \text { (nominal stator } \\
\text { voltage) }\end{array}$ & $380 \mathrm{~V}$ \\
\hline $\mathrm{R}_{\mathrm{r}}$ & $87 \mathrm{~m} \Omega$ & $\begin{array}{c}\mathrm{K}_{\mathrm{p}} \text { and } \\
\mathrm{K}_{\mathrm{i} \text { (rotor current regulators) }}\end{array}$ & 3 and 100 \\
\hline $\mathrm{Ls}$ & $16.25 \mathrm{mH}$ & Operating frequency & $50 \mathrm{~Hz}$ \\
\hline $\mathrm{Lr}$ & $16.3 \mathrm{mH}$ & Inertia of the DFIG & $0.1 \mathrm{~kg} \cdot \mathrm{m}^{2}$ \\
\hline $\mathrm{L}_{\mathrm{m}}$ & $16 \mathrm{mH}$ & Sampling time & $10^{-4} \mathrm{~s}$ \\
\hline
\end{tabular}

\section{References}

1. Andrade, J.R.; Bessa, R.J. Improving Renewable Energy Forecasting with a Grid of Numerical Weather Predictions. IEEE Trans. Sustain. Energy 2017, 8, 1571-1580. [CrossRef]

2. Siano, P.; Chen, P.; Chen, Z.; Piccolo, A. Evaluating maximum wind energy exploitation in active distribution networks. Gener. Transm. Distrib. IET 2010, 4, 598-608. [CrossRef]

3. Tian, J.; Zhou, D.; Su, C.; Blaabjerg, F.; Chen, Z. Maximum energy yield oriented turbine control in PMSG-based wind farm. J. Eng. 2017, 2017, 2455-2460. [CrossRef]

4. Vellaipatchi, N.; Kumaresan, N.; Gounden, N. A Single Sensor Based MPPT Controller for Wind-Driven Induction Generators Supplying DC Microgrid. IEEE Trans. Power Electron. 2015, 31, 1161-1172.

5. Dambrosio, L.; Fortunato, B. One-step-ahead adaptive control of a wind-driven, synchronous generator system. Energy 1999, 24, 9-20. [CrossRef]

6. Mahmoud, M.M.; Aly, M.M.; Salama, H.S.; Abdel-Rahim, A.-M.M. Dynamic evaluation of optimization techniques-based proportional-integral controller for wind-driven permanent magnet synchronous generator. Wind Eng. 2020, 45, 696-709. [CrossRef]

7. Lopes, L.A.C.; Almeida, R.G. Wind-driven self-excited induction generator with voltage and frequency regulated by a reducedrating voltage source inverter. IEEE Trans. Energy Convers. 2006, 21, 297-304. [CrossRef]

8. Mossa, M.A.; Gam, O.; Bianchi, N. Dynamic Performance Enhancement of a Renewable Energy System for Grid Connection and Stand-alone Operation with Battery Storage. Energies 2022, 15, 1002. [CrossRef]

9. Shaltout, A.A.; Abdel-Halim, M.A. Solid-State Control of a Wind-Driven Self-Excited Induction Generator. Electr. Mach. Power Syst. 1995, 23, 571-582. [CrossRef]

10. Puchalapalli, S.; Tiwari, S.K.; Singh, B.; Goel, P.K. A Microgrid Based on Wind-DrivenDFIG, DG, and Solar PV Array for Optimal Fuel Consumption. IEEE Trans. Ind. Appl. 2020, 56, 4689-4699. [CrossRef]

11. Mossa, M.A.; Bolognani, S. High performance Direct Power Control for a doubly fed induction generator. In Proceedings of the IECON 2016-42nd Annual Conference of the IEEE Industrial Electronics Society, Florence, Italy, 24-27 October 2016; pp. 1930-1935.

12. Marques, G.D.; Iacchetti, M.F. DFIG Topologies for DC Networks: A Review on Control and Design Features. IEEE Trans. Power Electron. 2019, 34, 1299-1316. [CrossRef]

13. Hassan, A.A.; El-Sawy, A.M.; Kamel, O.M. Direct Torque Control of a Doubly fed Induction Generator Driven by a Variable Speed Wind Turbine. JES J. Eng. Sci. 2013, 41, 199-216. [CrossRef]

14. Charles, C.M.R.; Vinod, V.; Jacob, A. Field Oriented Control of DFIG Based Wind Energy System Using Battery Energy Storage System. Procedia Technol. 2016, 24, 1203-1210. [CrossRef]

15. Pura, P.; Iwański, G. Rotor Current Feedback Based Direct Power Control of a Doubly Fed Induction Generator Operating with Unbalanced Grid. Energies 2021, 14, 3289. [CrossRef]

16. Mahfoud, S.; Derouich, A.; EL Ouanjli, N.; EL Mahfoud, M.; Taoussi, M. A New Strategy-Based PID Controller Optimized by Genetic Algorithm for DTC of the Doubly Fed Induction Motor. Systems 2021, 9, 37. [CrossRef]

17. Hassan, A.A.; Mohamed, Y.S.; El-Sawy, A.M.; Mossa, M.A. Control of a Wind Driven DFIG Connected to the Grid Based on Field Orientation. Wind Eng. 2011, 35, 127-143. [CrossRef] 
18. Amalorpavaraj, R.A.J.; Kaliannan, P.; Padmanaban, S.; Subramaniam, U.; Ramachandaramurthy, V.K. Improved Fault Ride Through Capability in DFIG Based Wind Turbines Using Dynamic Voltage Restorer with Combined Feed-Forward and Feed-Back Control. IEEE Access 2017, 5, 20494-20503. [CrossRef]

19. Mossa, M.; Mohamed, Y. Novel Scheme for Improving the Performance of a Wind Driven Doubly Fed Induction Generator During Grid Fault. Wind Eng. 2012, 36, 305-334. [CrossRef]

20. Huang, Q.; Zou, X.; Zhu, D.; Kang, Y. Scaled Current Tracking Control for Doubly Fed Induction Generator to Ride-Through Serious Grid Faults. in IEEE Trans. Power Electron. 2016, 31, 2150-2165. [CrossRef]

21. Mossa, M.A.; Echeikh, H.; Diab, A.A.Z.; Quynh, N.V. Effective Direct Power Control for a Sensor-Less Doubly Fed Induction Generator with a Losses Minimization Criterion. Electronics 2020, 9, 1269. [CrossRef]

22. Mossa, M.A.; Al-Sumaiti, A.S.; Do, T.D.; Diab, A.A.Z. Cost-Effective Predictive Flux Control for a Sensorless Doubly Fed Induction Generator. IEEE Access 2019, 7, 172606-172627. [CrossRef]

23. Prasad, R.M.; Mulla, M.A. Mathematical Modeling and Position-Sensorless Algorithm for Stator-Side Field-Oriented Control of Rotor-Tied DFIG in Rotor Flux Reference Frame. IEEE Trans. Energy Convers. 2020, 35, 631-639. [CrossRef]

24. Amrane, F.; Chaiba, A.; Francois, B.; Babes, B. Experimental design of stand-alone field oriented control for WECS in variable speed DFIG-based on hysteresis current controller. In Proceedings of the 15th International Conference on Electrical Machines, Drives and Power Systems (ELMA), Sofia, Bulgaria, 1-3 June 2017; pp. 304-308.

25. Elmahfoud, M.; Bossoufi, B.; Taoussi, M.; Ouanjli, N.E.; Derouich, A. Rotor Field Oriented Control of Doubly Fed Induction Motor. In Proceedings of the 2019 5th International Conference on Optimization and Applications (ICOA), Kenitra, Morocco, 25-26 April 2019; pp. 1-6.

26. Arbi, J.; Ghorbal, M.J.; Slama-Belkhodja, I.; Charaabi, L. Direct Virtual Torque Control for Doubly Fed Induction Generator Grid Connection. IEEE Trans. Ind. Electron. 2009, 56, 4163-4173. [CrossRef]

27. Gundavarapu, A.; Misra, H.; Jain, A.K. Direct Torque Control Scheme for DC Voltage Regulation of the Standalone DFIG-DC System. IEEE Trans. Ind. Electron. 2017, 64, 3502-3512. [CrossRef]

28. Kashkooli, M.R.A.; Madani, S.M.; Lipo, T.A. Improved Direct Torque Control for a DFIG under Symmetrical Voltage Dip With Transient Flux Damping. IEEE Trans. Ind. Electron. 2020, 67, 28-37. [CrossRef]

29. El Daoudi, S.; Lazrak, L.; El Ouanjli, N.; Lafkih, M.A. Sensorless fuzzy direct torque control of induction motor with sliding mode speed controller. Comput. Electr. Eng. 2021, 96, 107490. [CrossRef]

30. Rodrigues, L.L.; Vilcanqui, O.A.; Murari, A.L.; Filho, A.J. Predictive Power Control for DFIG: A FARE-Based Weighting Matrices Approach. IEEE J. Emerg. Sel. Top. Power Electron. 2019, 7, 967-975. [CrossRef]

31. Mossa, M.A.; Bolognani, S. Robust Predictive Current Control for a Sensorless IM Drive Based on Torque Angle Regulation. In Proceedings of the 2019 IEEE Conference on Power Electronics and Renewable Energy (CPERE), Aswan City, Egypt, 23-25 October 2019; pp. 302-308.

32. Filho, A.J.S.; Oliveira, A.L.d.; Rodrigues, L.L.; Costa, E.C.M.; Jacomini, R.V. A Robust Finite Control Set Applied to the DFIG Power Control. IEEE J. Emerg. Sel. Top. Power Electron. 2018, 6, 1692-1698. [CrossRef]

33. Bektache, A.; Boukhezzar, B. Nonlinear predictive control of a DFIG-based wind turbine for power capture optimization. Int. J. Electr. Power Energy Syst. 2018, 101, 92-102. [CrossRef]

34. Cheng, C.; Nian, H. Low-Complexity Model Predictive Stator Current Control of DFIG Under Harmonic Grid Voltages. IEEE Trans. Energy Convers. 2017, 32, 1072-1080. [CrossRef]

35. Mossa, M.A.; Kamel, O.M.; Bolognani, S. Explicit Predictive Voltage Control for an Induction Motor Drive. In Proceedings of the 2019 21st International Middle East Power Systems Conference (MEPCON), Cairo, Egypt, 17-19 December 2019 ; pp. $258-264$.

36. Bonfiglio, A.; Cantoni, F.; Oliveri, A.; Procopio, R.; Rosini, A.; Invernizzi, M.; Storace, M. An MPC-Based Approach for Emergency Control Ensuring Transient Stability in Power Grids With Steam Plants. IEEE Trans. Ind. Electron. 2019, 66, 5412-5422. [CrossRef]

37. Morstyn, T.; Hredzak, B.; Aguilera, R.P.; Agelidis, V.G. Model Predictive Control for Distributed Microgrid Battery Energy Storage Systems. IEEE Trans. Control Syst. Technol. 2018, 26, 1107-1114. [CrossRef]

38. Kou, P.; Liang, D.; Li, J.; Gao, L.; Ze, Q. Finite-Control-Set Model Predictive Control for DFIG Wind Turbines. IEEE Trans. Autom. Sci. Eng. 2018, 15, 1004-1013. [CrossRef]

39. Zanelli, A.; Kullick, J.; Eldeeb, H.M.; Frison, G.; Hackl, C.M.; Diehl, M. Continuous Control Set Nonlinear Model Predictive Control of Reluctance Synchronous Machines. IEEE Trans. Control. Syst. Technol. 2021, 30, 130-141. [CrossRef]

40. Petkar, S.; Thippiripati, V.K. Enhanced Predictive Current Control of PMSM Drive with Virtual Voltage Space Vectors. IEEE J. Emerg. Sel. Top. Ind. Electron. 2021. [CrossRef]

41. Liu, M.; Chan, K.W.; Hu, J.; Xu, W.; Rodriguez, J. Model Predictive Direct Speed Control With Torque Oscillation Reduction for PMSM Drives. IEEE Trans. Ind. Inform. 2019, 15, 4944-4956. [CrossRef]

42. Mokhtari, M.; Davari, S.A. Predictive torque control of DFIG with torque ripple reduction. In Proceedings of the 2016 IEEE International Conference on Power and Energy (PECon), Melaka, Malaysia, 28-29 November 2016; pp. 763-768.

43. Zhang, Y.; Zhu, J.; Hu, J. Model predictive direct torque control for grid synchronization of doubly fed induction generator. In Proceedings of the 2011 IEEE International Electric Machines \& Drives Conference (IEMDC), Niagara Falls, ON, Canada, 15-18 May 2011; pp. 765-770. 
44. Mossa, M.A.; Bolognani, S. Effective sensorless model predictive direct torque control for a doubly fed induction machine. In Proceedings of the 2017 IEEE Nineteenth International Middle East Power Systems Conference (MEPCON), Cairo, Egypt, 19-21 December 2017; pp. 1201-1207.

45. Wei, X.; Cheng, M.; Zhu, J.; Yang, H.; Luo, R. Finite-Set Model Predictive Power Control of Brushless Doubly Fed Twin Stator Induction Generator. IEEE Trans. Power Electron. 2019, 34, 2300-2311. [CrossRef]

46. Vayeghan, M.M.; Davari, S.A. Torque ripple reduction of DFIG by a new and robust predictive torque control method. IET Renew. Power Gener. 2017, 11, 1345-1352. [CrossRef]

47. Zhang, Y.; Jiao, J.; Xu, D.; Jiang, D.; Wang, Z.; Tong, C. Model Predictive Direct Power Control of Doubly Fed Induction Generators Under Balanced and Unbalanced Network Conditions. IEEE Trans. Ind. Appl. 2020, 56, 771-786. [CrossRef]

48. Zarei, M.E.; Nicolás, C.V.; Arribas, J.R. Improved Predictive Direct Power Control of Doubly Fed Induction Generator During Unbalanced Grid Voltage Based on Four Vectors. IEEE J. Emerg. Sel. Top. Power Electron. 2017, 5, 695-707. [CrossRef]

49. Davari, S.A.; Nekoukar, V.; Garcia, C.; Rodriguez, J. Online Weighting Factor Optimization by Simplified Simulated Annealing for Finite Set Predictive Control. IEEE Trans. Ind. Inform. 2021, 17, 31-40. [CrossRef]

50. Mossa, M.A.; Bolognani, S. Effective model predictive current control for a sensorless IM drive. In Proceedings of the 2017 IEEE International Symposium on Sensorless Control for Electrical Drives (SLED), Catania, Italy, 18-19 September 2017 ; pp. 37-42.

51. Bozorgi, A.M.; Farasat, M.; Jafarishiadeh, S. Model predictive current control of surface-mounted permanent magnet synchronous motor with low torque and current ripple. IET Power Electron. 2017, 10, 1120-1128. [CrossRef]

52. Mossa, M.A.; Bolognani, S. Predictive Power Control for a Linearized Doubly Fed Induction Generator Model. In Proceedings of the 2019 21st International Middle East Power Systems Conference (MEPCON), Cairo, Egypt, 17-19 December 2019; pp. 250-257.

53. Mossa, M.A.; Bolognani, S. A novel sensorless direct torque control for a doubly fed induction machine. In Proceedings of the 2016 XXII International Conference on Electrical Machines (ICEM), Lausanne, Switzerland, 4-7 September 2016; pp. 942-948.

54. Mossa, M.A. Field Orientation Control of a Wind Driven DFIG Connected to the Grid. Wseas Trans. Power Syst. 2012, 4, 182-197.

55. Zhang, Y.; Xu, D. Direct power control of doubly fed induction generator based on extended power theory under unbalanced grid condition. In Proceedings of the 2017 IEEE 3rd International Future Energy Electronics Conference and ECCE Asia (IFEEC 2017-ECCE Asia), Kaohsiung, Taiwan, 4-7 June 2017; pp. 992-996.

56. Osorio, C.M.R.; Chaves, J.S.S.; Murari, A.L.L.F.; Filho, A.J.S. Comparative Analysis of the Doubly Fed Induction Generator (DFIG) Under Balanced Voltage Sag Using a Deadbeat Controller. IEEE Lat. Am. Trans. 2017, 15, 869-876. [CrossRef]

57. Franco, R.; Capovilla, C.E.; Jacomini, R.V.; Altana, J.A.T.; Filho, A.J.S. A deadbeat direct power control applied to doubly-fed induction aerogenerator under normal and sag voltages conditions. In Proceedings of the IECON 2014-40th Annual Conference of the IEEE Industrial Electronics Society, Dallas, TX, USA, 29 October-1 November 2014; pp. 1906-1911.

58. Mossa, M.A.; Do, T.D.; Al-Sumaiti, A.S.; Quynh, N.V.; Diab, A.A.Z. Effective Model Predictive Voltage Control for a Sensorless Doubly Fed Induction Generator. IEEE Can. J. Electr. Comput. Eng. 2021, 44, 50-64. [CrossRef] 